\title{
The Association Between Intimate Partner Violence and Functional Gastrointestinal Disorders and Symptoms Among Adult Women: Systematic Review
}

Ohud Shawqi Banjar, The University of Western Ontario

Supervisor: Ford-Gilboe, Marilyn, The University of Western Ontario

A thesis submitted in partial fulfillment of the requirements for the Master of Science degree in Nursing

(C) Ohud Shawqi Banjar 2020

Follow this and additional works at: https://ir.lib.uwo.ca/etd

Part of the Nursing Commons

\section{Recommended Citation}

Banjar, Ohud Shawqi, "The Association Between Intimate Partner Violence and Functional Gastrointestinal Disorders and Symptoms Among Adult Women: Systematic Review" (2020). Electronic Thesis and Dissertation Repository. 7083.

https://ir.lib.uwo.ca/etd/7083

This Dissertation/Thesis is brought to you for free and open access by Scholarship@Western. It has been accepted for inclusion in Electronic Thesis and Dissertation Repository by an authorized administrator of Scholarship@Western. For more information, please contact wlswadmin@uwo.ca. 


\begin{abstract}
Functional gastrointestinal disorders (FGIDs) and symptoms have been identified as possible health consequences of intimate partner violence (IPV). However, whether specific types of abuse (i.e., psychological, physical and sexual) affect the health of women in different ways, and the mechanisms that explain how these forms of abuse affect their health and quality of life (QOL) are not well understood. The aims of this systematic review were to examine the association between the different types of IPV and the risk of FGIDs and symptoms among adult women, identify the factors that mediate and/or moderate these health effects, and assess the impact of FGIDs and symptoms on women's QOL. Seven electronic databases were searched using the following criteria: English language studies of adult women (15 years or older) who had experienced IPV and reported FGIDs and symptoms; both quantitative descriptive and qualitative studies were included, and the timeline search was based on the first record from each included database until December 31, 2019. A quality assessment of each included study was completed using either published guidelines from Hoya et al. (2012) for quantitative studies or the Critical Skills Appraisal Program (CASP; 2010) tool for qualitative studies. A total of 15 studies satisfied our inclusion criteria. Results provide evidence of an association between various types of IPV and FGIDs and symptoms but none of the included studies examined factors that might mediate and/or moderate this association. Further, limited attention was given to examining the association of FGIDs and QOL in the context of IPV. The findings of this study emphasize the importance of adapting nursing practice, education, and research to improve care for women who have experienced IPV and are suffering from FGIDs. Keywords: Intimate partner violence, functional gastrointestinal disorders, quality of life, systematic review
\end{abstract}




\section{Summary for Lay Audience}

Intimate partner violence (IPV) is consistently associated with a broad range of adverse health outcomes. Functional gastrointestinal disorders (FGIDs) are considered to be one of these long-term negative health outcomes. FGIDs are common disorders characterized by persistent and recurring gastrointestinal (GI) symptoms that are not caused by structural (e.g., tumours or masses) or biochemical abnormalities. FGIDs are also the most common diagnosis in gastroenterology. Women with FGIDs appear to access health care services more frequently than men and women without FGIDs.

The literature shows that there is a significant world-wide prevalence of FGIDs among women who have experienced IPV and that FGIDs negatively affect women's quality of life (QOL) outcomes. A systematic review was conducted to address some critical gaps in specific areas where the evidence is unclear. The purposes of this systematic review were to: a) examine the association between different types of IPV (i.e., physical, sexual, and psychological abuse) and the risk of FGIDs and symptoms among adult women; b) identify the factors that might mediate or moderate these health effects; and, c) examine how FGIDs might affect aspects of women's QOL (e.g., health, social life, and economic status).

Overall, we found that there is an association between IPV and FGIDs. The results also show that there is a lack of theory-driven investigation into the mechanisms that mediate and/or moderate this relationship. Additionally, among the included studies, limited attention was given to examining FGIDs and QOL in the context of IPV. These findings may provide direction for nursing practice in women's health and suggest priorities for future research. 


\section{CO-AUTHORSHIP STATEMENT}

Ohud Banjar completed this systematic review for her master's thesis under the supervision of Dr. Marilyn Ford-Gilboe, Dr. Carol Wong, and Dr. Deanna Befus, and in collaboration with Bayan Alilyyani, who will be co-authors on presentations and publications resulting from the manuscript presented in Chapter 2. 


\section{DEDICATION}

To the women of the world 


\section{ACKNOWLEDGEMENTS}

I would like to extend my sincere appreciation and gratitude to God for giving me the strength to keep going, and for always being there for me.

Also, I would like to thank most sincerely Saudi Arabia's Ministry of Education for granting me a scholarship to pursue my master's degree in Canada, and the Saudi Cultural Bureau in

Canada and Western University for their support throughout my educational journey.

Special thanks go to Dr. Marilyn Ford-Gilboe at Western University. She consistently encouraged me to develop my own research interests and helped keep me on track whenever I needed it. Without her passionate participation and input, this systematic review could not have been successfully conducted.

Thank you to Dr. Carol Wong and Dr. Deanna Befus for supporting my research and for helping me to gain the knowledge needed to perform this systematic review. Your advice on research has been invaluable and helped me to grow as a research scientist in nursing. Your guidance allowed this thesis to be my work while keeping me on the right path.

Also, I must express my very profound gratitude to my parents, Asmaa Al-Hazmi and Shawqi Banjar, and my sisters, Khulood Banjar, Dr. Shorooq Banjar, and Dr. Nujood Banjar, for believing in me and never leaving my side.

Finally, to all my friends, especially Bayan Alilyyani and Nada Alaidarous, thank you for being with me throughout the highs and lows of this experience.

God bless you all. 


\section{Table of Contents}

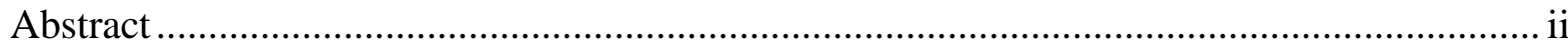

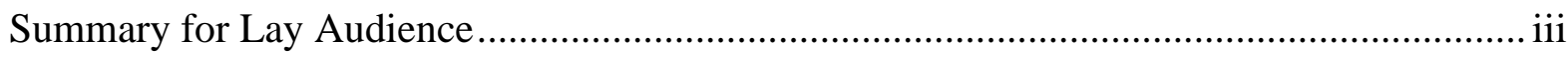

CO-AUTHORSHIP STATEMENT ...................................................................... iv

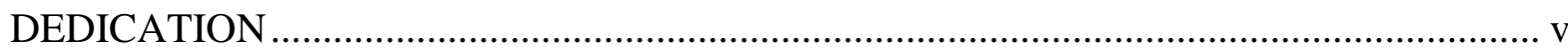

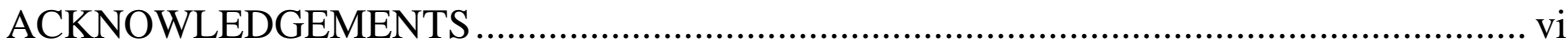

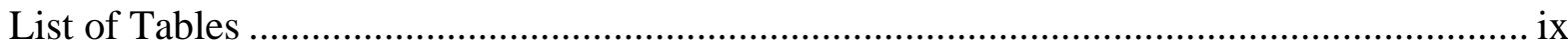

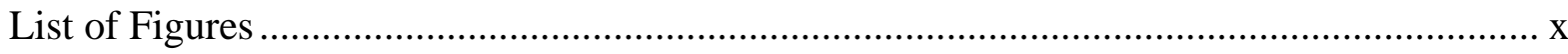

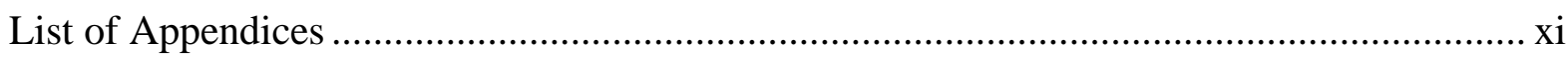

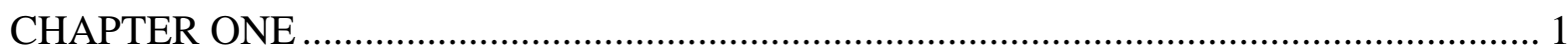

Intimate Partner Violence .................................................................................. 3

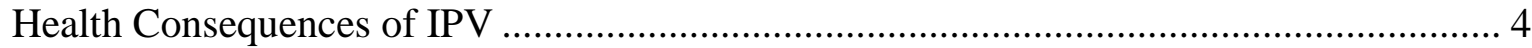

Functional Gastrointestinal Disorders (FGIDs) and Symptoms ..................................... 6

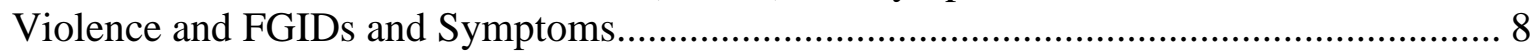

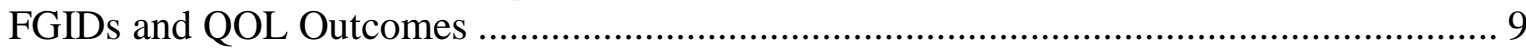

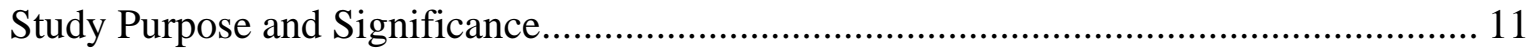

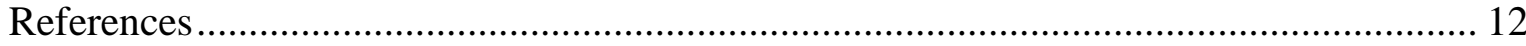

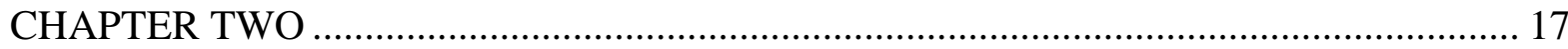

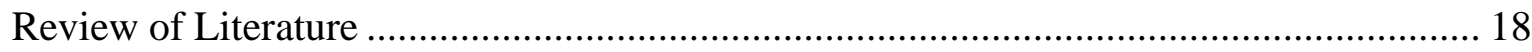

The Relationship between IPV and FGIDs.................................................... 18

Systematic Reviews Addressing Risk Factors for the Development of FGIDs............. 20

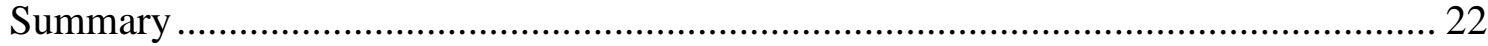

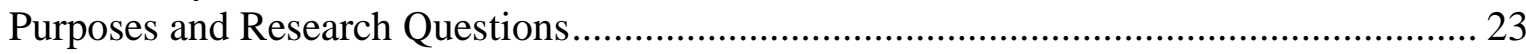

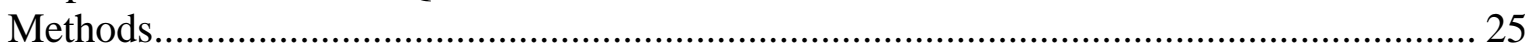

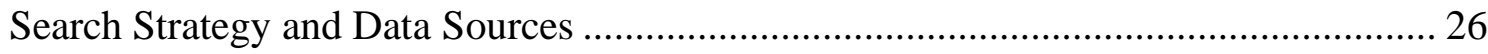

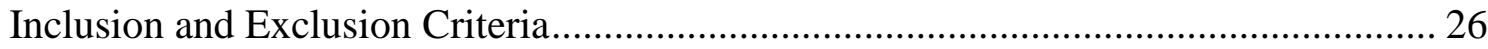

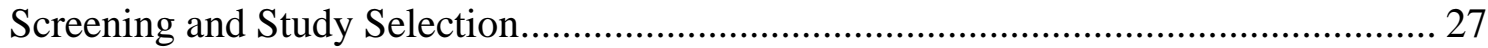

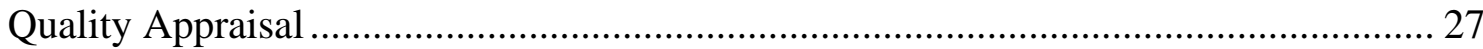

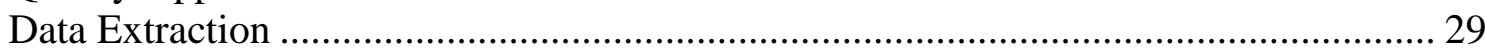

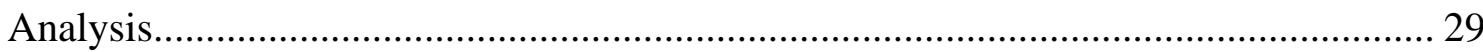

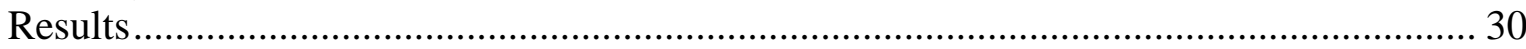

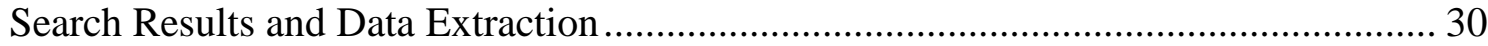

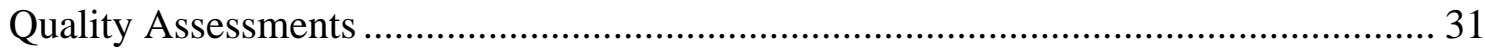

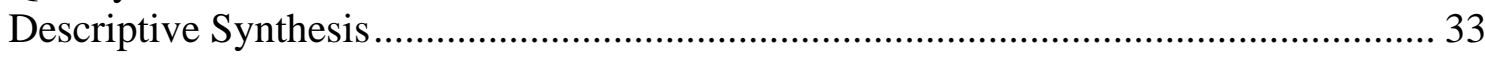

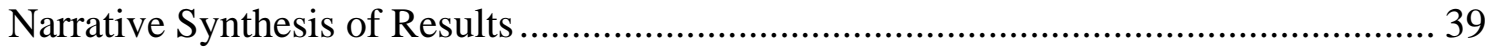

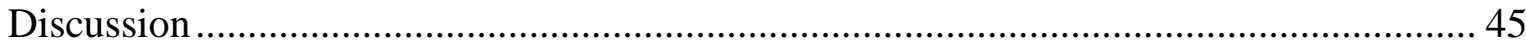

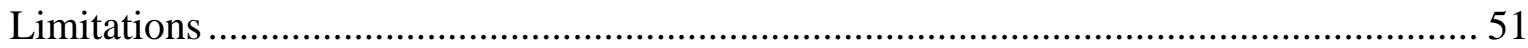

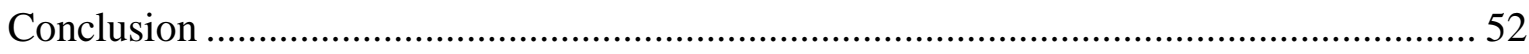

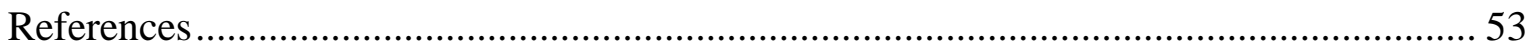

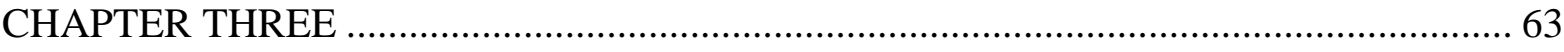

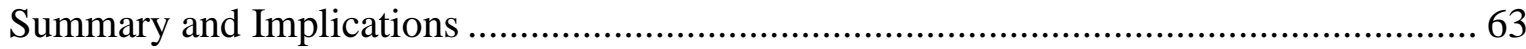


Implications for Nursing Practice and Health Care .................................................. 64

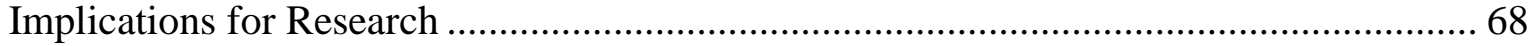

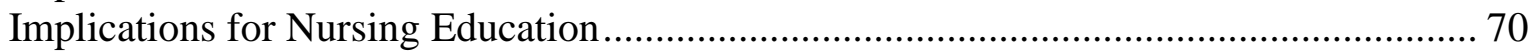

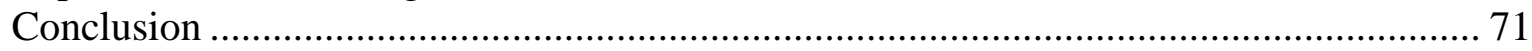

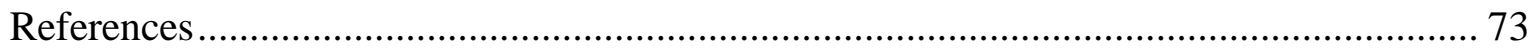




\section{List of Tables}

Table Description Page

Table 1 Definitions of Study Concepts 24

Table 2 Summary of Quality Assessment for Quantitative Studies (n=14) 32

Table $3 \quad$ Summary of Quantitative Study Results 41 


\section{List of Figures}

Figure

Description

PRISMA 2009 Flow Diagram

Figure 1
Page 


\section{List of Appendices}

$\begin{array}{lll}\text { Appendix Description } & \text { Page }\end{array}$

$\begin{array}{lll}\text { Appendix A Prisma-P-Checklist } & 84\end{array}$

$\begin{array}{lll}\text { Appendix B PICO Framework } & 86\end{array}$

$\begin{array}{lll}\text { Appendix C } & \text { Search Results } & 89\end{array}$

$\begin{array}{lll}\text { Appendix D Quality Assessment Tool for Quantitative Studies } & 91\end{array}$

Appendix E Quality Assessment Tool for Qualitative Studies 93

Appendix F Detailed Summary of Quality Assessment for each Quantitative 94 Study

Appendix G The Data Extraction Table for Quantitative and Qualitative $\quad 81$ Studies

$\begin{array}{lll}\text { Appendix H } \quad \text { Curriculum Vitae } & 96\end{array}$ 


\section{CHAPTER ONE}

According to the World Health Organization (2013), almost 30\% of all women who have been in a relationship have experienced physical and/or sexual violence by their intimate partner, worldwide. In 2016, Statistics Canada reported that one-third of all incidents of violence reported to police were incidents of intimate partner violence (IPV) and eight out of ten of the victims of reported IPV were female (Burczycka \& Conroy, 2018); further, women are five times more likely to be killed by an intimate partner than are men (Beattie, David, \& Roy, 2018). However, because women throughout the world tend to be silent about their abuse, it has been argued that IPV against women is frequently underreported (Palermo, Bleck, \& Peterman, 2014). In addition, data collection tends to be based on questions that emphasize physical and sometimes sexual violence, such that psychological abuse experiences are often not fully captured (Ford-Gilboe et al., 2016).

In recent years, research has shown that women who have experienced physical, sexual, and/or psychological IPV in adulthood are at greater risk of both mental health and physical health problems that can result in significant, long-term health burdens (Dillon, Hussain, Loxton, \& Rahman, 2013; Stockman, Hayashi, \& Campbell, 2015). Although there has been more emphasis on the relationship between IPV and mental health outcomes such as depression (Beydoun, Beydoun, Kaufman, Lo, \& Zonderman, 2012) or post-

traumatic stress disorder (PTSD; Lagdon, Armour, \& Stringer, 2014), there is evidence that IPV also affects physical health. For example, women who have experienced IPV have been shown to be at increased risk of chronic pain (Alhalal, Ford-Gilboe, Wong, \& Albuhairan, 2018; Wuest et al., 2008), gastrointestinal symptoms (Campbell, 2002; Perona et al., 2005), and migraine (Cripe, Sanchez, Gelaye, Sanchez, \& Williams, 2011), although it has also been argued the effects of IPV on physical health requires further study (Cripe et al., 2011). 
Functional gastrointestinal disorders (FGIDs) and symptoms are considered to be among the long-term health problems experienced by abused women (Coker, Smith, Bethea, King, \& McKeown, 2000; Perona et al., 2005; Wong \& Mellor, 2014). Several studies have provided support for the idea that there is a relationship between IPV - whether psychological, physical, or sexual - and FGIDs and symptoms, and that experiencing FGIDs has a negative effect on women's quality of life (QOL) outcomes. The available evidence shows that women with FGIDs and symptoms are more likely to have experienced IPV than women who have not experienced IPV (Campbell et al., 2002; Perona et al., 2005).

Additionally, women who suffer with FGIDs often experience associated challenges such as income insecurity as a result of a reduced ability to work, increased the health care costs, and being subjected to unnecessary medical tests and procedures; these challenges may increase the negative impact on women's QOL outcomes (Perona et al., 2005; Leserman \& Drossman, 2007).

FGIDs and symptoms comprise a heterogeneous group of chronic conditions that are not associated with structural or biochemical abnormalities (Drossman, 2016). The majority of FGIDs and symptoms, particularly irritable bowel syndrome (IBS), bloating, constipation, and chronic functional abdominal pain, are more prevalent in women than men (Chang et al., 2006). The illness experience of women with FGIDs, such as IBS, is similar to those who live with other chronic conditions of uncertain etiology and ambiguous diagnostic criteria, with negative effects on various aspects of their QOL: economic insecurity (Leserman \& Drossman, 2007), poor mental health including emotional distress, a perceived lack of support, and unsatisfactory experiences with health care providers (Basnayake et al., 2020). In this thesis, evidence on the relationships between IPV and FGIDs and symptoms, and the association between FGIDs and QOL outcomes among women was systematically 
reviewed. To provide a foundation for this study, a brief overview of the literature addressing IPV, the health consequences of IPV, and FGIDs in the context of violence are provided in this chapter, followed by the main study report in Chapter 2. In Chapter 3, the study findings and their implications are summarized and recommendations for future studies and clinical practice are provided.

\section{Intimate Partner Violence}

IPV is defined as "any behaviour by a current or former intimate partner that causes physical, sexual or psychological harm, including acts of physical aggression, sexual coercion, psychological abuse and controlling behaviours" (WHO, 2017, p.2). It is a major global problem and a violation of women's human rights that occurs in all socioeconomic, religious, and cultural groups and in all settings (Heise \& García-Moreno, 2012). Women overwhelmingly bear the global burden of IPV since the majority of IPV perpetrators are men and a minority of victims are men (Heise \& García-Moreno, 2012; Tarzia, Forsdike, Feder, \& Hegarty, 2020). However, health care professionals are generally not well-prepared to respond to patients, male or female, who are experiencing and/or perpetrating violence in their intimate relationships (Arboit, Padoin, \& Vieira, 2020).

The social and economic costs of IPV are enormous and its effects reverberate throughout society (WHO, 2017). Many scholars have studied the negative effects of IPV on women's lives, including economic (Borchers, Lee, Martsolf, \& Maler, 2016; Oduro, Deere, \& Catanzarite, 2015; Showalter \& McCloskey, 2020), social (WHO, 2017; Heise \& GarcíaMoreno, 2012), physical (Ford- Gilboe et al., 2015; Dekel, Shaked, Ben-Porat, \& Itzhaky, 2020), and psychological consequences (Ahmadabadi et al., 2020). Women experiencing IPV may experience isolation and an inability to work, which can lead to a loss of financial resources, an inability to participate in regular activities, and a reduced ability to care for 
themselves and their children (WHO, 2017). Also, a woman's financial dependence on her abuser can leave her trapped in a state of fear of abuse (Oduro et al., 2015). There is evidence to show that an economic power imbalance in marriage or intimate relationships increases vulnerability to IPV, whereas factors such as a woman's homeownership might be a deterrent to IPV (Kumar \& Casey, 2020; Oduro et al., 2015).

\section{Health Consequences of IPV}

To date, epidemiological and clinical research has shown that IPV is consistently associated with a broad range of negative health outcomes (Dekel et al., 2020). Mental health issues associated with IPV are the same as those associated with other forms of trauma (Coker et al., 2000), such as depression, PTSD, anxiety, suicide and other forms of self-harm, and psychological distress (Dillon et al., 2013). Physical health concerns including both functional and chronic physical health problems, such as high levels of chronic pain, cardiovascular, circulatory, and respiratory problems, and gynecological symptoms, are also associated with IPV (Dillon et al., 2013). Research has also shown that women who leave an abusive partner can become impoverished as a result of the longstanding chronic health problems associated with IPV, such as FGIDs and symptoms (Wuest, Ford-Gilboe, MerrittGray, \& Berman, 2003), showing that the economic and health consequences of IPV are linked.

A person exposed to repeated trauma, such as IPV, has an opportunity to anticipate and develop strategies for managing the trauma and stress associated with it, but also faces a period of prolonged fear (Woods \& Gill, 2011). Exposure to the ongoing traumatic stress associated with IPV adversely affects women's physiologic balance and well-being through its effects on the dynamic interplay between the physiologic, immunologic, and psychological responses to stress (Woods \& Gill, 2011). During acute stress, the body 
undergoes a physiologic fight-or-flight response consisting of activation of the hypothalamicpituitary-adrenal (HPA) axis and sympathetic nervous system (SNS); this activation results in the release of stress-responsive hormones such as cortisol, epinephrine, and norepinephrine (NE; van der Kolk, 1994; Woods \& Gill, 2011). The release and interactions of these mediators are adaptive as a short-term response to stress; however, prolonged exposure leads to a negative feedback loop that results in the dysregulation of HPA axis which leads to the development of diseases (van der Kolk, 1994). These biological changes explain, in part, the mental and physical health consequences of IPV (Woods \& Gill, 2011). Several theories have been posited to explain alterations in neuroendocrine and inflammatory immune activity in people who have experienced chronic traumatic stress.

Allostatic load refers to the consequences of chronic traumatic stress or the inefficient operation of the stress hormone response system on both body and brain (Kendall-Tackett, 2009). Allostatic load involves primary (or physiological) mediators, secondary outcomes, and tertiary (or clinical) outcomes (Li, Rosemberg, \& Seng, 2018). The primary mediators are the physiological factors that respond to rapid change or acute stress, such as the neuroendocrine system (i.e., cortisol, epinephrine, and NE; Li et al., 2018; Kendall-Tackett, 2009). When these primary mediating hormones are activated to deal with long-term stress via the HPA axis, the secondary outcome, dysregulation of body systems (e.g., immune, cardiovascular, and metabolic systems) occurs (Li et al., 2018; Kendall-Tackett, 2009). Tertiary or clinical outcomes are the clinical manifestations, including morbidity and mortality, that result from prolonged exposure to the secondary outcome (Li et al., 2018; Kendall-Tackett, 2009). Allostatic load takes place when physiological mediators remain at abnormally levels over time in response to prolonged stress, resulting in morbidity and mortality (tertiary or clinical outcomes) from chronic exposure to the physiological mediators 
(Li et al., 2018). Cardiovascular parameters, metabolic functions, immune and inflammatory defenses, and the nervous system are the systems most likely to be affected by high allostatic load (Kendall-Tackett, 2009).

Exposure to chronic traumatic stress such as abuse in childhood or adulthood (whether psychological, physical, or sexual abuse) is widely accepted as a stressor with longterm consequences for both mental health (Li et al., 2018; Scheuer et al., 2000) and physical health (Horan \& Widom, 2015; Woods, Hall, Campbell, \& Angott, 2008). For example, allostatic load as a result of IPV has been found to be a precursor to post-traumatic stress disorder (PTSD; Woods et al., 2008), and maternal PTSD can have adverse effects on birth outcomes (Li et al., 2018). Due to the joint actions of underlying stress mediators, more severe levels of IPV may be linked to higher levels of physical and mental health symptoms (Kendall-Tackett, 2009).

\section{Functional Gastrointestinal Disorders (FGIDs) and Symptoms}

FGIDs are a group of chronic gastrointestinal symptoms that are associated with various alterations in the brain-gut axis, such as motor derangements, visceral hypersensitivity, and abnormal central processing of sensory signals, but with no organic cause (Aziz, Palsson, Whitehead, Sperber, Simrén, \& Törnblom, 2019). FGIDs include IBS, functional dyspepsia (FD)/indigestion (i.e., pain or discomfort in the upper abdominal area, feeling of fullness, bloating or nausea), chronic abdominal pain symptoms, frequent diarrhea and constipation, and vomiting and nausea disorders (Lacy, Ford, \& Talley, 2018). FGIDs

are the most common diagnoses in gastroenterology (Drossman, 2016), impacting more than 1 in 5 Americans and their families (Talley, 2020). Furthermore, 30\% of the general population in the United States, Canada, and the United Kingdom are affected by FD, and $70 \%$ of these have FD (Mounsey, Barzin, \& Rietz, 2020). 
The Rome criteria are the result of an international effort to standardize the diagnosis and treatment of FGIDs and symptoms (Drossman, 2016). The Rome Foundation was established in the late 1980s at a time when there was little understanding of the pathophysiology of FGIDs, no established classification system, and no guidelines for standardized research into these disorders (Drossman, 2016). The first set of Rome criteria, issued in 1989, were diagnostic criteria established by consensus by experts on IBS around the world (Drossman, 2016). However, because IBS is not the only FGID, the Rome criteria evolved through the Rome Classification System for IBS in 1990 to Rome I in 1994 for IBS and FGIDs, and then to Rome II in 1999 and Rome III in 2006 which incorporated pediatric criteria to the consensus. Rome IV, which was published ten years later in May 2016, covers epidemiology, pathophysiology, psychosocial and clinical features, and diagnostic evaluation and treatment recommendations for 33 adult and 17 pediatric FGIDs (Drossman, 2016).

The Rome IV criteria (Drossman, 2016) currently used by clinicians to diagnose patients with FGIDs are based primarily on symptoms rather than physiological criteria according to anatomic regions (i.e., esophageal, gastroduodenal, bowel, biliary, and anorectal; Drossman, 2016). While 24 separate disorder groups are delineated by the Rome IV classification system for adults, the most common disorders are IBS and FD (Drossman \& Hasler, 2016). Several studies have shown a relationship between genetic, environmental, psychosocial, and physiological factors and FGIDs, most notably IBS (Chitkara, van Tilburg, Blois-Martin \& Whitehead, 2008). A few studies have highlighted the importance of perceived stress in FGIDs. For example, in laboratory studies, persons with IBS have been found to show greater psychological and biological reactivity to stressors, which might influence their perception of gastrointestinal discomfort and pain (Bach et al., 2006). 


\section{Violence and FGIDs and Symptoms}

Some research has documented a significant association between adult IBS and childhood factors including childhood sexual, emotional, and verbal abuse (Chitkara et al., 2008) and between IPV and FGIDs and symptoms in adult women (Becker-Dreps et al., 2010; Coker et al., 2000). The primary theoretical framework used to study FGIDs and symptoms and violence is the biopsychosocial model (Becker-Dreps et al., 2010; Nakphong \& Von Ehrenstein, 2020). Developed by Drossman (1999), this model focuses on the complex interactions between biologic factors (i.e., dysregulation in functions via the braingut axis, which is the interplay between the gastrointestinal mucosa, the enteric nervous system, and the central nervous system) and psychosocial factors (i.e., psychological state, stressors, inadequate coping skills, lack of social support) thought to be responsible for the development and maintenance of FGIDs and symptoms in people who are experiencing, or have experienced, abuse.

According to Becker-Dreps et al. (2010), trauma (e.g., IPV, childhood sexual abuse) influences physiological functioning by stimulating the HPA axis; dysregulation of the HPA axis due to chronic activation, along with the enteric nervous system, are thought to be involved in the development of FGIDs and symptoms. More severe FGIDs and symptoms are associated with increased hospital visits and poorer QOL outcomes (Drossman, 2016). However, Drossman proposes that psychosocial factors, such as the availability of supportive relationships and well-developed coping skills, may prevent the development of, or reduce the severity of, FGIDs and symptoms.

A limited body of research examining the role of psychosocial factors identified in the biopsychosocial model, including whether they mediate or moderate relationships between IPV and FGIDs, has produced mixed and unclear results. For example, Koloski, 
Talley, and Boyce (2005) found that abuse experienced as an adult was significantly associated with IBS and/or FD, and proposed (based on theory) that psychosocial factors (e.g., a lack of supportive interpersonal relationships, ineffective coping style, and a lack of social support) may mediate the association. Similarly, Perona et al. (2005) found that the development of FGIDs among women reporting domestic violence to the police was associated with higher levels of psychological distress but did not test for mediation. In contrast, in a population-based study of women in Nicaragua, community support was found to moderate the association between IPV and IBS (Backer-Dreps et al, 2010). These findings are consistent with results of a recent systematic review focussed specifically on IBS (Lee et al., 2017). Results of this review showed that IBS symptoms can be affected by both psychosocial factors, such as psychological problems and life stressors, and physiological factors through the brain-gut axis and that psychosocial factors (i.e., anxiety and depression), which are common in IBS patients, moderate the association. Whether these or other factors mediate the relationship between IPV and FGIDs is a gap in understanding.

\section{FGIDs and QOL Outcomes}

Given that the etiology of FGIDs remains unclear, treatments are mostly aimed at reducing symptoms, not curing the disorder. Difficulty establishing a diagnosis is common, such that patients with FGIDs and symptoms are often subject to unnecessary tests and procedures, which can lead to frustration for both patients and health care providers and contribute to higher health care costs (Becker-Dreps et al., 2010; Leserman \& Drossman, 2007). According to Leserman and Drossman (2007), patients with IBS report more pain and more health care visits than patients with other chronic diseases, such as diabetes, end-stage renal disease, and asthma (Leserman \& Drossman, 2007). FGIDs and symptoms can lead to unpleasant outcomes and consequences that affect women's QOL outcomes including their 
economic position (e.g., their ability to work), social life and relationship (e.g., their relationships with friends and family), and mental health (Becker-Dreps et al., 2010; Choi \& Jung, 2011; Leserman \& Drossman, 2007).

Women who have experienced violence face particular challenges such as safety risks, social isolation and poor physical and mental health as a result of injury or trauma, yet limited attention has been given to understanding their experience of FGIDs and how these experiences influence women's QOL outcomes over time. The WHO QOL Working Group (1998) defined QOL as “individuals' perceptions of their position in life in the context of the culture and value systems in which they live and in relation to their goals, expectations, standards and social relations. It is a broad ranging concept affected in a complex way by the person's physical health, psychological state, level of independence, social relationships and their relationship to salient features of their environment" (p. 25). As the definition shows, there are many domains of QOL: economic, physical health, mental health, environment, and social relationships. There is some evidence that women who have experienced FGIDs report significantly lower QOL in several domains: health (Becker-Dreps et al., 2010), social relationships (Koloski et al., 2005), economic situation (Leserman \& Drossman, 2007), and psychological health (Lee et al., 2017). However, limited attention has been given to understanding the impacts of women's FGIDs and symptoms on a wide range of QOL outcomes over time. Given the potential burden associated with FGIDs, a better understanding of the association between IPV and FGIDs and symptoms as well as the impacts on women's QOL outcomes is needed. 


\section{Study Purpose and Significance}

Although there is now considerable research in the area of IPV and FGIDs and symptoms, no systematic review has been conducted. This systematic review was undertaken to address some critical gaps in specific areas where the evidence is unclear. Specifically, the purposes of this study were to: a) examine the association between different types of IPV (i.e., physical, sexual, and psychological abuse) and the risk of FGIDs and symptoms (such as chronic abdominal pain symptoms, IBS, FD, frequent diarrhea, frequent constipation, and vomiting and nausea disorders) among adult women, b) identify the mechanisms that might mediate or moderate these health effects, and, c) examine how FGIDs affect aspects of women's QOL (e.g., health, social life, and economic status). A review of the kind proposed can consolidate what is known, identify priorities for future research and provide a foundation for improving clinical interventions, including those specifically developed for women with FGIDs and symptoms who have experienced IPV. 


\section{References}

Ahmadabadi, Z., Najman, J. M., Williams, G. M., Clavarino, A. M., d’Abbs, P., \& Tran, N. (2020). Intimate partner violence and subsequent depression and anxiety disorders. Social Psychiatry and Psychiatric Epidemiology,55(5), 611620. https://doi.org/10.1007/s00127-019-01828-1

Alhalal, E., Ford-Gilboe, M., Wong, C., \& Albuhairan, F. (2018). Factors mediating the impacts of child abuse and intimate partner violence on chronic pain: A cross-sectional study 11 Medical and Health Sciences 1117 Public Health and Health Services 17 Psychology and Cognitive Sciences 1701 Psychology. BMC Women's Health, 18(1), 115. https://doi.org/10.1186/s12905-018-0642-9

Arboit, J., Padoin, S. M. de M., \& Vieira, L. B. (2020). Violence against women in Primary Health Care: Potentialities and limitations to identification. Atencion Primaria, 52(1), 14-21. https://doi.org/10.1016/j.aprim.2018.09.008

Aziz, I., Palsson, O. S., Whitehead, W. E., Sperber, A. D., Simrén, M., \& Törnblom, H. (2019). Epidemiology, clinical characteristics, and associations for Rome IV functional nausea and vomiting disorders in adults. Clinical Gastroenterology and Hepatology, 17(5), 878-886.https://doi.org/10.1016/j.cgh.2018.05.020

Basnayake, C., Kamm, M. A., Salzberg, M. R., Wilson-O’Brien, A., Stanley, A., \& Thompson, A. J. (2020). Delivery of care for functional gastrointestinal disorders: A systematic review. Journal of Gastroenterology and Hepatology (Australia), 35(2), 204-210. https://doi.org/10.1111/jgh.14830

Beattie, S., David, J., \& Roy, J. (2018). Homicide in Canada, 2017. https://www150.statcan.gc.ca/n1/pub/85-002- x/2018001/article/54980-eng.htm

Becker-Dreps, S., Morgan, D., Peña, R., Cortes, L., Martin, C. F., \& Valladares, E. (2010). Association Between Intimate Partner Violence and Irritable Bowel Syndrome: A Population-Based Study in Nicaragua. Violence Against Women, 16(7), 832-845. https://doi.org/10.1177/1077801210374816

Beydoun, H. A., Beydoun, M. A., Kaufman, J. S., Lo, B., \& Zonderman, A. B. (2012). Intimate partner violence against adult women and its association with major depressive disorder, depressive symptoms and postpartum depression: a systematic review and meta-analysis. Social Science \& Medicine, 75(6), 959-975. https://doi.org/10.1016/j.socscimed.2012.04.025

Borchers, A., Lee, R. C., Martsolf, D. S., \& Maler, J. (2016). Employment maintenance and intimate partner violence. Workplace Health and Safety, 64(10), 469-478. https://doi.org/10.1177/2165079916644008

Burczycka, M., \& Conroy, S. (2018). Family violence in Canada: A statistical profile, 2016. Juristat: Canadian Centre for Justice Statistics, 37(1), 1-96. http://search.proquest.com/docview/2001355630/ 
Campbell, J. C. (2002). Health consequences of intimate partner violence. The Lancet, 359(9314), 1331-1336. https://doi.org/10.1016/S0140-6736(02)08336-8

Chang, L., Toner, B. B., Fukudo, S., Guthrie, E., Locke, G. R., Norton, N. J., \& Sperber, A. D. (2006). Gender, age, society, culture, and the patient's perspective in the functional gastrointestinal disorders. Gastroenterology, 130(5), 1435-1446. https://doi.org/10.1053/j.gastro.2005.09.071

Chitkara, D. K., van Tilburg, M. A. L., Blois-Martin, N., \& Whitehead, W. E. (2008). Early life risk factors that contribute to irritable bowel syndrome in adults: A systematic review. The American Journal of Gastroenterology, 103(3), 765774. https://doi:10.1111/j.1572-0241.2007.01722.x

Choi, M. G., \& Jung, H. K. (2011). Health related quality of life in functional gastrointestinal disorders in Asia. Journal of Neurogastroenterology and Motility, 17(3), 245-251. https://doi.org/10.5056/jnm.2011.17.3.245

Coker, A. L., Smith, P. H., Bethea, L., King, M. R., \& McKeown, R. E. (2000). Physical health consequences of physical and psychological intimate partner violence. Archives of Family Medicine, 9(5), 451-457. https://doi.org/10.1001/archfami.9.5.451

Cripe, S. M., Sanchez, S. E., Gelaye, B., Sanchez, E., \& Williams, M. A. (2011). Association between intimate partner violence, migraine and probable migraine. Headache, 5l(2), 208-219. https://doi.org/10.1111/j.1526-4610.2010.01777.x

Dekel, R., Shaked, O., Ben-Porat, A., \& Itzhaky, H. (2020). The interrelations of physical and mental health: Self-rated health, depression, and PTSD among female IPV survivors. Violence Against Women, 26(3-4), 379-394. https://doi.org/10.1177/1077801219832916

Dillon, G., Hussain, R., Loxton, D., \& Rahman, S. (2013). Mental and physical health and intimate partner violence against women: A review of the literature. International Journal of Family Medicine, 2013(2013), 1-15. https://doi.org/10.1155/2013/313909

Drossman, D. A. (2016). Functional gastrointestinal disorders: History, pathophysiology, clinical features, and Rome IV. Gastroenterology, 150(6), 1262-1279.e2. https://doi.org/10.1053/j.gastro.2016.02.032

Drossman, D. A., \& Hasler, W. L. (2016). Rome IV—functional GI disorders: Complications of gut-brain interaction. Gastroenterology, 150(6), 1257-1261. https://doi.org/10.1053/j.gastro.2016.03.035

Ford-Gilboe, M., Varcoe, C., Noh, M., Wuest, J., Hammerton, J., Alhalal, E., \& Burnett, C. (2015). Patterns and Predictors of Service Use Among Women Who Have Separated from an Abusive Partner. Journal of Family Violence, 30(4), 419-431. https://doi.org/10.1007/s10896-015-9688-8

Ford-Gilboe, M., Wathen, C., Varcoe, C., Macmillan, H., Scott-Storey, K., Mantler, T., ... Perrin, N. (2016). Development of a brief measure of intimate partner violence 
experiences: The Composite Abuse Scale (Revised)—Short Form (CAS R -SF). BMJ Open, 6(12), e012824. https://doi.org/10.1136/bmjopen-2016-012824

Heise, L., \& García-Moreno, C. (2012). Violence by intimate partners. https://www.paho.org/hq/dmdocuments/2012/vawipv.

Horan, J. M., \& Widom, C. S. (2015). Cumulative childhood risk and adult functioning in abused and neglected children grown up. Development and Psychopathology, 27(3), 927-941. https://doi.org/10.1017/S095457941400090X

Kendall-Tackett, K. (2009). The psychoneuroimmunology of chronic disease: Exploring the links between inflammation, stress, and illness. Washington, DC: American Psychological Association.

Koloski, N. A., Talley, N. J., \& Boyce, P. M. (2005). A history of abuse in community subjects with irritable bowel syndrome and functional dyspepsia: The role of other psychosocial variables. Digestion, 72(2-3), 86-96. https://doi.org/10.1159/000087722

Kumar, S., \& Casey, A. (2020). Work and intimate partner violence: Powerful role of work in the empowerment process for middle-class women in abusive relationships. Community, Work and Family, 23(1), 1-18. https://doi.org/10.1080/13668803.2017.1365693

Lacy, B. E., Ford, A. C., \& Talley, N. J. (2018). Quality of care and the irritable bowel syndrome: Is now the time to set standards? American Journal of Gastroenterology, 113(2), 167-169. https://doi.org/10.1038/ajg.2017.442

Lagdon, S., Armour, C., \& Stringer, M. (2014). Adult experience of mental health outcomes as a result of intimate partner violence victimisation: A systematic review. European Journal of Psychotraumatology, 5(1). Article 24794.

https://doi.org/10.3402/ejpt.v5.24794

Lee, C., Doo, E., Choi, J. M., Jang, S. ho, Ryu, H. S., Lee, J. Y., ... Kim, Y. S. (2017). The increased level of depression and anxiety in irritable bowel syndrome patients compared with healthy controls: Systematic review and meta-analysis. Journal of

Neurogastroenterology and Motility, 23(3), 349-362. https://doi.org/10.5056/jnm16220

Leserman, J., \& Drossman, D. A. (2007). Relationship of abuse history to functional gastrointestinal disorders and symptoms: Some possible mediating mechanisms. Trauma, Violence, and Abuse, 8(3), 331-343. https://doi.org/10.1177/1524838007303240

Li, Y., Rosemberg, M. A. S., \& Seng, J. S. (2018). Allostatic load: A theoretical model for understanding the relationship between maternal posttraumatic stress disorder and adverse birth outcomes. Midwifery, 62, 205-213. https://doi.org/10.1016/j.midw.2018.04.002

Nakphong, M. K., \& Von Ehrenstein, O. S. (2020). Intimate partner violence and childhood illnesses in Cambodia: A cross-sectional study. Archives of Disease in Childhood, 
105(3) 223-228. https://doi.org/10.1136/archdischild-2019-317663

Mounsey, A., Barzin, A., \& Rietz, A. (2020). Functional dyspepsia: Evaluation and management. American Family Physician, 101(2), 84-88.

Oduro, A. D., Deere, C. D., \& Catanzarite, Z. B. (2015). Women's wealth and intimate partner violence: Insights from Ecuador and Ghana. Feminist Economics, 21(2), 1-29. https://doi.org/10.1080/13545701.2014.997774

Palermo, T., Bleck, J., \& Peterman, A. (2014). Tip of the iceberg: Reporting and genderbased violence in developing countries. American Journal of Epidemiology, 179(5), 602-612. https://doi.org/10.1093/aje/kwt295

Perona, M., Benasayag, R., Perelló, A., Santos, J., Zárate, P., Zárate, N., \& Mearin, F. (2005). Prevalence of functional gastrointestinal disorders in women who report domestic violence to the police. Clinical Gastroenterology and Hepatology, 3(5), 436441. https://doi:10.1016/S1542-3565(04)00776-1

Scheuer, H., Gwinner, W., Hohbach, J., Gröne, E. F., Brandes, R. P., Malle, E., ... \& Gröne, H. J. (2000). Oxidant stress in hyperlipidemia-induced renal damage. American Journal of Physiology-Renal Physiology, 278(1), F63-F74. https://doi.org/10.1152/ajprenal.2000.278.1.F63

Showalter, K., \& McCloskey, R. J. (2020). A Qualitative study of intimate partner violence and employment instability. Journal of Interpersonal Violence. https://doi.org/10.1177/0886260520903140

Stockman, J., Hayashi, H., \& Campbell, J. (2015). Intimate partner violence and its health impact on ethnic minority women. Journal of Women's Health, 24(1), 62-79. https://doi.org/10.1089/jwh.2014.4879

Tarzia, L., Forsdike, K., Feder, G., \& Hegarty, K. (2020). Interventions in health settings for male perpetrators or victims of intimate partner violence. Trauma, Violence, and Abuse, 2l(1), 123-137. https://doi.org/10.1177/1524838017744772

The WHOQOL Group. (1998). The World Health Organization quality of life assessment (WHOQOL): Development and general psychometric properties. Social Science \& Medicine, 46(12), 1569-1585. https://doi.org/10.1016/S0277-9536(98)00009-4

van der Kolk, B. A. (1994). The body keeps the score: Memory and the evolving psychobiology of posttraumatic stress. Harvard Review of Psychiatry, 1(5), 253-265.

Woods, S. J., Hall, R. J., Campbell, J. C., \& Angott, D. M. (2008). Physical health and posttraumatic stress disorder symptoms in women experiencing intimate partner violence. Journal of Midwifery \& Women's Health, 53(6), 538-546. https://doi.org/10.1016/j.jmwh.2008.07.004

Woods, S., \& Gill, J. (2010). Family violence: Long-term health consequences of trauma. In Humphreys, J., Campbell, J.C., (Eds.), Family violence and nursing practice (pp. 29- 
50). New York, NY: U.S. Springer Publishing Company

Wong, J., \& Mellor, D. (2014). Intimate partner violence and women's health and wellbeing: Impacts, risk factors and responses. Contemporary Nurse, 46(2), 170-179. https://doi.org/10.5172/conu.2014.46.2.170

World Health Organization (2013). Global and regional estimates of violence against women: Prevalence and health effects of intimate partner violence and non-partner sexual violence.

https://www.who.int/reproductivehealth/publications/violence/9789241564625/en/

World Health Organization (2017). Violence against women. https://www.who.int/newsroom/fact-sheets/detail/violence-against-women

Wuest, J., Merritt-Gray, M., Ford-Gilboe, M., Lent, B., Varcoe, C., \& Campbell, J. C. (2008). Chronic pain in women survivors of intimate partner violence. Journal of Pain, 9(11), 1049-1057. https://doi.org/10.1016/j.jpain.2008.06.009

Wuest, J., Ford-Gilboe, M., Merritt-Gray, M., \& Berman, H. (2003). Intrusion: The central problem for family health promotion among children and single mothers after leaving an abusive partner. Qualitative Health Research, 13(5), 597-622.

https://doi:10.1177/1049732303013005002 


\section{CHAPTER TWO}

Globally, about 1 in 3 women have experienced either physical and/or sexual intimate partner violence (IPV) or non-partner sexual violence in their lifetime and as many as $38 \%$ of murders of women are committed by a male intimate partner (World Health Organization, 2017, 2020). IPV is defined as "any behaviour by a current or former intimate partner that causes physical, sexual or psychological harm, including acts of physical aggression, sexual coercion, psychological abuse and controlling behaviours" (WHO, 2017, p 2). Given that IPV can result in short and/or long-term health problems that have significant, undesirable effects on women's health, well-being and quality of life (QOL; WHO, 2019), it is understood as a critical global public health problem. There is now a large body of research documenting the relationship between IPV and mental health outcomes including depression (Beydoun, Beydoun, Kaufman, Lo, \& Zonderman, 2012) and post-traumatic stress disorder (PTSD; Lagdon, Armour, \& Stringer, 2014).

IPV has also been found to increase women's risk of physical health problems such as chronic pain (Alhalal, Ford-Gilboe, Wong, \& AlBuhairan, 2018; Wuest, Merritt-Gray, FordGilboe, Lent, Varcoe, \& Campbell, 2008), gastrointestinal symptoms (Campbell, 2002; Perona et al., 2005) and migraine (Cripe, Sanchez, Gelaye, Sanchez, \& Williams, 2011), with significant impacts for women's lives. However, research on the physical health consequences of IPV has been identified as an important gap in knowledge and a priority area for future research (Alhalal et al., 2018; Cripe et al., 2011). To begin addressing this issue, in this study, we conducted a systematic review of research examining IPV and a common physical health problem, Functional Gastrointestinal Disorders (FGIDs), that has been linked to IPV. Although there is recent growth in studies addressing this issue, a synthesis of the current research has not yet been conducted. 


\section{Review of Literature}

FGIDs and symptoms are a broad class of disturbances of the middle or lower digestive tract characterized by chronic abdominal pain or discomfort and disturbed bowel function without an identified etiology (Coker, Smith, Bethea, King, \& McKeown, 2000; Longstreth, Thompson, Chey, Houghton, Mearin, \& Spiller, 2006; Wong \& Mellor, 2014). Since there are no structural changes associated with FGIDs and symptoms, a symptombased classification is necessary for clinical diagnosis, evidence-based management, and research. These disorders include irritable bowel syndrome (IBS), functional bloating, functional constipation, functional diarrhea, and unspecified functional bowel disorder (Longstreth et al., 2006). FGIDs and symptoms are the most common gastrointestinal (GI) disorders among adults (Marrie et al., 2019). Worldwide, IBS affects approximately $1.1 \%$ to $29.2 \%$ of adults (Oshima \& Miwa , 2016), is more common among women than men (Jahng \& Kim, 2017; Kim \& Kim, 2018), and causes significant disruption to daily life such that it affects women's QOL outcomes (Marrie et al., 2019). Negative effects include a reduction in mental and physical health and increase in health care utilization (Koloski, Talley, \& Boyce, 2000) and a reduction in work productivity (Dean et al., 2005). However, the impacts of FGIDs on the QOL outcomes of women living with IPV is not well understood (BeckerDreps, Morgan, Peña, Cortes, Martin, \& Valladares, 2010; Choi \& Jung, 2011).

\section{The Relationship between IPV and FGIDs}

There is some evidence that women living with FGIDs and symptoms are more likely to have experienced IPV in adulthood, including rape and life-threatening physical abuse, than women with organic GI diseases (Drossman, 1999; Wong \& Mellor, 2014). Drossman et al. (1996) also found that individuals with FGIDs report having experienced psychological trauma (e.g., sexual and/or physical abuse) more often than either patients with organic GI 
diseases or healthy individuals. Furthermore, in some recent studies (Coker et al., 2000; Perona et al., 2005; Kelly, 2010), an association has been found between IPV (whether psychological, physical and/or sexual) and FGIDs and symptoms in women. For example, in a study of 70 women who had experienced physical, and/or psychological IPV and were seeking help from police, Perona et al (2005) found that 71\% of women had an FGID, while Kelly (2010) found that $63.6 \%$ of a sample of U.S. Latina women $(n=33)$ who had accessed domestic violence services reported gastrointestinal symptoms. These studies documented relatively high rates of FGIDs and symptoms in women who had experienced different forms of IPV (i.e. psychological, physical and sexual abuse), yet the sample sizes were small.

There is also some evidence of increased risk of FGIDs in studies of women experiencing IPV. For example, Becker-Dreps et al., (2010) found that Latina women who had experienced physical and sexual IPV had a significantly greater risk of IBS than other women from the same population. Coker et al.'s (2000) study looking at the association between IPV and physical health in women seeking primary health care found that FGIDs were more common among women who had experienced psychological IPV than among those who had experienced other forms of IPV. However, whether the strength of the association between different types of abuse and FGIDs and symptoms varies has not been examined. This is an important gap in understanding the health consequences of IPV, since researchers have tended to focus on the impacts of physical and sexual violence and ignore psychological violence, in spite of some evidence that psychological abuse and coercive control can have impacts that are the same as or more substantial than, physical or sexual abuse (Heise, Pallitto, García-Moreno, \& Clark, 2019; Myhill, 2015; Myhill \& Hohl, 2019). 


\section{Systematic Reviews Addressing Risk Factors for the Development of FGIDs}

Three systematic reviews were published between 2008 and 2017 examining factors that contribute to the risk of FGIDs and symptoms. Chitkara, Miranda, Tilburg, Blois-Martin, and Whitehead (2008) examined early childhood factors that contribute to the development of IBS in adolescents and adults drawing on 25 studies identified from the PubMed database between 1966 and 2007. The result of this systematic review showed that IBS symptoms in adolescence and adulthood are associated with childhood factors: persistent childhood gastrointestinal symptoms, socioeconomic status, traumatic events during infancy and childhood, and social learning of illness behavior. However, findings of this study may not be generalizable to the population because many reviewed studies examined childhood factors in selective populations such as those who sought medical care or had histories of physical and sexual abuse in childhood. There is also a possibility of recall bias since many studies relied on retrospective reports of childhood experiences.

More recently, Afari et al. (2014) conducted a systematic review and meta-analysis to explore the association between psychological trauma, PTSD and functional somatic syndromes such as fibromyalgia, chronic widespread pain, chronic fatigue syndrome, temporomandibular disorder, and IBS using 71 articles identified in several electronic databases: PubMed/Medical Literature On-Line (MEDLINE) (1948 - January 2012), PsyINFO (1860 - January 2012), and Google Scholar (up to January 2012). Both a history of psychological trauma and PTSD were strongly associated with having a functional somatic syndrome. However, PTSD was more strongly related to functional somatic syndromes than either physical or sexual abuse, suggesting that current and lifetime PTSD may lead to functional somatic syndromes, raising questions about whether PTSD may mediate the effects of IPV on functional somatic symptoms, including FGIDs. Further, a history of 
psychological trauma was more strongly associated with chronic fatigue syndrome than IBS (Afari et al., 2014). According to Afari et al. (2014), the findings highlight the importance of conducting prospective, hypothesis-driven studies of the mechanisms that explain the links between trauma and PTSD and different functional somatic syndromes.

Lee et al. (2017) conducted a systematic review and meta-analysis similar to that of Afari et al. (2014) to compare depression and anxiety levels of IBS patients with those of a control group, taking into account IBS subtypes and patient gender using results of 27 studies identified from PubMed, EMBASE, MEDLINE, and the Cochrane library electronic databases (Lee et al., 2017). IBS patients with histories of abuse were found to experience more severe depression, anxiety, and somatic symptoms than those who had not experienced abuse, suggesting that mental health symptoms may mediate the relationship between abuse and FGIDs. Because data in this systematic review did not distinguish between female and male patients, the effect of gender on psychological factors in IBS patients could not be examined (Lee et al., 2017). Therefore, Lee et al. (2017) suggested that prospective studies are needed to evaluate whether there are gender differences in psychological distress among IBS patients.

There are some limitations in the systematic reviews described above. First, Chitkara et al.'s (2008) study is now more than 10 years old and did not address whether abuse in adulthood is a risk factor for FGIDs and symptoms. Afari et al.'s (2014) and Lee et al.'s (2017) systematic reviews are more recent, but neither focused specifically at IPV. Instead, they examined other types of abuse, trauma, or psychological factors. Thus, no systematic reviews have specifically examined the association between IPV and FGIDs among adult women. Second, the reviews conducted by Chitkara et al.'s (2008) and Lee et al. (2017) focused specifically on IBS, but did not include a wider range of FGIDs and symptoms, such 
as functional dyspepsia (FD)/indigestion, frequent diarrhea, frequent constipation, and vomiting and nausea disorder, that may have negative impacts on women's lives. Finally, while Afari et al.'s (2014) and Chitkara et al.'s (2008) systematic reviews included studies focused on either physiological mechanisms or psychosocial mechanisms, how these factors mediated and/or moderated the relationship between IPV and FGIDs was not addressed. There are now a number of concepts and theories that explain the effects of chronic traumatic stress and violence, including IPV, on health outcomes. These include the concept of allostatic load (Li, Rosemberg \& Seng, 2018; Kendall-Tackett, 2009) and biopsychosocial model (Drossman, 1999), which explain both how chronic traumatic stress can lead to dysregulation in functions of the brain-gut axis and the role of psychosocial factors in the development and maintenance of FGIDs and symptoms in people with histories of abuse. Given that theory has potential to enhance understanding of the direction of relationships and mechanisms among a broad set of concepts, a lack of theory-driven research included in these systematic reviews is noteworthy.

Importantly, since these three reviews were completed, a number of studies examining the physical and mental health consequences of IPV for women have been published. Accordingly, there is a need to conduct a systematic review to examine the evidence that links experiences of various types of IPV with FGIDs and symptoms among adult women and identify mechanisms that may mediate and/or moderate this association.

\section{Summary}

The association between women's experiences of IPV (i.e., sexual, physical, and/or psychological abuse) and FGIDs and symptoms (such as IBS, and FD) is recognized in clinical practice, and there is research that supports this relationship (Campbell et al., 2002; Kelly, 2010; Koloski et al., 2005; Perona et al., 2005). However, a number of gaps in 
knowledge remain. Specifically, extant research tends to focus on the consequences of physical and sexual IPV and overlook the impacts of psychological IPV. Whether different types of abuse (i.e., psychological, physical and sexual) affect physical health and mental health differently, including the relationship between different forms of IPV and FGIDs and symptoms, is unclear. There are a number of theoretical explanations about the role of life stressors in the development of chronic health problems, including explanations about how physiological and psychosocial mechanisms produce these effects. However, both the psychosocial and physiological factors that might contribute specifically to FGIDs and symptoms, and the impacts of FGIDs on women's QOL outcomes in the context of IPV are poorly understood. An exploration of the empirical evidence available and what is already known is needed to guide future research.

\section{Purposes and Research Questions}

The purposes of this systematic review were: a) to examine the association between different types of IPV (i.e., physical, sexual, and psychological abuse) and the risk of FGIDs and symptoms (such as chronic abdominal pain symptoms, IBS, FD, frequent diarrhea, frequent constipation, and vomiting and nausea disorders) among adult women, b) to identify psychosocial and physiological factors that might mediate and/or moderate these health effects (i.e. mechanisms), and c) to identify how FGIDs and symptoms are associated women's QOL outcomes in the context of IPV. The main concepts included in this review are defined in Table 1. The three research questions were:

1. What is the relationship between various types of IPV and FGIDs and symptoms in adult women?

2. What psychosocial and physiological factors might mediate and/or moderate the relationship between IPV and FGIDs and symptoms in adult women? 
3. What are the associations of FGIDs and symptoms and QOL outcomes among women who have experienced IPV?

The results of this systematic review will make the available evidence on this topic more accessible to health care providers to both enhance their understanding and to help them develop interventions that ultimately improve clinical practice with women who have experienced IPV. This systematic review may also inform the direction of future research by exploring what has already been established in this area and identifying important gaps.

\section{Table 1. Definitions of Study Concepts}

\begin{tabular}{|c|c|}
\hline Concept & Definitions \\
\hline $\begin{array}{l}\text { Intimate Partner } \\
\text { Violence (IPV) }\end{array}$ & $\begin{array}{l}\text { Behaviour within an intimate relationship (past or current) that causes or has the } \\
\text { potential to cause physical, sexual, or psychological harm, including acts of } \\
\text { physical aggression, sexual coercion, psychological abuse, and controlling } \\
\text { behaviours (WHO, 2010). }\end{array}$ \\
\hline $\begin{array}{l}\text { Functional } \\
\text { Gastrointestinal } \\
\text { Disorders (FGIDs) } \\
\text { and Symptoms }\end{array}$ & $\begin{array}{l}\text { A group of disorders classified by GI symptoms related to any combination of the } \\
\text { following: motility disturbance, visceral hypersensitivity, altered mucosal and } \\
\text { immune function, altered gut microbiota, and altered central nervous system } \\
\text { (CNS) processing (Drossman, 2016). }\end{array}$ \\
\hline $\begin{array}{l}\text { Irritable Bowel } \\
\text { Syndrome (IBS) } \\
\text { (Spastic colon) }\end{array}$ & $\begin{array}{l}\text { A disorder characterized by persistent or recurrent abdominal pain or discomfort, } \\
\text { altered bowel function, and bloating or abdominal distention (Drossman, 2016). }\end{array}$ \\
\hline $\begin{array}{l}\text { Functional } \\
\text { dyspepsia (FD) } \\
\text { (indigestion) }\end{array}$ & $\begin{array}{l}\text { A disorder involving frequent pain or discomfort in the upper abdomen including } \\
\text { symptoms such as belching or eructation, nausea with or without vomiting, } \\
\text { bloating, and early satiety (fullness on eating small quantities) (Drossman, 2016). }\end{array}$ \\
\hline $\begin{array}{l}\text { Functional } \\
\text { abdominal pain } \\
\text { syndrome (FAPS) }\end{array}$ & $\begin{array}{l}\text { Pain that persists for at least six months that it is related to poor gut function and is } \\
\text { associated with some loss of daily activities (Drossman, 2016) [note: also called } \\
\text { 'chronic idiopathic abdominal pain' or 'chronic functional abdominal pain'). }\end{array}$ \\
\hline $\begin{array}{l}\text { Functional } \\
\text { constipation }\end{array}$ & $\begin{array}{l}\text { A group of functional disorders characterized by persistent difficult, infrequent, or } \\
\text { seemingly incomplete defecation (International Foundation of Gastrointestinal } \\
\text { Disorders, 2019). }\end{array}$ \\
\hline Functional diarrhea & $\begin{array}{l}\text { Continuous or recurrent passage of loose or watery stools without abdominal pain } \\
\text { (International Foundation of Gastrointestinal Disorders, 2019). }\end{array}$ \\
\hline $\begin{array}{l}\text { Nausea and } \\
\text { vomiting disorders }\end{array}$ & $\begin{array}{l}\text { Nausea is a subjective symptom defined as an unpleasant sensation of the } \\
\text { imminent need to vomit typically experienced in the epigastrium or throat. } \\
\text { Vomiting refers to the forceful oral expulsion of gastric or intestinal content } \\
\text { associated with contraction of the abdominal and chest wall muscles (Metrics, } \\
\text { 2005). }\end{array}$ \\
\hline $\begin{array}{l}\text { Quality of Life } \\
\text { (QOL) outcomes }\end{array}$ & $\begin{array}{l}\text { An "individual's perception of their position in life in the context of the culture and } \\
\text { value systems in which they live and in relation to their goals, expectations, } \\
\text { standards and concerns." (WHO, 2014, p.1). A multidimensional concept, QOL } \\
\text { covers a wide range of domains, such as economic, health, and social relationships } \\
\text { (Jaradat \& Ford-Gilboe, 2018). }\end{array}$ \\
\hline
\end{tabular}




\begin{tabular}{|l|l|}
\hline Psychosocial & $\begin{array}{l}\text { Psychosocial factors are personal, and social characteristics that have the potential } \\
\text { to affect health outcomes including: life stressors (e.g. poverty, a history of abuse } \\
\text { or an early life experience abuse or trauma, and job loss), psychological states (e.g. } \\
\text { depression, anxiety, and self-efficacy and self-esteem), cognitive and coping } \\
\text { behaviors (e.g. adaptive strategies, help-seeking, and substance use), social support } \\
\text { (e.g. relationship quality, sense of belonging, and availability of help or } \\
\text { assistance), and environmental influences (e.g., sociocultural context) (Drossman, } \\
\text { 2016). }\end{array}$ \\
\hline $\begin{array}{l}\text { Physiological } \\
\text { Factors }\end{array}$ & $\begin{array}{l}\text { Physiological factors are often pathophysiological abnormalities that lead to } \\
\text { disease (McEwen \& Wingfield, 2003). For example, an overexpression of } \\
\text { glucocorticoid hormones has an undesirable effect on the body's systems, such as } \\
\text { the neuroendocrine, immune, and cardiovascular systems. }\end{array}$ \\
\hline
\end{tabular}

\section{Methods}

A systematic review was conducted to identify, evaluate, and synthesize current knowledge about the relationship between IPV among women and FGIDs and symptoms. The PRISMA guideline for systematic reviews (Moher, Liberati, Tetzlaff, \& Altman, 2010), including the 27-item Prisma-P-Checklist (Appendix A) was used to facilitate the development and reporting of this systematic review. This protocol can be accessed on the PRISMA website: http://www.prisma-statement.org/Extensions/Protocols.aspx. By prespecifying the outcomes of primary interest, and approaches for extracting and summarizing the outcome data, a guideline can reduce the likelihood of biased post-hoc decisions about how to conduct the review, such as selective outcome reporting (Moher et al., 2009).

The study was registered on the Prospero website (https://www.crd.york.ac.uk/prospero; Registration number: CRD42020123745).

Registration of a systematic review reduces the risk of multiple reviews that address the same question, reduces publication bias, and provides greater transparency when updating systematic reviews (Liberati et al., 2009). A search of the Prospero website was completed using the primary research question: What is the relationship between various types of IPV and FGIDs and symptoms in adult women? No records were found. 


\section{Search Strategy and Data Sources}

The searches for this systematic review were completed on December 31, 2019 using the following electronic databases: MEDLINE (Medical Literature On-Line) - Searched via PubMed, CINAHL (Cumulative Index to Nursing Allies Health Literature), Cochrane Database of Systematic Reviews, ProQuest-Nursing \& Allied Health, PsycINFO (Psychology Information), Scopus, and Social Work Abstracts. The searches included databases that publish health-related research and contain a large body of research on IPV and women's health problems, including FGIDs. Additionally, a manual search of the reference lists of the included studies was conducted to find studies that did not appear in the databases searched.

The search terms were selected based on a preliminary review of the literature to gain an overview of the range and depth of the existing research. A combination of similar search terms was used to search in all included databases (Appendix C). A preliminary review of the literature was completed in December 2018. Search terms were finalized in consultation with a university librarian and supervisory committee in May 2019. A new search in all included databases was completed on June 5, 2019. The Covidence reference management system (Covidence Systematic Review Software, 2017) was used to organize studies included in this review. This search was repeated in December 31, 2019 and no new studies were found.

\section{Inclusion and Exclusion Criteria}

The inclusion and exclusion criteria for this systematic review were identified based on the research questions and the PICO framework (population, interventions, comparators, and outcomes; Appendix B). Titles and abstracts were selected for further screening if they met all of the following inclusion criteria: English language; full-text of the publication is available; the study population was women aged 15 and above, who had experienced IPV 
(past or current) and reported FGIDs and symptoms (e.g., IBS, FD, FAPS, functional constipation, functional diarrhea, or nausea and vomiting disorders); the timeline search was based on the first record from each included database until December 31, 2019. Among all included databases, the earliest publication date was 1970, when research on both IPV and FGIDs first appeared in the literature in the 1970s (Drossman, Powell, \& Sessions, 1977), while the most recent publication was on June 5, 2019 (see Appendix C). Descriptive (i.e., cross-sectional, retrospective), qualitative (i.e. studies exploring women's experiences of IPV, including their health and well-being), and mixed-method studies that examined the association between women's experiences of IPV and FGIDs and symptoms were included. Respectfully, grey literature such as dissertations and theses, and articles from Clinicaltrials.gov were not included because they have not been peer reviewed.

\section{Screening and Study Selection}

Studies were selected by screening articles identified from databases and manual searches using the following steps: a) each article title and abstract was reviewed using the inclusion and exclusion criteria developed from the research question and the PICO framework; b) all articles identified as potentially relevant went through a screening of the full text. The screening was completed by the two researchers ( $\mathrm{OB}$ and $\mathrm{BA})$, while the supervisors (MFG, DB) provided advice and consultation on the screening process and reviewed the results in order to ensure validity of the screening process. The study selection process was summarized using the PRISMA 209 flow diagram.

\section{Quality Appraisal}

A quality appraisal of each study was conducted during the data extraction stage, so that the risk of bias for each study could be considered in the analysis stage of this systematic review. Different quality appraisal tools were used for qualitative and quantitative studies, 
and the appraisals were done by two reviewers, OB and BA, independently; discrepancies in results obtained were resolved through discussion.

The quantitative observational studies were evaluated for methodological quality using the 10-item risk-of-bias tool for observational studies developed by Hoya et al. (2012). Hoya et al.'s (2012) quality appraisal tool has been used in two previously published systematic reviews (Alhalal, Ta'an \& Alhalal, 2019; Mazidi, Banach, \& Kengne, 2018). This tool was used to evaluate the internal and external validity of each study using 10 criteria: (1) national representativeness, (2) target population representativeness, (3) random selection, (4) nonresponse bias, (5) data collection, (6) acceptability of case definition, (7) validity and reliability of study instrument, (8) mode of data collection, (9) length of the shortest prevalence period, and (10) appropriateness of the parameter. For each study, risk of bias was assessed for each of the 10 quality criteria using standard template and scoring, where higher scores reflected lower risk of bias. Specifically, the score range from 0 to 10 , and total scores were classified into one of these risk categories: a) low risk of bias - score of 8 or >; b) medium risk of bias - score of 6 or 7 ; c) high risk of bias - scores $<6$ (Appendix D).

The Critical Skills Appraisal Program (CASP) qualitative tool (Critical Skills Appraisal Program, 2010) was used to assess the quality of the qualitative studies. This tool has been widely used in other systematic reviews (Alilyyani, Wong, \& Cummings, 2018; Colvin et al., 2013). It includes ten questions related to study rigor, credibility and relevance used to evaluated whether each study meets or does not meet the criterion (yes/no). A point is awarded for each 'yes', such that the highest quality rating is a score of 9 or 10 (Appendix E). 


\section{Data Extraction}

After identifying the studies to be included in this review, data from each study were extracted and entered into separate tables based on the study design (quantitative or qualitative). The information in the data extraction tables included: title, authors and year of publication; study purpose and theoretical framework; study design and data collection method; sample characteristics and size; study variables (i.e., IPV characteristic, FGIDs and symptoms, mechanisms, QOL outcomes, and data analysis methods) and measurement; and results (i.e., abuse results among women, relationship between IPV and FGIDs, mechanism, and QOL outcomes). Initial extraction was completed by OB with assistance from BA; MFG and DB reviewed the tables and provided feedback to finalize the tables, and disagreements were resolved through discussion.

\section{Analysis}

After the data were extracted and quality appraisals were completed, the findings were summarized using descriptive and narrative syntheses. The descriptive synthesis summarizes the details of the included studies (e.g., authors, where studies were completed, years of study completion, characteristics of participants, study purpose and theoretical or conceptual frameworks used, instruments used to examine all variables, and analytic techniques utilized), including quality appraisals, and highlights of commonalities and differences across studies (Moher et al., 2009).

A narrative synthesis offers an analysis and interpretation of the synthesized evidence by exploring the relationships within and between studies (Moher et al., 2009). Even though there is no strict set of rules for the production of a narrative synthesis, use of a general framework is recommended to maintain transparency and credibility of the process (Center for Reviews and Dissemination, 2009). Thus, for the purposes of this review, results of the 
included studies (i.e., quantitative and qualitative) were reviewed for common characteristics and grouped into categories according to the three research questions which focused on the association between IPV and FGIDs and symptoms; mediators and/or moderators of the relationship between IPV and FGIDs and symptoms; and the associations of FGIDs and symptoms on women's QOL outcomes in the context of IPV. The results of the qualitative studies were compared and grouped with the other review findings from quantitative studies.

Meta-analysis was not used for the review as selected studies were considered too heterogeneous in terms of measurement of the outcomes. Further, because this systematic review was based on well-defined research questions, a more descriptive approach was suitable.

\section{Results}

\section{Search Results and Data Extraction}

The search of the electronic databases yielded 2008 titles and abstracts, and a manual search found one additional abstract (Appendix C). From these 2009 titles and abstracts, 565 duplicate studies were removed using the Covidence reference management system. The remaining 1444 titles and abstracts were independently screened by two team members (OB, BA) using the review's inclusion and exclusion criteria. The 51 manuscripts identified through initial screening were submitted to full-text review by the same team members. In all, 36 studies were excluded for the following reasons: specific outcomes such as FGID and symptoms were not examined ( $n=5)$; abuse was not specific to an intimate partner $(n=13)$; instruments used to measure IPV or FGIDs were not described ( $n=3)$; language of publication was not English ( $n=3)$; duplicate entry $(n=2)$; and ineligible study design such as case reports or review studies $(n=10)$. After the final full-text review, 15 studies remained. The PRISMA 2009 flow chart used to map out the study selection process represents a 
summary of the search strategy and screening process (Moher et al., 2009; see Figure 1). The details of each study are summarized in Appendix G.

Figure 1. PRISMA 2009 Flow Diagram

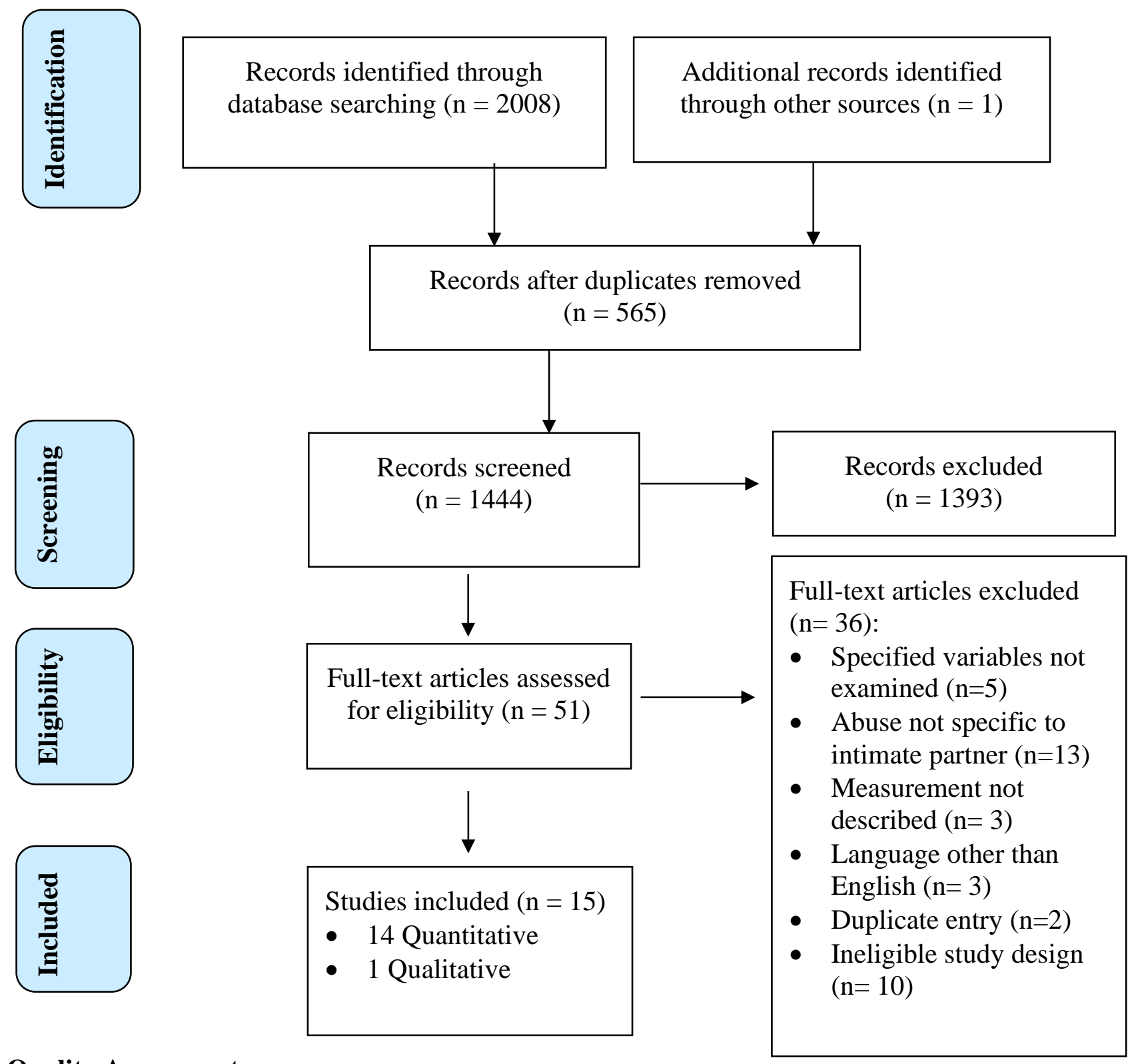

\section{Quality Assessments}

The final 15 studies comprised one qualitative descriptive study (Puri, Tamang, \& Shah, 2011) and 14 quantitative descriptive observational studies using the following designs: cross-sectional studies $(n=13)$ and case-control studies ( $n=1$; Campbell et al., 2002).

The single qualitative study included in this review was scored as high quality $($ score $=9$ ). 
This study had a clear statement of the aims and used an appropriate study design and methodology. Among the quantitative studies, three studies were rated as at moderate risk of bias (Bonomi et al., 2009; John et al., 2004; Nedd, 2001), while risk of bias in the remaining 11 studies was low. No studies were excluded from the review based on risk of bias. Across the quantitative studies, the greatest risk of bias was related to limitations in measurement (7 studies, $50 \%$ ), followed by non-random sample selection ( 5 studies, $36 \%$ ) and poorly defined case definition (4 studies, 29\%). The results of the quality assessments for quantitative studies are reported in Table 2. Details of quality assessment for each quantitative study are provided in Appendix F.

Table 2. Summary of Quality assessment for Quantitative Studies (n=14)

\begin{tabular}{|l|c|}
\hline \multicolumn{1}{|c|}{ Criteria } & $\begin{array}{c}\text { Criteria Met } \\
\text { n (\%) }\end{array}$ \\
\hline \multicolumn{1}{|c|}{ External validity } & $14(100 \%)$ \\
\hline $\begin{array}{l}\text { 1.Was the study's target population a close representation of the national } \\
\text { population in relation to relevant variables, e.g. age, sex, occupation? }\end{array}$ & $14(100 \%)$ \\
\hline $\begin{array}{l}\text { 2.Was the sampling frame a true or close representation of the target } \\
\text { population? }\end{array}$ & $9(64 \%)$ \\
\hline $\begin{array}{l}\text { 3. Was some form of random selection used to select the sample, OR, } \\
\text { was a census undertaken? }\end{array}$ & $11(79 \%)$ \\
\hline 4. Was the likelihood of non-response bias minimal? & $14(100 \%)$ \\
\hline $\begin{array}{l}|c| \\
\text { 5. Were data collected directly from the subjects (as opposed to a } \\
\text { proxy)? }\end{array}$ & $10(71 \%)$ \\
\hline $\begin{array}{l}\text { 6. Was an acceptable case definition used in the study? } \\
\text { 7. Was the study instrument that measured the parameter of interest (e.g. } \\
\text { prevalence of low back pain) shown to have reliability and validity (if } \\
\text { necessary)? }\end{array}$ & $7(50 \%)$ \\
\hline \begin{tabular}{l} 
8. Was the same mode of data collection used for all subjects? \\
\hline $\begin{array}{l}\text { 9. Was the length of the shortest prevalence period for the parameter of } \\
\text { interest appropriate? }\end{array}$
\end{tabular} & $14(100 \%)$ \\
\hline $\begin{array}{l}\text { 10. Were the numerator(s) and denominator(s) for the parameter of } \\
\text { interest appropriate }\end{array}$ & $14(100 \%)$ \\
\hline
\end{tabular}




\section{Descriptive Synthesis}

\section{Characteristics of Included Studies}

The details of each study in this systematic review are presented in Appendix G. All included studies were published between 2001 and 2018 in a range of different types of journals. Most $(n=10)$ were published in medical journals, two studies in violence journals (Becker-Dreps et al., 2010; Schollenberger et al., 2003) and one study each in a public health (Puri et al., 2011), psychology (Díez et al., 2009), and nursing journal (Nedd, 2001). The majority of the studies were conducted in the United States $(n=6)$ with one study completed in each of the following countries: Nicaragua (Becker-Dreps et al., 2010), Brazil (Coronel \& Silva, 2018), Ecuador, (Díez et al., 2009), Australia (Hegarty, Gunn, Chondros, \& Taft, 2008), the United Kingdom (John, Johnson, Jukreja, Found, \& Lindow, 2004), Spain (Perona

et al., 2005), Bangladesh (Salam, Alim, \& Noguchi, 2006), Canada (Wuest et al., 2008), and Nepal (Puri et al., 2011).

\section{Study Purposes and Theoretical Frameworks}

The qualitative study explored the definition of sexual violence by married women and its different forms and consequences and described the coping mechanisms women used to avoid sexual violence (Puri et al., 2011). The majority of studies $(n=13)$ evaluated the prevalence of IPV and examined the association between IPV and a wide range of physical and mental health consequences including FGIDs and symptoms. One study aimed to identify physical symptoms and sociodemographic factors that predicted IPV for women seeking primary care (Hegarty et al., 2008). Two out of 14 quantitative studies explicitly used a theoretical framework (i.e., the biopsychosocial model) in the review of the literature to help frame the problem (Becker-Dreps et al., 2010; Perona et al., 2005). 


\section{Sample, Setting and Data Collection}

The single qualitative study included 30 women recruited from the community in Nepal (i.e., Tharu and Brahmin/Chhetri) and interviewed them in a private location away from the participants' homes (Puri, Tamang, \& Shah, 2011). A total of 12,227 participants were included in the 14 quantitative studies, the majority of women $(n=10,329)$ were recruited from health care settings, and the remainder $(n=1,948)$ recuited from the community. The inclusion criteria for all studies were: adult women aged 15 years and above who were married, divorced, or in an intimate relationship.

In six studies (Becker-Dreps et al., 2010; Bonomi et al., 2009; Nedd, 2001; Salam et al., 2006; Schollenberger et al., 2003; Wuest et al., 2008), the setting for data collection was not identified but data were collected via telephone surveys, structured interviews, or surveys. In another seven studies, data collection was conducted in a health care setting via a written or telephone surveys or structured interviews (Campbell et al., 2002; Coker et al., 2000; Coronel \& Silva, 2018; Díez et al., 2009; Fisher \& Regan, 2006; Hegarty et al., 2008; John et al., 2004), while one study was completed in a police department via questionnaires (Perona et al., 2005).

\section{Instruments}

Measurement of IPV. IPV was measured using four different approaches across all quantitative studies: 1) established self-report scales, including the Conflict Tactics Scales (Straus, 1979), Women's Experience with Battering (WEB) Scale (Smith, Earp \& DeVillis, 1995), Index of Spouse Abuse (Hudson, 1991; Hudson \& McIntosh, 1981), and the Composite Abuse Scale (CAS; Hegarty, Bush, \& Sheehan, 2005). These scales are considered to be valid and reliable for the evaluation of violence; 2) IPV Screening tools, including the Woman Abuse Screening Tool (WAST; Brown, Lent, Schmidt, and Sas, 2000), 
and the Abuse Assessment Screen (Soeken, McFarlane, Parker,\& Lominack, 1998), both of which have been established as reliable and valid screening methods; 3) questions adapted from a large scale surveys including the Women's Health and Relationship Survey (WHRS; Basile \& Saltzman, 2002; Bonnie \& Wallace, 2002) and the Centers for Disease Control and Prevention's Behavioral Risk Factor Surveillance System (BRFSS) Survey (Bonomi et al., 2006; Thompson et al., 2006); and, 4) researcher-developed questionnaires for which no reliability and validity information was provided (Perona et al., 2005; Salam et al., 2006).

Two of the studies in this review used more than one instrument to measure IPV (Bonomi et al., 2009; Coker et al., 2000). Most $(n=8)$ of the studies examined all types of IPV, with four studies focused on the measurement of physical and sexual IPV (BeckerDreps et al., 2010; Campbell et al., 2002; John et al., 2004; Schollenberger et al., 2003), and two studies focused on psychological/emotional and physical IPV (Nedd, 2001 Perona et al., 2005). Further, violence that occurred at different points in life (i.e. during childhood, adolescence, adulthood, and among older adults) was measured in five studies (Becker-Dreps et al., 2010; Coker et al., 2000; Coronel \& Silva 2018; John et al., 2004; Wuest et al., 2008). A few (n=3) studies (Coker et al., 2000; John et al., 2004; Schollenberger et al., 2003) examined IPV occurrence in the past, while others (Coker et al., 2000; Wuest et al., 2008) measured both past and ongoing IPV.

Overall, all studies focused on measuring the presence/absence of IPV. Moreover, one study measured the IPV severity (Wuest et al., 2008) and two studies measured IPV frequency (Fisher \& Regan, 2006; Salam et al., 2006) among women. Two studies (Fisher \& Regan, 2006; Wuest et al., 2008) used self-report scales that allowed the researchers to collect more detailed information about the severity and frequency of IPV. Two studies used 
Women's Experience with Battering (WEB) self-report scale but did not report any result about the frequency or severity of IPV (Bonomi et al., 2009; Coker et al., 2000).

Measurement of FGIDs. FGIDs and symptoms were measursed using both clinical diagnostic criteria and women's reports of symptoms. In three studies where the primary focus of the research was to study FGIDs and symptoms, different versions of the Rome Criteria (Drossman, 1999; Drossman \& Dumitrascu, 2006) were used to classify women as experiencing FGIDS: Rome II criteria (Drossman, 1999) were used in two studies to measure FGIDs and symptoms (Perona et al., 2005) and to measure IBS (Becker-Dreps et al., 2010); Rome III criteria (Drossman \& Dumitrascu, 2006) were used to measure intestinal constipation (Coronet \& Silva, 2018). The Bristol Scale (Riegler \& Esposito, 2001) was also used by Coronel and Silva (2018) to characterize of functional intestinal constipation.

The remaining 11 quantitative studies focused on a broad range of mental and physical health consequences of IPV, rather than FGIDs and symptoms specifically. Not surprisingly, these studies used self-report measures or survey questions about the health consequences of IPV that included only a few questions about FGIDs. For example, two studies (Campbell et al., 2002; Schollenberger et al., 2003) used items from the Miller Abuse Physical Symptoms and Injury Scale (MAPSAIS) (Miller \& Campbell, 1993), a scale developed to measure the presence/absence and frequency of physical problems secondary to abuse, while a third study (Wuest et al., 2008) used the Partner Abuse Symptom Scale (PASS), a newer scale that extends the MAPSAIS to measure the frequency and severity of a broader range of mental and physical health problems associated with IPV; however, limited information about the PASS's validity and reliability was provided by the study authors. Nedd (2001) used the Health Response Scale (Brown, 1986) a reliable self-report scale that 
measures general health status defined as the presence, frequency, and severity of physical health problems.

Items from national surveys were used in some studies to capture symptoms experienced by women. Coker et al., (2000) used National Health Interview Survey data to assess the prevalence of a range of health outcomes for abused women (Bureau of the Census, 1994), while Hegarty et al., (2008) used checklists of common physical symptoms based on previous research conducted in Australian General Practice settings (Britt, 1999). Bonomi et al., (2009) used the International Disease Classification, 9th Revision (ICD-9) to capture range of primary and secondary diagnoses related to women's health (Starfield, Weiner, Mumford, \& Steinwachs, 1991). In a few (n=3) studies, researchers developed their own surveys or checklist (Salam et al., 2006; Díez et al., 2009; John et al., 2004) but did not provide information about the reliability and validity of the measures. Overall, measures in all studies emphasized the presence/absence of FGIDs and symptoms, but did not capture other qualities such as symptom frequency, severity, or impacts (such as disability). Only one study (Perona et al., 2005) measured the intensity of pain experienced by women with FGIDs who had consulted physician.

Measurement of Potential Mediating or Moderating Variables. The mechanisms (e.g., mediators and/or moderators) that explain the relationship between IPV and FGIDs and symptoms were not tested in any of the studies reviewed. However, in two studies (Hegarty et al., 2008; Nedd, 2001) mental health outcomes were measured using a number of reliable and valid self-report measures. Mental health has been identified as mediating or moderating the effects of IPV on physical health outcomes (Alhalal, Ford-Gilboe, Wong, \& AlBuhairan, 2017; Wuest et al., 2010), and as potential mechanism for FGIDs. Specifically, in both studies, depressive symptoms were measured using the Beck Inventory (Beck \& Beck, 
1972), an established self-report measure which has demonstrated both reliability and validity, including among people who experienced IPV. Hegarty et al., (2008) also used the Edinburgh Postnatal Depression Scale (EPDS; Murray \& Carothers, 1990) to measure postpartum depression, the mental health score from the SF-36 (McHorney, Ware, Lu, \& Sherbourne, 1994) to measure general mental health, and women's own reports of experiencing anxiety and depression.

Measurement of potential aspects of QOL. Four studies examined the association between FGIDs and symptoms and different aspects of women's QOL in the context of IPV. The Unsatisfied Basic Needs Assessment (Renzi \& Agurto, 1993) was used by Becker-Dreps et al., (2010) to measure poverty, an economic dimension of QOL. Three studies examined aspects of women' help-seeking using questions developed by the researchers to measure women's access to medical treatment (e.g., consultations), emergency department visits, and hospitalization (John et al., 2004; Perona et al., 2005; Schollenberger et al., 2003).

\section{Data Analysis Method}

Demographic information, such as age, education level, employment status, and household income were reported in all the studies. One study used only bivariate data analyses (Schollenberger et al., 2003) while the majority of the included studies used multivariate data analyses. Only two study used both bivariate and multivariate analysis (Fisher \& Regan, 2006; Hegarty et al., 2008). All included studies used the following statistical tests: descriptive statistics, ANOVA, t-tests or chi-square, and logistic regression to determine odds ratios (ORs) or relative risk (RR). None of the included studies used advanced statistical measures such as structural equation modeling (SEM). 


\section{Narrative Synthesis of Results}

The results of studies in this narrative synthesis are organized using the study's key questions to delineate the following categories: (a) association between IPV and FGIDs and symptoms; (b) mechanisms by which IPV affects FGIDs and symptoms; and (c) the association of FGIDs and symptoms on women's QOL outcomes in the context of IPV.

\section{Association Between IPV and FGID Disorders and Symptoms}

Relationship between IPV and FGIDs. The single qualitative study (Puri et al., 2011) explored sexual violence within marriage and found that abdominal pain was the most common symptom reported by women who had experienced IPV ( $n=10,67 \%)$. Since 13 of the 14 quantitative studies used cross-sectional designs and one used a case-control design (Campbell et al., 2002), they do not provide evidence of causation. In one of the 14 studies, the association between IPV and FGIDs was not directly examined. Rather, Salam et al., (2006) assessed reproductive health problems among women who had experienced spousal violence and reported rates of these reproductive health issues including pelvic pain $(81.8 \%)$, reproductive tract infection (RTI; 52.2\%), and symptoms of IBS (51.9\%); while IPV was significantly associated with some reproductive health problems such as RTI, the association between IPV and IBS was not examined.

In 13 out of the 14 quantitative studies, the association between IPV and FGIDs and symptoms was reported. Among these studies, consistent support was found for an association between IPV and a wide range of FGIDs and symptoms: chronic abdominal pain (Bonomi et al., 2009; Campbell et al., 2002; Díez et al., 2009; Hegarty et al., 2008; John et al., 2004; Schollenberger et al., 2003; Puri et al., 2011); IBS (Becker-Dreps et al., 2010; Bonomi et al., 2009; Coker et al., 2000; Fisher \& Regan 2006; Perona et al., 2005); FD (Coker et al., 2000; Perona et al., 2005); frequent diarrhea (Coker et al., 2000; Hegarty et al., 
2008; Perona et al., 2005); and frequent constipation (Coker et al., 2000; Coronel \& Silva, 2018; Perona et al., 2005). Only one study examined general gastrointestinal symptoms without specifying a particular disorder or symptoms (Nedd, 2001). In another, Wuest et al., (2008) examined chronic pain among women and reported rates of pain by site, including pain from bowel problems (49.7\%) and stomach pain/heartburn (46.4\%); however, the positive association found between the severity of IPV and presence of chronic pain was not limited to abdominal pain, but included disabling chronic pain from all locations in the body. None of the studies specifically examined vomiting and nausea disorders.

Included studies examined the relationship between IPV and FGIDs and symptoms using different analytic methods. In half of the studies $(n=7)$, the relationship between IPV and FGIDs and symptoms was examined using logistic regression or Pearson's Chi-square to determine the odds ratio (OR) or relative risk (RR) of experiencing FGIDs and symptoms among women who had and had not experienced IPV. Results of these studies consistently showed that the odds of experiencing FGIDs and symptoms ranged from between 1.60 to 2.71 times higher among women who had experienced IPV compared to those with no history of IPV for the following: IBS (Becker-Dreps et al., 2010; Díez et al., 2009; Fisher \& Regan, 2006), abdominal pain (Díez et al., 2009), functional intestinal constipation (Coronel \& Silva., 2018; Hegarty et al., 2008), or diarrhea (Hegarty et al., 2008). Two further studies (Bonomi et al., 2009; Coker et al., 2000) focused on relative risk (RR) and found increased RR (ranging from 1.05 to 3.74) of IBS (Bonomi et al., 2009; Coker et al., 2000), undifferentiated abdominal pain (Bonomi et al., 2009), and frequent dyspepsia, constipation, and diarrhea (Coker et al., 2000) among women who had experienced IPV compared to never-abused women. 
In five studies, associations between IPV and FGIDs and symptoms were reported using the significance value of the statistical test (i.e., p-value) but the size of the association (e.g., odds ratio or correlation coefficient) was not given. Campbell et al. (2002) found a significant difference $(p \leq .05)$ in the prevalence of abdominal pain in abused women compared to never abused women using unweighted logistic regression while John et al. (2004) found a significant difference $(p<.001)$ in the rate of bowel symptoms and $(p<.01)$ of lower abdominal pain in women with a history of domestic violence compared to women without such a history using Chi square. Perona et al. (2005) found a significant association between IPV and FGIDs using $t$-test and Chi square. Schollenberger et al. (2003) found a significant difference in the prevalence of abdominal pain $(p<.004)$ in abused compared to never abused women using bivariate analyses (i.e., Chi square); Wuest et al. (2008) found a positive association between the severity of IPV and the presence of chronic pain, including pain from bowel problems, in women who had experienced IPV using Chi square and t-tests.

The association between IPV and FGIDs and symptoms was not significant in only one study (Nedd, 2001); specifically, using ANOVA, reports of gastrointestinal upset were not significantly different between women who had and had not experienced emotional abuse (Table 3).

Relationship between various types of IPV and FGIDs. IPV occurs in different forms. While 13 of the 14 quantitative studies included in this review examined the relationship between IPV in general and FGIDs, a few $(n=5)$ examined and reported the relationship between specific types of IPV and FGIDs and symptoms: Becker-Dreps et al. (2010) found that, compared to women without IBS, women with IBS were more likely to have suffered sexual IPV (OR=2.85) compared to physical IPV (OR=2.08); Coker et al. (2000) found that experiences of psychological IPV were associated with significantly increased risk of 


\section{Table 3. Summary of Quantitative Studies Results}

\begin{tabular}{|c|c|c|}
\hline Study & Analysis & Results \\
\hline $\begin{array}{l}\text { Becker-Dreps } \\
\text { et al., (2010) }\end{array}$ & $\begin{array}{l}\text { Logistic } \\
\text { regression -OR }\end{array}$ & $\begin{array}{l}\text { A significant association was found between having } \\
\text { experienced IPV (physical, OR=2.08, and sexual OR=2.85) and } \\
\text { IBS }\end{array}$ \\
\hline $\begin{array}{l}\text { Bonomi et al., } \\
\text { (2009) }\end{array}$ & $\begin{array}{l}\text { Logistic } \\
\text { regression - RR }\end{array}$ & $\begin{array}{l}\text { A significant association between having experienced IPV and } \\
\text { both IBS }(R R=1.05) \text { and undifferentiated abdominal pain } \\
(\mathrm{RR}=1.48)\end{array}$ \\
\hline $\begin{array}{l}\text { Campbell, et } \\
\text { al (2002) }\end{array}$ & $\begin{array}{l}\text { Logistic } \\
\text { regression }\end{array}$ & $\begin{array}{l}\text { Abuse women reported more abdominal pain than never abused } \\
\text { women }(p \leq .05)\end{array}$ \\
\hline $\begin{array}{l}\text { Coker et al., } \\
(2000)\end{array}$ & $\begin{array}{l}\text { Logistic } \\
\text { regression - RR }\end{array}$ & $\begin{array}{l}\text { Psychological IPV was associated with IBS }(\mathrm{RR}=3.62) \text {, } \\
\text { frequent dyspepsia, and frequent constipation and diarrhea } \\
(\mathrm{RR}=1.30) \text {. Physical IPV was associated with IBS }(\mathrm{RR}=3.74) \text {, } \\
\text { frequent dyspepsia, and frequent constipation and diarrhea } \\
(\mathrm{RR}=1.60)\end{array}$ \\
\hline $\begin{array}{l}\text { Coronel \& } \\
\text { Silva }(2018)\end{array}$ & $\begin{array}{l}\text { Pearson's Chi- } \\
\text { square - OR }\end{array}$ & $\begin{array}{l}\text { Experiencing IPV was associated with FIC (functional } \\
\text { intestinal constipation); women with abuse histories were more } \\
\text { likely }(\mathrm{OR}=2.71) \text { to suffer from FIC versus those with no abuse } \\
\text { histories }\end{array}$ \\
\hline $\begin{array}{l}\text { Díez et al., } \\
\text { (2009) }\end{array}$ & $\begin{array}{l}\text { Logistic } \\
\text { regression - } \\
\text { OR) }\end{array}$ & $\begin{array}{l}\text { Experiencing IPV was associated with abdominal pain } \\
(\mathrm{OR}=2.19) \text { and lack of appetite }(\mathrm{OR}=3.81)\end{array}$ \\
\hline $\begin{array}{l}\text { Fisher \& } \\
\text { Regan (2006) }\end{array}$ & $\begin{array}{l}\text { Logistic } \\
\text { regression - } \\
\text { OR }\end{array}$ & $\begin{array}{l}\text { Experiencing only psychological/emotional abuse was } \\
\text { associated with having digestive problems (IBS, and ulcer or } \\
\text { heartburn })(\mathrm{OR}=1.70) \text {. Any experience of abuse increased the } \\
\text { likelihood }(\mathrm{OR}=1.60) \text { of women reporting digestive problems }\end{array}$ \\
\hline $\begin{array}{l}\text { Hegarty et al. } \\
(2008)\end{array}$ & $\begin{array}{l}\text { Logistic } \\
\text { regression - } \\
\text { OR }\end{array}$ & $\begin{array}{l}\text { Experiencing partner abuse (previous } 12 \text { months) was } \\
\text { associated with increased likelihood of diarrhea }(\mathrm{OR}=1.8) \text { and } \\
\text { chronic abdominal pain }(\mathrm{OR}=1.7) \text { compared to never } \\
\text { experiencing abuse }\end{array}$ \\
\hline $\begin{array}{l}\text { John et al. } \\
(2004)\end{array}$ & Chi square & $\begin{array}{l}\text { Women who had expereinced IPV were more likely to report } \\
\text { bowel symptoms and lower abdominal pain than women with } \\
\text { no history of IPV }\end{array}$ \\
\hline Nedd (2001) & ANOVA & $\begin{array}{l}\text { No differences in gastrointestinal upset was found between } \\
\text { women who did and did not report expereincing emotional IPV }\end{array}$ \\
\hline $\begin{array}{l}\text { Perona et al. } \\
(2005)\end{array}$ & $\begin{array}{l}\text { Chi square and } \\
t \text {-test }\end{array}$ & $\begin{array}{l}\text { A significant association was reported between IPV and FGIDs } \\
\text { based on t-tests and Chi square }\end{array}$ \\
\hline $\begin{array}{l}\text { Salam et al. } \\
(2006)\end{array}$ & $\begin{array}{l}\text { Descriptive } \\
\text { analysis }\end{array}$ & $\begin{array}{l}\text { Sexual violence adversely affected women's health; more than } \\
80 \% \text { of sexually violated women complained of pelvic pain, } \\
\text { more than } 50 \% \text { reported reproductive tract infections, and more } \\
\text { than } 50 \% \text { reported symptoms of irritable bowel syndrome. }\end{array}$ \\
\hline $\begin{array}{l}\text { Schollenberger } \\
\text { et al (2003) }\end{array}$ & $\begin{array}{l}\text { Bivariate } \\
\text { analyses - } \\
\text { Chi square }\end{array}$ & $\begin{array}{l}\text { Compared to non-abused women, those who reported abuse } \\
\text { were also more likely to reported abdominal pain }(p<.004)\end{array}$ \\
\hline $\begin{array}{l}\text { Wuest et al } \\
(2008)\end{array}$ & $\begin{array}{l}\text { Chi square and } \\
t \text {-test }\end{array}$ & $\begin{array}{l}\text { A positive association found between the severity of IPV and } \\
\text { presence of chronic pain, including pain from bowel problems, } \\
\text { in women who had experienced IPV. }\end{array}$ \\
\hline
\end{tabular}


developing IBS $(\mathrm{RR}=3.62)$, frequent dyspepsia, and frequent constipation and diarrhea (1.30); Fisher and Regan (2006) found that the odds of reporting digestive problems (specifically IBS) were 1.7 times higher in women who had experienced psychological/emotional abuse or coercive control compared to those who had not experinced abuse. Furthermore, repeated psychological/emotional abuse was significantly associated with increased odds (1.45) of digestive problems (Fisher \& Regan, 2006).

However, in two studies (Nedd, 2001; Perona et al., 2005), the strength of the association between specific types of IPV (physical, psychological) and FGIDS was found to be similar suggesting that psychological abuse, as well as physical abuse, is an important predictor of FGIDs among women. Specifically, Perona at al. (2005) found no difference in the risk of FGIDs and symptoms in women suffering psychological versus physical abuse. Similarly, Nedd (2001) found no difference in gastrointestinal upset among women who had experienced emotional abuse versus physical abuse.

In summary, the few $(n=5)$ studies that examined the relationship between specific types of IPV and FGIDs and symptoms provide initial evidence that each type of IPV (psychological, physical, sexual) is associated with FGIDs on its own, as well as in combination with other types of IPV.

FGIDs and History of Abuse. Five out of 14 studies included in this review reported women's histories of abuse beyond recent abuse from a partner or ex-partner, including abuse in childhood, adolescence, and non-partner abuse in adulthood from other family members (Becker-Dreps et al., 2010; Coker et al., 2000; Coronel \& Silva 2018; John et al., 2004; Wuest et al., 2008) or strangers (John et al., 2004; Wuest et al., 2008). However, the relationship between histories of abuse beyond recent abuse from a partner or ex-partner and FGIDs and symptoms was examined in only two studies (Becker-Dreps et al., 2010; Coronel 
\& Silva 2018). Becker-Dreps et al. (2010) found that women with IBS were twice as likely to have experienced childhood sexual abuse compared to women without IBS. Similarly, Coronel and Silva (2018) found that women who had experienced any abuse over their lifetime were 2.7 times more likely to suffer from functional intestinal constipation than women without such a history. Wuest et al., (2008) found support for an association between various types of violence, including a history of child abuse and non-partner sexual assult, and chronic pain in general, although women in that study reported bowel problems and abdominal pain.

\section{Potential Mediators and/or Moderators of the Relationship Between IPV and FGIDs}

The mechanisms that explain the relationship between IPV and FGIDs and symptoms were not tested directly in any of the studies reviewed. Thus, mediators and moderators of the relationship between IPV and FGIDs remain unclear. However, in comparison to women who had not experienced abuse, Hegarty, et al., (2008) found that abused women were more likely to be depressed and to experience suicidal thoughts, while Nedd (2001) found that women who had experienced emotional abuse had significantly higher levels of depression and stress. In both studies (Hegarty, et al., 2008; Nedd, 2001), a strong association was found between experiences of IPV and mental health issues (i.e. depression and anxiety), but whether poorer mental health mediates and/or moderates the association between IPV and FGIDs was not examined.

Perona et al. (2005) refer to the biopsychosocial model in discussing their results, suggesting that this model takes account of both physiologic factors (such as gut motility, sensation, and flora) and psychosocial factors (psychological state, stressors, coping mechanisms, and social support) that moderate the relationship between IBS and IPV. However, they did not test these effects. Although the exact mechanisms explaining the 
relationship between IPV and IBS are unclear, Becker-Dreps et al. (2010) found an association between violence-related stress and neuroendocrine signalling that supports their understanding of the pathophysicology of IBS, that is, episodes of IPV stimulate the HPA axis, which is thought to be involved in the pathogenesis and maintenance of IBS (BeckerDreps et al., 2010). Like Perona et al. (2005), Becker-Dreps et al. (2010) interpreted their results based on their understanding of the biospychosocial model, but did not test for mediation directly.

\section{Effects of FGIDs and Symptoms on Women's QOL Outcomes}

Four of the quantitative studies reported the effects of FGIDs on women's QOL outcomes in context of IPV. Three of these studies showed that women who had reported health problems including FGIDs and symptoms as result of IPV sought medical care in the form of primary care physician visits (John et al., 2004; Perona et al., 2005) and emergency department visits and hospitalizations (Schollenberger et al., 2003) more often than women without health problems. Perona et al. (2005) reported a positive association between experiencing IPV and consulting a physician for the FGIDs and reported that women who consulted a physician for their FGIDs and symptoms reported higher pain intensity $(p=.044)$ compared to women without FGIDs. Becker-Dreps et al., (2010) reported the effects of IBS on women's QOL using the Unsatisfied Basic Needs Assessment to measure poverty; they found no difference in level of poverty between women with IBS and those without IBS.

\section{Discussion}

Over the past 30 years, research has led to growing awareness of the pervasive effects of abuse on women's physical and mental health, and it is now recognized that violence has substantial long-term negative health consequences for women that can persist even after the abuse has ended (Campbell, 2002; Crofford, 2007; Kendall-Tackett, 2009; Koss, Koss, \& 
Woodruff, 1991; WHO, 2012). This systematic review was undertaken to consolidate evidence about the relationship between IPV and FGIDs and symptoms which are common and often disabling health concerns for women. Although existing systematic reviews have shown that childhood experiences, including abuse, are associated with FGIDs and symptoms (Chitkara et al., 2008) and psychological trauma is associated with poorer mental health (Afari et al., 2014), no systematic review had specifically examined the association between IPV and FGIDs among women. Therefore, this review builds on and extends 3 previous systematic reviews by specifically examining the quality of the evidence linking IPV to FGIDs and symptoms, and by exploring what is known about the mechanisms explaining this relationship and identifying evidence related to the consequences of FGIDS on women's QOL.

As the first systematic review that has been done in the area of IPV and FGIDs, this study makes a unique contribution to our understanding of FGIDs in the context of IPV. Specifically, this review provides consistent evidence that adult women who have experienced IPV frequently report of FGIDs and symptoms and at higher rates than women who have not experienced IPV. However, most of the studies (i.e. 12 out of 15) included in this review reviewed did not focus solely on FGIDs and symptoms but examined the association of IPV and women's physical and mental health more broadly. Although there is some evidence from the single qualitative study (Puri et al., 2011) that women who had experienced sexual IPV reported abdominal pain, and five out of the 14 quantitative studies reported that different types of IPV (operationalized as some combination of physical, sexual and psychological abuse) are associated with FGIDs and symptoms (Becker-Dreps et al., 2010; Coker et al., 2000; Fisher \& Regan, 2006; Nedd, 2001; Perona et al., 2005), these studies provide beginning evidence that psychological abuse, as well as physical and sexual 
abuse, is associated with FGIDs among women. Similarly, while only four studies examined QOL outcomes associated with FGIDs in the context of IPV (Becker-Dreps et al., 2010; John et al., 2004; Perona et al., 2005; Schollenberger et al., 2003), these studies consistently point to increased help-seeking of women within health care settings (John et al., 2004; Perona et al., 2005; Schollenberger et al., 2003). Finally, no studies reviewed sought to determine the mechanisms explaining the relationship between IPV and FGIDs and symptoms. Further study into these matters would increase our understanding of the current findings.

The finding of an association between experiences of IPV and FGIDs and symptoms is consistent with Drossman's (2016) biopsychosocial model, with the Rome criteria used in the diagnosis and treatment of FGIDs and symptoms, and with the now substantial body of research showing that women who have experienced IPV are more likely than other women to experience a range of psychological and physical symptoms and illnesses including FGIDs and symptoms (Dillon, Hussain, Loxton, and Rahman's, 2013). However, only three of the studies reviewed (Becker-Dreps et al., 2010; Coronet \& Silva, 2018; Perona et al., 2005) used comprehensive approaches to measure FGIDs and symptoms such as the Rome Criteria (Drossman \& Dumitrascu, 2006); the remaining studies identified FGIDs and symptoms among participants using only a few items from general instruments that measure women's physical and mental health problems. The use of measures that can provide in-depth information about women's experiences of FGIDs and symptoms of FGIDs is important in order to inform appropriate treatment and intervention; thus, further studies are required. However, the inclusion of studies from a variety of countries in this review allowed a broad picture of the relationship between IPV and FGIDs to be drawn. As a global women's health issue, it is essential to also understand whether and how cultural and other contextual factors affect women's willingness to report IPV, willingness to seek medical help for FGIDs and 
symptoms, and their perceptions of these symptoms. These are significant areas for future research.

Most of the available studies tended to focus on the measurement of physical and/or sexual IPV (Becker-Dreps et al., 2010; Campbell et al., 2002; John et al., 2004; Schollenberger et al., 2003), with less attention given to the unique effects of psychological/emotional abuse and coercive control (Nedd, 2001; Perona et al., 2005). However, the results of this review show that psychological abuse, and not only physical and sexual abuse, is associated with FGIDs. This finding is important because of the tendency to assume that more overt and sensational acts of violence are more important than the more subtle or 'non-physical' acts. Indeed, the results of this review are consistent with Kimerling, Alvarez, Pavao, Mack, Smith, \& Baumrind's (2009) finding that psychological abuse is a critical aspect of IPV and that, in some cases, the adverse effects may be worse than for physical violence.

As noted in a number of the studies reviewed (Becker-Dreps et al., 2010, Bonomi et al., 2009; Díez et al., 2009; Perona et al., 2005), psychological abuse it is often entangled with the other types of abuse. The results of this review support recent research demonstrating that psychological/emotional and coercive control abuse are often accompanied by either physical or sexual abuse or both (Scott-Storey, 2011). Despite the fact that there are significant detrimental effects on women's health associated with any type of abuse (i.e., sexual, physical, or psychological/ emotional abuse), it is difficult to assess the independent effects of different types of abuse on health outcomes (Myhill, 2015; ScottStory, 2011). Based on a review of literature, Scott-Story (2011) makes an important argument about the need to consider the cumulative effects of abuse on women's health. Thus, FGIDs and symptoms may be worse for women experiencing multiple types of IPV, 
either co-occurring, or compounded by other experiences of abuse over a lifetime. Future research examining the effects of the cumulative, co-occurring, and multiple types of IPV on FGIDs and symptoms would provide a greater understanding of these relationships.

Although a purpose of this systematic review was to identify mechanisms that explain the relationship between IPV and FGIDs and symptoms in adult women, no evidence was found for factors that either mediate or moderate this relationship. Two studies drew on the biopsychosocial model and made assumptions based on it (Becker-Dreps et al., 2010; Perona et al., 2005) but did not test any physiological and/or psychological mechanisms based on this theory (Van Oudenhove et al., 2016). As revealed in this review, Becker-Dreps et al. (2010) proposed that psychological distress mediates the relationship between IPV and FGIDs using the biopsychosocial model. Using the same model, Perona et al. (2005) also suggested that both physiologic factors (such as gut motility, sensation, and flora) and psychosocial factors (psychological state, stressors, coping mechanisms, and social support) moderate the relationship between IBS and IPV. This assumption is consistent with Fond et al.'s (2014) review showing that psychological factors (e.g., depression, anxiety, and somatization) appear to play a particularly important role as moderators of symptom severity, symptom persistence, decisions to seek treatment, and response to treatment and suggests that anxiety and depression be routinely addressed in treatment for IBS. While our findings do not provide evidence that psychological factors moderate the relationship between IPV and FGIDs, in two studies (Hegarty, et al., 2008; Nedd, 2001) anxiety and depression were associated with IPV, a finding that is consistent with a large body of research (Ahmadabadi, Najman, Williams, Clavarino, d'Abbs, \& Tran, 2020; Mapayi et al., 2013). This finding is important since poorer mental health among women who have experienced IPV is also an important context for living and managing FGIDs. 
In terms of physiological factors, a study by Stasi, Rosselli, Bellini, Laffi, \& Milani (2012) showed that IBS symptoms may be caused by alterations either primarily in the central nervous system (top-down model), or in the gut (bottom-up model), or a combination of both. However, this mechanism has been identified only for IBS and further research with respect to other FGIDs and symptoms is needed. A lack of understanding of the psychological factors moderating and physiological factors that mediate experiences of abuse and the development of FGIDs makes treatment challenging. This area is a critical priority for future research as a step toward improving clinical practice for women living with FGIDs.

We defined $Q O L$ outcomes as an "individual's perception of their position in life in the context of the culture and value systems in which they live and in relation to their goals, expectations, standards and concerns." (WHO, 2014, p.1). A multidimensional concept, QOL covers a wide range of domains, such as economic, health, and social relationships (Jaradat \& Ford-Gilboe, 2018). The results of this review support the notion that FGIDs and symptoms are associated with two different aspects of QOL among women who have experienced IPV - women's economic situation and their access to health care, specifically increase use of medical care (e.g., consultations), emergency department visits, and hospitalization (John et al., 2004; Perona et al., 2005; Schollenberger et al., 2003). That women seek health services is consistent with research showing that women with FGIDs try to actively manage the symptoms, make more health care visits and are more likely to be prescribed opioids, which leads to other complications (Drossman, 2016). Furthermore, women who have experienced IPV have also been shown to access health services at higher rates than women in the general population (Satyen, Toumbourou, Heerde, Supol \& Ranganathan, 2020). In some contexts, a greater need for health care results in greater 
economic burdens among women living with chronic health conditions (Mearin \& Malfertheiner, 2017). However, there is also a lack of research into women's perspectives about the helpfulness of formal services, such as the quality of health care providers' responses to women suffering from FGIDs. Given that both FGIDs and IPV are associated with stigma (Feder, Hutson, Ramsay, \& Taket, 2006; Hearn, Whorwell, \& Vasant, 2020), studies that develop and test models of care that are welcoming, safe, acceptable and effective for these women are needed. Another valuable area for future research might be research examining the effects of FGIDs on other aspects of QOL, such as social relationships, and coping behavior, among women who have experienced IPV.

\section{Limitations}

Despite the application of rigorous methods in this review, and as the current review is the first to analyze the literature on IPV and FGIDs disorders and symptoms, there are some limitations. First, because dissertations, theses, and grey literature databases were not included in this review, it may not be representative of all relevant work in the field. As well, only studies reported in English were included and this may have also excluded other potentially relevant studies. Second, all included studies were cross-sectional studies and do not allow for the establishment of a causal relationship; thus, biases may have occurred due to uncontrolled variables. Third, there is a need for increased methodological rigour as well as more data on the long-term effects of IPV and FGIDs on women's overall health and pathways to recovery. The quality assessments conduced in this review revealed that $50 \%$ of the quantitative studies did not employ measures with established reliability and validity. Self-report measures are considered to be the standard in measuring the IPV; however, a few numbers of studies used screening tools rather than more established self-report measures, 
and this affects the quality of sensitivity of the measurement. Also, FGIDs were most often measured using single items, rather than more comprehensive, validated approaches such as ROME criteria. Fourth, statisitcal analyses primarily focused on logistic regression and Chi square to determine ORs, RR or association; none of the included studies used advanced statistical techniques such as structural equation modeling (SEM) that could be used to examine the inter-relationships among IPV, FGIDS, QOL and other factors. Also, because the studies were not grounded in theories about the mechanisms by which IPV affects physical health, they were unable to come to any conclusions about this. Despite these limitations, consistent results were found across ten different countries, enhancing external validity. Importantly, this systematic review provides valuable information about critical gaps in knowledge useful in guiding future research.

\section{Conclusion}

This review summarizes findings about the association between IPV and FGIDs and symptoms. Our findings show that women who have experienced IPV in one or more of its various types are more likely to report FGIDs and symptoms (e.g., IBS, FD, FAPS, functional constipation, functional diarrhea, or nausea and vomiting disorders) and that FGIDs are associated with the health and economic domains of women's QOL. While limited attention has been given to measuring the effects of psychological/emotional IPV and coercive control, and comparing these with the effects of physical and sexual abuse, this review also provides initial evidence that psychological abuse, as well as physical and sexual IPV, are associated with FGIDs. Finally, while this review provides no evidence about mediators or moderators of the relationship between IPV and FGIDs, we identify this as a critical gap and a priority for future research. 


\section{References}

Afari, N., Ahumada, S. M., Wright, L. J., Mostoufi, S., Golnari, G., Reis, V., \& Cuneo, J. G. (2014). Psychological trauma and functional somatic syndromes: a systematic review and meta-analysis. Psychosomatic Medicine, 76(1), 2-11. https://doi: 10.1097/PSY.0000000000000010

Ahmadabadi, Z., Najman, J. M., Williams, G. M., Clavarino, A. M., d’Abbs, P., \& Tran, N. (2020). Intimate partner violence and subsequent depression and anxiety disorders. Social Psychiatry and Psychiatric Epidemiology,55(5), 611620. https://doi.org/10.1007/s00127-019-01828-1

Alhalal, E., Ford-Gilboe, M., Wong, C., \& AlBuhairan, F. (2018). Factors mediating the impacts of child abuse and intimate partner violence on chronic pain: a crosssectional study. BMC Women's Health, 18(1), 1-15. https://doi.org/10.1002/nur.21837

Alhalal, E., Ford-Gilboe, M., Wong, C., \& AlBuhairan, F. (2017). Reliability and validity of the Arabic PTSD Checklist Civilian Version (PCL-C) in women survivors of intimate partner violence. Research in Nursing \& Health, 40(6), 575-

585. https://doi.org/10.1002/nur.21837

Alhalal, E., Ford-Gilboe, M., Wong, C., \& Albuhairan, F. (2019). The reliability and validity of the Arabic Version of the Composite Abuse Scale. Violence and Victims, 34(1), 3-27. https://doi: 10.1891/0886-6708.VV-D-17-00111

Alhalal, E., Ta'an, W., \& Alhalal, H. (2019). Intimate partner violence in Saudi Arabia: A Systematic review. Trauma, Violence, \& Abuse. https://doi.org/10.1177/1524838019867156

Alilyyani, B., Wong, C., \& Cummings, G. (2018). Antecedents, mediators, and outcomes of authentic leadership in healthcare: A systematic review. International Journal of Nursing Studies, 83, 34-64. https://doi.org/10.1016/j.ijnurstu.2018.04.001

Basile, K. C., \& Saltzman L. E. (2002). Sexual violence surveillance: Uniform definitions and recommended data elements (Version 1.0). Atlanta, GA: Centers for Disease Control and Prevention, National Center for Injury Prevention and Control.

Beck, A. T., \& Beck, R. W. (1972). Screening depressed patients in family practice: A rapid technic. Postgraduate Medicine, 52(6), 81-85. https://doi.org/10.1080/00325481.1972.11713319

Becker-Dreps, S., Morgan, D., Peña, R., Cortes, L., Martin, C. F., \& Valladares, E. (2010). Association between intimate partner violence and irritable bowel syndrome: A population-based study in nicaragua. Violence Against Women, 16(7), 832-845. https://doi.org/10.1177/1077801210374816 
Beydoun, H. A., Beydoun, M. A., Kaufman, J. S., Lo, B., \& Zonderman, A. B. (2012). Intimate partner violence against adult women and its association with major depressive disorder, depressive symptoms and postpartum depression: A systematic review and meta-analysis. Social Science \& Medicine, 75(6), 959-975. https://doi:10.1016/j.socscimed.2012.04.025

Bonnie, R. \& Wallace, R. (2002). Elder Abuse: Abuse, neglect and exploitation in an aging America. National Academies of Sciences. National Academy Press. Washington, DC.

Bonomi, A. E., Anderson, M. L., Reid, R. J., Rivara, F. P., Carrell, D., \& Thompson, R. S. (2009). Medical and psychosocial diagnoses in women with a history of intimate partner violence. Archives of Internal Medicine, 169(18), 1692-1697. https://doi:10.1001/archinternmed.2009.292

Bonomi, A. E., Thompson, R. S., Anderson, M., Reid, R. J., Carrell, D., Dimer, J. A., \& Rivara, F. P. (2006). Intimate partner violence and women's physical, mental, and social functioning. American Journal of Preventive Medicine, 30(6), 458-466. https://doi.org/10.1016/j.amepre.2006.01.015

Brasil-MS-Secretaria de Vigilância em Saúde, (2006). Ficha de Notificação ão/Investigac ão Individual: Violência Doméstica, sexual elou outras violências interpessoais. http://bvsms.saude.gov.br/bvs/folder/ficha notificacaoviolenciadomestic

Britt H (1999). Bettering the evaluation and care of health: General practice activity in Australia (1998-99), Australian Institute of Health and Welfare, Canberra.

Brown, J.B., Lent, B., Schmidt, G.S., and Sas, G. (2000). Application of the Woman Abuse Screening Tool (WAST) and WAST-Short in the family practice setting. The Journal of Family Practice, 49(10), 896-903.

Campbell, J. C. (2002). Health consequences of intimate partner violence. The Lancet, 359(9314), 1331-1336. https://doi.org/10.1016/S0140-6736(02)08336-8

Campbell, J., Jones, A. S., Dienemann, J., Kub, J., Schollenberger, J., O'Campo, P., . . . Wynne, C. (2002). Intimate partner violence and physical health consequences. Archives of Internal Medicine, 162(10), 1157-1163. https://doi:10.1001/archinte.162.10.1157

Center for Reviews and Dissemination (CRD). (2009). Systematic reviews: CRD's guidelines for undertaking reviews in healthcare. Layerthorpe, York: CRD, University of York.

Chang, M. C., Shapiro, D., Joshi, A., Shahabi, L., Tan, S., Smith, S., ... \& Naliboff, B. D. (2014). Stress reactivity in traditional Chinese medicine-based subgroups of patients with irritable bowel syndrome. The Journal of Alternative and Complementary Medicine, 20(4), 276-283. https://doi.org/10.1089/acm.2013.0197 
Choi, M. G., \& Jung, H. K. (2011). Health related quality of life in functional gastrointestinal disorders in Asia. Journal of Neurogastroenterology and Motility, 17(3), 245-251. https://doi.org/10.5056/jnm.2011.17.3.245

Chitkara, D. K., van Tilburg, M. A. L., Blois-Martin, N., \& Whitehead, W. E. (2008). Early life risk factors that contribute to irritable bowel syndrome in adults: A systematic review. The American Journal of Gastroenterology, 103(3), 765-774. https://doi:10.1111/j.1572-0241.2007.01722.X

Coker, A. L., Smith, P. H., Bethea, L., King, M. R., \& McKeown, R. E. (2000). Physical health consequences of physical and psychological intimate partner violence. Archives of Family Medicine, 9(5), 451-457. http://dx.doi.org/10.1001/archfami.9.5.451

Colvin, C. J., Smith, H. J., Swartz, A., Ahs, J. W., de Heer, J., Opiyo, N., ... \& George, A. (2013). Understanding careseeking for child illness in sub-Saharan Africa: a systematic review and conceptual framework based on qualitative research of household recognition and response to child diarrhoea, pneumonia and malaria. Social Science \& Medicine, 86(C), 66-78. https://doi.org/10.1016/j.socscimed.2013.02.031

Coronel, A. L. C., \& Silva, H. T. H. (2018). Interrelation between functional constipation and domestic violence. Journal of Coloproctology, 38(2), 117-123. https://doi.org/10.1016/j.jcol.2017.12.003

Covidence Systematic Review Software, (2017). Better systematic review management. https://www.covidence.org.

Cripe, S. M., Sanchez, S. E., Gelaye, B., Sanchez, E., \& Williams, M. A. (2011). Association between intimate partner violence, migraine and probable migraine. Headache: The Journal of Head and Face Pain, 51(2), 208-219. https://doi.org/10.1111/j.15264610.2010.01777.x

Critical Appraisal Skills Programme (CASP), (2010). 10 questions to help you make sense of qualitative research. http://media.wix.com/ugd/dded87_29c5b002d99342f788c6ac670e49f274.pdf

Crofford, L. J. (2007). Violence, stress, and somatic syndromes. Trauma, Violence, \& Abuse, 8(3), 299-313. https://doi.org/10.1177/1524838007303196

Dean, B. B., Aguilar, D., Barghout, V., Kahler, K. H., Frech, F., Groves, D., \& Ofman, J. J. (2005). Impairment in work productivity and health-related quality of life in patients with IBS. The American journal of managed care, 11(1 Suppl), S17-26.

Díez, S. U., Escutia, C. V., Pacheco, B. N., Martínez, M. S., Caracena, N. V., \& Contreras, A. O. (2009). Prevalence of intimate partner violence and its relationship to physical and psychological health indicators. International Journal of Clinical and Health Psychology, 9(3), 411-427. http://www.redalyc.org/articulo.oa?id=33712038004

Dillon, G., Hussain, R., Loxton, D., \& Rahman, S. (2013). Mental and physical health and intimate partner violence against women: A review of the literature. International Journal of Family Medicine, 2013(2013), 1-15. https://doi.org/10.1155/2013/313909 
Drossman, D. A. (2016). Functional gastrointestinal disorders: history, pathophysiology, clinical features, and Rome IV. Gastroenterology, 150(6), 1262-1279. https://doi.org/10.1053/j.gastro.2016.02.032

Drossman, D. A. (1999). The functional gastrointestinal disorders and the Rome II process. Gut, 45(2), II1-II5. https://doi:10.1136/gut.45.2008.ii1

Drossman, D. A., Camilleri, M., Mayer, E. A., \& Whitehead, W. E. (2002). AGA technical review on irritable bowel syndrome. Gastroenterology, 123(6), 2108-2131. https://doi.org/10.1053/gast.2002.37095

Drossman, D. A., \& Dumitrascu, D. L. (2006). Rome III: New standard for functional gastrointestinal disorders. Journal of Gastrointestinal and Liver Diseases, 15(3), 237241.

Drossman, D. A., Powell, D. W., \& Sessions Jr, J. T. (1977). The irritable bowel syndrome. Gastroenterology, 73(4), 811-822. https://doi.org/10.1016/S00165085(19)31790-1

Feder, G., Hutson, M., Ramsay, J., \& Taket, A. (2006). Women exposed to intimate partner violence: Expectations and experiences when they encounter health care professionals: A meta-analysis of qualitative studies. Archives of Internal Medicine, 166(1), 22-37. https://doi.org/10.1001/archinte.166.1.22

Fisher, B. S., \& Regan, S. L. (2006). The extent and frequency of abuse in the lives of older women and their relationship with health outcomes. The Gerontologist, 46(2), 200209. https://doi.org/10.1093/geront/46.2.200

Fond, G., Loundou, A., Hamdani, N., Boukouaci, W., Dargel, A., Oliveira, J., ... \& Boyer, L. (2014). Anxiety and depression comorbidities in irritable bowel syndrome (IBS): a systematic review and meta-analysis. European Archives of Psychiatry and Clinical Neuroscience, 264(8), 651-660. https://doi.org/10.1007/s00406-014-0502-Z

Hearn, M., Whorwell, P. J., \& Vasant, D. H. (2020). Stigma and irritable bowel syndrome: a taboo subject?. The Lancet Gastroenterology \& Hepatology, 5(6), 607-615. https://doi.org/10.1016/S2468-1253(19)30348-6

Heise, L., Pallitto, C., García-Moreno, C., \& Clark, C. J. (2019). Blending psychological abuse by intimate partners: Constructing a cross-cultural indicator for the Sustainable Development Goals. SSM-Population Health, 9, 100377. https://doi.org/10.1016/j.ssmph.2019.100377

Hegarty, K., Bush, R., \& Sheehan, M. (2005). The composite abuse scale: further development and assessment of reliability and validity of a multidimensional partner abuse measure in clinical settings. Violence and Victims, 20(5), 529-547. https://doi: 10.1891/vivi.2005.20.5.529

Hegarty, K., Gunn, J., Chondros, P., \& Taft, A. (2008). Physical and social predictors of partner abuse in women attending general practice: a cross-sectional study. $\mathrm{Br} \mathrm{J} \mathrm{Gen}$ Pract, 58(552), 484-487. https://doi.org/10.3399/bjgp08X299245 
Hoy, D., Brooksb, P., Woolfc, A., Blythd, F., Marchd, L., Baina, C., . . Buchbinder, R. (2012). Assessing risk of bias in prevalence studies: Modification of an existing tool and evidence of interrater agreement. Journal of Clinical Epidemiology, 65(9), 934939. https://doi.org/10.1016/j.jclinepi.2011.11.014

Hudson, W. W. (1991). Partner abuse scale: Physical. Tempe, Ariz: Walmyr Publishing Co.

Hudson, W. W., \& McIntosh, S. R. (1981). The assessment of spouse abuse: Two quantifiable dimensions. Journal of Marriage and the Family, 43(4), 873-888. https://doi: 10.2307/351344

International Foundation of Gastrointestinal Disorders (2019). GI disorders functional GI disorders motility disorders upper GI disorders lower GI disorders other disorders kids \& teens. https://www.iffgd.org/gi-disorders/functional-gi-disorders.html

Jahng, J., \& Kim, Y. S. (2017). Why should we contemplate on gender difference in functional gastrointestinal disorders? Journal of Neurogastroenterology and Motility, 23(1), 1-2. https://doi.org/10.5056/jnm16209

Jaradat, D., \& Ford-Gilboe, M. (2018). Women's quality of life after leaving an abusive relationship: The effects of past and ongoing intimate partner violence, mastery and social support. Electronic Thesis and Dissertation Repository. 5786. https://ir.lib.uwo.ca/etd/5786

John, R., Johnson, J. K., Kukreja, S., Found, M., \& Lindow, S. W. (2004). Domestic violence: prevalence and association with gynaecological symptoms. BJOG: An International Journal of Obstetrics \& Gynaecology, 111(10), 1128-1132. https://doi.org/10.1111/j.1471-0528.2004.00290.x

Kelly, U. (2010). Intimate partner violence, physical health, posttraumatic stress disorder, depression, and quality of life in Latinas. Western Journal of Emergency Medicine, 11(3), 247-251.

Kendall-Tackett, K. (2009). The psychoneuroimmunology of chronic disease: Exploring the links between inflammation, stress, and illness. Washington, DC: American Psychological Association.

Kim, Y. S., \& Kim, N. (2018). Sex-gender differences in irritable bowel syndrome. Journal of Neurogastroenterology and Motility, 24(4), 544-558. https://doi:10.5056/jnm18082

Kimerling, R., Alvarez, J., Pavao, J., Mack, K. P., Smith, M. W., \& Baumrind, N. (2009). Unemployment among women: Examining the relationship of physical and psychological intimate partner violence and posttraumatic stress disorder. Journal of Interpersonal Violence, 24(3), 450-463. https://doi.org/10.1177/0886260508317191

Koloski, N. A., Talley, N. J., \& Boyce, P. M. (2005). A history of abuse in community subjects with irritable bowel syndrome and functional dyspepsia: the role of other 
psychosocial variables. Digestion, 72(2-3), 86-96.

https://doi.org/10.1159/000087722

Koloski, N. A., Talley, N. J., \& Boyce, P. M. (2000). The impact of functional gastrointestinal disorders on quality of life. The American Journal of Gastroenterology, 95(1), 67-71. https://doi.org/10.1016/S0002-9270(99)00794-7

Koss, M. P., Koss, P. G., \& Woodruff, W. J. (1991). Deleterious effects of criminal victimization on women's health and medical utilization. Archives of Internal Medicine, 151(2), 342-347. https://doi:10.1001/archinte.1991.00400020092019

Lagdon, S., Armour, C., \& Stringer, M. (2014). Intimate partner violence and mental health adult experience of mental health outcomes as a result of intimate partner violence victimisation: A systematic review. European Journal of Psychotraumatology, 5(1), 24794. https://doi.org/10.3402/ejpt.v5.24794

Lee, C., Doo, E., Choi, J. M., Jang, S., Ryu, H., Lee, J. Y., . . Brain-Gut Axis Research Group of Korean Society of Neurogastroenterology and Motility. (2017). The increased level of depression and anxiety in irritable bowel syndrome patients compared with healthy controls: Systematic review and meta-analysis. Journal of Neurogastroenterology and Motility, 23(3), 349-362. https://doi:10.5056/jnm16220

Leserman, J., \& Drossman, D. A. (2007). Relationship of abuse history to functional gastrointestinal disorders and symptoms: Some possible mediating mechanisms. Trauma, Violence, \& Abuse: A Review Journal, 8(3), 331-343. https://doi:10.1177/1524838007303240

Li, Y., Rosemberg, M. A. S., \& Seng, J. S. (2018). Allostatic load: A theoretical model for understanding the relationship between maternal posttraumatic stress disorder and adverse birth outcomes. Midwifery, 62, 205-213.

https://doi.org/10.1016/j.midw.2018.04.002

Liberati, A., Altman, D. G., Tetzlaff, J., Mulrow, C., Gotzsche, P. C., Ioannidis, J. P., \& Moher, D. (2009). The PRISMA statement for reporting systematic reviews and meta-analyses of studies that evaluate health care interventions: Explanation and elaboration. Journal of Clinical Epidemiology, 62(10), e1-e34. https://doi:10.1016/j.jclinepi.2009.06.006

Longstreth, G. F., Thompson, W. G., Chey, W. D., Houghton, L. A., Mearin, F., \& Spiller, R. C. (2006). Functional bowel disorders. Gastroenterology, 130(5), 1480-1491. https://doi.org/10.1053/j.gastro.2005.11.061

Mapayi, B., Makanjuola, R. O. A., Mosaku, S. K., Adewuya, O. A., Afolabi, O., Aloba, O. O., \& Akinsulore, A. (2013). Impact of intimate partner violence on anxiety and depression amongst women in Ile-Ife, Nigeria. Archives of women's mental health, 16(1), 11-18. https://doi.org/10.1007/s00737-012-0307-x 
Marrie, Ruth, Ann MD, PhD, Leung, Stella, Tyry, Tuula, Cutter, Gary, Fox, Robert, et al. (2019). Functional gastrointestinal disorders negatively affect health-related quality of life in MS. Neurology Clinical Practice, 9(5), 381-390. https://doi.org/10.1212/CPJ.0000000000000668

Mazidi, M., Banach, M., \& Kengne, A. (2018). Prevalence of childhood and adolescent overweight and obesity in Asian countries: A systematic review and metaanalysis. Archives of Medical Science, 14(6), 1185-1203. https://doi.org/10.5114/aoms.2018.79001

Mearin, F., \& Malfertheiner, P. (2017). Functional gastrointestinal disorders: Complex treatments for complex pathophysiological mechanisms. Digestive diseases (Basel, Switzerland), 35 Suppl 1(1), 1-4. https://doi.org/10.1159/000485407

McEwen, B. S., \& Wingfield, J. C. (2003). The concept of allostasis in biology and biomedicine. Hormones and Behavior, 43(1), 2-15. https://doi.org/10.1016/S0018-506X(02)00024-7

McHorney, C. A., Ware Jr, J. E., Lu, J. R., \& Sherbourne, C. D. (1994). The MOS 36-item Short-Form Health Survey (SF-36): III. Tests of data quality, scaling assumptions, and reliability across diverse patient groups. Medical Care, 30(1), 40-66. https://www.jstor.org/stable/3766189

Miller, C. D., \& Campbell, J. C. (1993). Reliability and validity of the miller abuse physical symptom and injury scale (MAPSAIS). Chicago, IL: Midwest Nursing Research Society.

Moher, D., Liberati, A., Tetzlaff, J., \& Altman, D. G. (2010). Preferred reporting items for systematic reviews and meta-analyses: the PRISMA statement. Annals of Internal Medicine, 151(4), 264-269. https://doi: 10.1136/bmj.b2535

Murray, L., \& Carothers, A. D. (1990). The validation of the Edinburgh Post-natal Depression Scale on a community sample. The British Journal of Psychiatry, 157(2), 288-290. https://doi.org/10.1192/bjp.157.2.288

Myhill, A. (2015). Measuring coercive control: What can we learn from political population surveys? Violence Against Women, 21(3), 355-375. https://doi.org/10.1177/1077801214568032

Myhill, A., \& Hohl, K. (2019). The "golden thread": Coercive control and risk assessment for domestic violence. Journal of Interpersonal Violence, 34(21-22), 44774497. https://doi.org/10.1177/0886260516675464

Nedd, D. M. (2001). Self-supported health status and depression of battered black women. ABNF Journal, 12(2), 32-35. 
Oshima, T., \& Miwa, H. (2016). Gastrointestinal mucosal barrier function and diseases. Journal of Gastroenterology, 51(8), 768-778.

https://doi.org/10.1007/s00535-016-1207-z

Paluzzi, P. A., P., \& Houde-Quimby, C. (1996). Domestic violence: Implications for the American College of Nurse-Midwives and its members. Journal of Nurse-Midwifery, 41(6), 430-427. https://doi.org/10.1016/S0091-2182(96)00064-X

Perona, M., Benasayag, R., Perelló, A., Santos, J., Zárate, P., Zárate, N., \& Mearin, F. (2005). Prevalence of functional gastrointestinal disorders in women who report domestic violence to the police. Clinical Gastroenterology and Hepatology, 3(5), 436-441. https://doi:10.1016/S1542-3565(04)00776-1

Puri, M., Tamang, J., \& Shah, I. (2011). Suffering in silence: Consequences of sexual violence within marriage among young women in Nepal. BMC Public Health, 11(1), 29. https://doi.org/10.1186/1471-2458-11-29

Salam, M. A., Alim, M. A., \& Noguchi, T. (2006). Spousal abuse against women and its consequences on reproductive health: A study in the urban slums in Bangladesh. Maternal and Child Health Journal, 10(1), 83-94. https://doi.org/10.1007/s10995-005-0030-6

Satyen, L., Toumbourou, J. W., Heerde, J., Supol, M., \& Ranganathan, A. (2020). The Royal Commission into Family Violence: Trends in the Reporting of Intimate Partner Violence and Help-Seeking Behavior. Journal of Interpersonal Violence. https://doi.org/10.1177/0886260519897341

Schollenberger, J., Campbell, J., Sharps, P. W., O’Campo, P., Gielen, A. C., Dienemann, J., \& Kub, J. (2003). African American HMO enrollees: Their experiences with partner abuse and its effect on their health and use of medical services. Violence Against Women, 9(5), 599-618. https://doi.org/10.1177/1077801202250451

Scott-Storey, K. (2011). Cumulative Abuse: Do Things Add Up? An Evaluation of the Conceptualization, Operationalization, and Methodological Approaches in the Study of the Phenomenon of Cumulative Abuse. Trauma, Violence, \& Abuse, 12(3), 135150. https://doi.org/10.1177/1524838011404253

Smith, P. H., Earp, J. A., \& DeVellis, R. (1995). Measuring battering: Development of the Women's Experience with Battering (WEB) Scale. Women's Health: Research on Gender, Behavior, \& Policy, 1(4), 273-288.

Soeken, K. L., McFarlane, J., Parker, B., \& Lominack, M. C. (1998). The abuse assessment screen: A clinical instrument to measure frequency, severity, and perpetrator of abuse against women. In J. Campbell (Ed.), Empowering survivors of abuse: Health care for battered women and their children (pp. 195-203). Thousand Oaks, CA: Sage. 
Starfield, B., Weiner, J., Mumford, L., \& Steinwachs, D. (1991). Ambulatory care groups: a categorization of diagnoses for research and management. Health Services Research, 26(1), 53-74.

Stasi, C., Rosselli, M., Bellini, M., Laffi, G., \& Milani, S. (2012). Altered neuro-endocrineimmune pathways in the irritable bowel syndrome: The top-down and the bottom-up model. Journal of Gastroenterology, 47(11), 1177-1185. https://doi.org/10.1007/s00535-012-0627-7

Straus, M. A. (1979). Measuring intrafamily conflict and violence. The Conflict Tactics (CT) Scales. Journal of Marriage and the Family, 41(1), 75-88. https://doi: $10.2307 / 351733$

Renzi, M. R., \& Agurto, S. (1993). Situación económica y social de León, Managua y Granada. Managua, Nicaragua: Fundación Internacional para el Desafio Económica Global (FIDEG).

Riegler, G., \& Esposito, I. (2001). Bristol scale stool form: A still valid help in medical practice and clinical research. Techniques in Coloproctology, 5(3), 163-164. https://doi.org/10.1007/s101510100019

Talley, N. J., Stanghellini, V., Heading, R. C., Koch, K. L., Malagelada, J. R., \& Tytgat, G. N. J. (1999). Functional gastroduodenal disorders. Gut, 45(suppl 2), II37-II42. http://dx.doi.org/10.1136/gut.45.2008.ii37

The American Community Survey, (2009). US Census Bureau Web site. http://www.census.gov/acs/www/

Thompson, R. S., Bonomi, A. E., Anderson, M., Reid, R. J., Dimer, J. A., Carrell, D., \& Rivara, F. P. (2006). Intimate partner violence: Prevalence, types, and chronicity in adult women. American Journal of Preventive Medicine, 30(6), 447-457. https://doi.org/10.1016/j.amepre.2006.01.016

Thompson, W. G., Longstreth, G. F., Drossman, D. A., Heaton, K. W., Irvine, E. J., \& Müller-Lissner, S. A. (1999). Functional bowel disorders and functional abdominal pain. Gut, 45(suppl 2), 1143-1147. http://dx.doi.org/10.1136/gut.45.2008.ii43

Van Oudenhove, L., Levy, R. L., Crowell, M. D., Drossman, D. A., Halpert, A. D., Keefer, L., ... \& Naliboff, B. D. (2016). Biopsychosocial aspects of functional gastrointestinal disorders: How central and environmental processes contribute to the development and expression of functional gastrointestinal disorders. Gastroenterology, 150(6), 1355-1367. https://doi.org/10.1053/j.gastro.2016.02.027

Weiner, J. P., Starfield, B. H., Steinwachs, D. M., \& Mumford, L. M. (1991). Development and application of a population-oriented measure of ambulatory care casemix. Medical care, 29(5), 452-472. https://www.jstor.org/stable/3766037 
Wong, J., \& Mellor, D. (2014). Intimate partner violence and women's health and wellbeing: Impacts, risk factors and responses. Contemporary Nurse, 46(2), 170-179. https://doi.org/10.5172/conu.2014.46.2.170

Woods, S. J., Hall, R. J., Campbell, J. C., \& Angott, D. M. (2008). Physical health and posttraumatic stress disorder symptoms in women experiencing intimate partner violence. Journal of Midwifery \& Women's Health, 53(6), 538-546. https://doi.org/10.5172/conu.2014.46.2.170

World Health Organization (2019). Violence and Injury Prevention; Intimate partner and sexual violence (violence against women). https://www.who.int/violence_injury_prevention/violence/sexual/en/

World Health Organization (2017). Violence against women. https://www.who.int/newsroom/fact-sheets/detail/violence-against-women

World Health Organization. (2014). WHOQOL: Measuring quality of life. https://www.who.int/healthinfo/survey/whoqol-qualityoflife/en/

World Health Organization (2013). Global and regional estimates of violence against women: Prevalence and health effects of intimate partner violence and non-partner sexual violence. https://www.who.int/reproductivehealth/publications/violence/9789241564625/en/

World Health Organization. (2012). Understanding and addressing violence against women: Intimate partner violence (No. WHO/RHR/12.36). https://apps.who.int/iris/bitstream/handle/10665/77432/WHO_RHR_12.36_eng.pdf

Wuest, J., Ford-Gilboe, M., Merritt-Gray, M., \& Berman, H. (2003). Intrusion: The central problem for family health promotion among children and single mothers after leaving an abusive partner. Qualitative Health Research, 13(5), 597-622. https://doi:10.1177/1049732303013005002

Wuest, J., Ford-Gilboe, M., Merritt-Gray, M., Wilk, P., Campbell, J. C., Lent, B., ... \& Smye, V. (2010). Pathways of chronic pain in survivors of intimate partner violence. Journal of Women's Health, 19(9), 1665-1674. https://doi.org/10.1089/jwh.2009.1856

Wuest, J., Merritt-Gray, M., Ford-Gilboe, M., Lent, B., Varcoe, C., \& Campbell, J. C. (2008). Chronic pain in women survivors of intimate partner violence. The Journal of Pain, 9(11), 1049-1057. https://doi.org/10.1016/j.jpain.2008.06.009 


\section{CHAPTER THREE \\ Summary and Implications}

Substantial evidence highlighting a high prevalence of IPV among married and dating couples and its association with poorer mental and physical health outcomes among women has generated a great deal of interest from scholars, social activists, and health service providers (Capaldi, Knoble, Shortt \& Kim, 2012; Pierotti, 2013). This systematic review was conducted to explore the relationship between intimate partner violence (IPV) and functional gastrointestinal disorders and symptoms (FGIDs) and symptoms. To our knowledge, this is the first review of research into the relationship between IPV and FGIDs and symptoms among adult women. The main goals of this systematic review were to identify what research in the field of IPV and FGIDs and symptoms has accomplished and to explore the current state of the literature to determine directions for future research.

This systematic review included 15 studies: 1 qualitative and 14 quantitative studies. Based on the results, it is evident that there is an association between IPV and FGIDs. Although the included studies did not, for the most part, measure FGIDs and symptoms using appropriate instruments, and most (11 out of 15) of the included studies examined the association of IPV and women's physical and mental health outcomes more broadly, the results do provide evidence supporting an association between IPV and FGIDs and symptoms in women. The majority of the included studies examined IPV in general. However, the few that examined the relationship between specific types of IPV and FGIDs and symptoms provide initial evidence that each type of IPV (psychological, physical, sexual) is associated with FGIDS on its own, as well as in combination with other types of IPV. The results also show that there is a lack of research-based theory and evidence for 
identifying the mechanisms that mediate and/or moderate this relationship. Additionally, among the included studies, limited attention was given to examining the effects of FGIDs on QOL outcomes in the context of IPV ( $n=4$ out of 15 studies); although these suggest that women suffering both IPV and FGIDs make more visits to health care providers, overall, there was a lack of research on women's pathways to recovery. These findings provide direction and suggest priorities for future research in women's health. The implications of these findings for nursing practice and health care, research, and education are discussed in the sections that follow.

\section{Implications for Nursing Practice and Health Care}

This review shows that abused women with FGIDs and symptoms have more physician visits and consultations, and are more likely than women without FGIDs or experiences of IPV, to visit hospital emergency departments (John et al., 2004; Perona et al., 2005; Schollenberger et al., 2003). Since the etiology of FGIDs remains unclear, best practices for managing FGIDs mostly focus on reducing symptoms, not curing the disorder (Van Oudenhove et al., 2016). Although women with FGIDs and symptoms require medical care for their symptoms, some are not treated at all, and others are only able to access substandard care (Drossman et al., 2018). According to Drossman (2016), women with FGIDs and symptoms have described inconsistencies in diagnoses from health professionals and a lack of appropriate referrals (Drossman, 2016). For example, they may be subjected to unnecessary tests and procedures such as x-rays, CT scans, blood tests, and endoscopic exams, which can lead to frustration for women and health care providers (Becker-Dreps et al., 2010; Leserman \& Drossman, 2007). Also, for some patients, IBS is just one aspect of a complex chronic pain condition that can produce even greater psychological distress and 
other negative effects, which in turn can further reduce QOL outcomes (Hearn, Whorwell, \& Vasant, 2020).

Greater awareness is needed among healthcare providers, including nurses who provide care to women with FGIDs and symptoms, about the possibility that such women could be experiencing abuse to allow them to serve this population more effectively. Greater awareness of the link between IPV and FGIDs could help women who have experienced IPV manage unpleasant health issues, including FGIDs, more effectively (Drossman, 2016). Health care providers should be familiar enough with FGIDs to be able to assess symptoms such as chronic abdominal pain, irritable bowel syndrome (IBS), functional dyspepsia (FD), frequent diarrhea, and frequent constipation using different tools to identify and diagnose patients with FGIDs. Given the assocaition between IPV and FGIDs, health assessments for women living with FDIGs should include case finding or clinical inquiry for IPV, which could prompt appropriate referrals for counselling as well as better treatment of the physical symptoms (World Health Organization, 2013). When these health problems are identified using appropriate approaches, health care providers and nursing are better able to offer effective treatment and support (Drossman, 2016; Nelson et al., 2004). Some specific pharmacologic treatments have been linked to positive outcomes for FGIDs (Basnayake, Kamm, Salzberg, Wilson-O’ Brien, Stanley, \& Thompson, 2020), including antidepressants, antibiotics, aperients, and non-laxative bowel stimulants (Basnayake et al., 2020). Nonpharmacological therapies appear to be safe and appropriate interventions as part of the management of patients with FGIDs including complementary therapies (Razeghi \& Ouyang, 2020), education about FGIDs (Basnayake et al., 2020) or about improving diet (Halmos, Power, Shepherd, Gibson, \& Muir, 2014). 
Diagnosis of FGIDs and symptoms using the Rome IV criteria is considered to be a more comprehensive, validated approach that specifically focuses on FGIDs and symptoms (Drossman, 2016). Indeed, the Rome IV criteria are currently commonly used by clinicians to diagnose patients with FGIDs (Drossman, 2016). However, a wide range of countries were included in this systemic review and the clinical implications may differ across that range. Across the world, some health care providers may support case finding of clinical inquiry about IPV among patients with health concerns including FGIDs and symptoms (WHO, 2013). In case finding, risk factors for IPV, such as poorer mental and physical health, help the health care provider consider whether to inquire about a history of current or past abuse (Becker-Dreps et al., 2010; Coronel \& Silva 2018) and to offer appropriate support and referral (WHO, 2013).

Because of the demonstrated association between IPV and FGIDs around the world, efforts to prevent IPV should be considered to reduce the associated adverse health outcomes, including FGIDs. Some of the studies included in this review show that abused women with FGIDs and symptoms access health services more frequently than women who have not experienced abuse, and that some abused women believe that health care providers' asking about their history of IPV might help them get the help they need (John et al., 2004; Perona et al., 2005; Schollenberger et al., 2003). Case finding and clinical inquiry using a structured questionnaire or direct interview is the best way to identify victims of IPV (Feder, Hutson, Ramsay, \& Taket, 2006; John et al., 2004). John et al. (2004) show that the rate of disclosure of abuse in health care settings without direct questioning and appropriate clinical inquiry is low. Proper training of health care providers in techniques to safely identify IPV among women also promotes health care providers' confidence in asking women about their IPV in order to provide follow up care, support information, and referrals (Wong, Wester, 
Mol, \& Lagro-Janssen, 2006). Based on a meta-analysis of qualitative studies, Feder et al., 2006) underscore that women who have experienced IPV want health care providers' responses to be nonjudgmental, nondirective, individually tailored, and appreciative of the complexity of IPV; they also want reassurance that the abuse is not their fault and that their negative feelings are understandable.

Clinical inquiry by health care providers has the potential to increase women's awareness of the possible relationship between IPV and health problems they are experiencing, including FGIDs, and how it affects their daily life and QOL outcomes. Clinicians who are aware of the abuse history of patients are in a better position to support them by providing information and referrals to help them to stop or reduce their ongoing victimization and overcome consequences of the abuse (WHO, 2013). Several studies have shown that advocacy services lead to better access to needed resources, a decrease in violence experienced, and an improved quality of life. Nurses and other health care providers can play a significant role in helping women access community resources, such as legal, housing, and income support services. In fact, advocating for abused women and helping them to navigate the health care system are key supports that nurses and other health care providers can provide to women who are in an abusive relationship (Crisis Prevention Institute, 2020). However, the goals of advocacy and system navigation must be matched to each woman's needs in order to be most effective (Rivas, Vigurs, Cameron, \& Yeo, 2019). For example, Varcoe et al. (2019) developed and tested a 6 month, health promotion intervention, which involved nurses and Indigenous elders working together to address the needs of Canadian Indigenous women who had experienced IPV. The results of this study suggest that this type of intervention can be effectively tailored to the specific needs of indigenous women with positive impacts for their health (Varcoe et al., 2019). 
Given that some countries do not have services that support abused women, some women may remain silent and not seek help (Puri, Tamang, \& Shah, 2011; WHO, 2012). For example, one of the included studies showed that sexual violence within marriage is common in Nepal, and various actions are needed to provide immediate support to the victims such as provide services to women who have experienced IPV (Puri et al., 2011). Across the world, there are factors that discourage women from seeking help, such as poverty, lack of services for abused women, patriarchal social norms, and a lack of civil rights, which can take the form of restrictive or inequitable divorce and marriage laws. However, health care providers and nurses should be aware of the factors that may prevent women from reporting abuse and should collaborate across sectors, such as with shelters and other adult protective services, to increase awareness about support service availability, to identify women who are experiencing abuse and to provide referrals for appropriate health care as needed.

\section{Implications for Research}

Theory is a fundamental guide for research as it describes important variables and identifies relationships between them that can be empirically tested (Shalley, 2012). A theory that holds up under empirical testing can increase our understanding of the relationships between variables and the mechanisms that may be involved in those relationships in a novel and innovative way. As only two of the included studies explicitly used a theoretical model, (Becker-Dreps et al., 2010; Perona et al., 2005), this systematic review showed that there is a lack of theory-based research in this area which explain the lack of identification of factors that moderate or/and mediate the relationship between IPV and FGIDs. When empirical findings can be synthesized within a theoretical framework, contradictory results can often be reconciled because contingent factors influencing the relationship in different studies can be more easily identified (Luborsky, Barber, \& Crits-Christoph, 1990). Also, a theoretical 
framework explains the association's underlying logic, which helps explain the key drivers, possible outcomes, and the underlying processes responsible for the association (Luborsky et al., 1990). Moreover, theories guide future research by helping researchers to identify constructs and relationships worthy of further investigation, to bridge gaps between theories, and to re-evaluate findings in a new light (Luborsky et al., 1990). There is a need for additional theory-based research into the relationship between IPV and FGIDs and effects FGIDs on women's QOL in the context of IPV in order to elucidate further the mechanisms linking IPV and FGIDs.

The biopsychosocial model, a well identified theory in the area of the FGIDs, is a more predictive than explanatory model (Francisconi et al., 2016). According to Shalley (2012), using theory in research is appropriate when the theory provides a compelling causal explanation of the underlying processes in the specific phenomenon being studied. Some theories explain the effects of chronic traumatic stress such as IPV on health. For example, allostatic load theory explains the effects of chronic traumatic stress on cardiovascular parameters, metabolic functions, immune and inflammatory defences, and the nervous system (McEwen, 2000). However, allostatic load theory has not been used to explain the effects of chronic traumatic stress such as IPV on the gastrointestinal system. Future studies are needed to develop a better understanding of the effects of chronic traumatic stress (e.g., IPV) on women health (e.g., FGIDs) using explanatory model such as allostatic load theory. In particular, it is important that we have theory-based research in both quantitative and qualitative studies to help explain the association between IPV and FGIDs.

All of the quantitative studies in the review used descriptive cross-sectional designs. Longitudinal studies are needed to more fully understand the pathways through which IPV predicts FGIDs and symptoms over time, which may help inform the development of 
interventions to help women. Also, future research should investigatde which types of intervention programs are most successful in reducing the harmful effects of IPV and improving women's ability to manage distressing symptoms associated with FGIDs. Only one qualitative descriptive study was identified in this review; there is a need for qualitative studies that explore what women with FGIDs do to manage their illness in the context of IPV, as well as women's perspectives on IPV and the services available to them in different cultural contexts.

\section{Implications for Nursing Education}

Women who have experienced and/or are experiencing IPV often trust health care providers enough to disclose these experiences (WHO, 2019). Therefore, regardless of where nurses work, whether in acute care or community settings, nurses are likely to encounter women who have experienced violence. Thus, undergraduate nursing studies should carefully educate nurses about the importance of properly identifying and responding to women who have experienced or are experiencing IPV and reporting signs of FGIDs and symptoms. Also, nurses and nursing students must be knowledgeable about the prevalence of abuse, the definition and dynamics of violence, its health consequences including FGIDs, the role of the nurse, community resources, consequences of the women's disclosure, and confidentiality and legal implications. FGIDs remains under-recognized in research and clinical practice as they are poorly understood and have an unclear etiology, prognosis, and clinical course (Longstreth, Thompson, Chey, Houghton, Mearin, \& Spiller, 2006; Wong \& Mellor, 2014). The development of cross-cultural competency and cross-cultural research could make a major contribution to our understanding of the biological and psychosocial factors that underlie these disorders, which could, in turn, facilitate their effective management. Accordingly, it is necessary to increase the curriculum content in nursing schools to include 
education about IPV and its health consequences, and to provide knowledge and skills for case-finding and clinical inquiries to respond appropriately and effectively.

In recognition of this, WHO (2019) published a new training curriculum to provide health care providers with the knowledge and skills they need to best help women who are living with violence. This curriculum is designed to help health care providers to learn how to deliver women-centred clinical care; identify women who are experiencing violence; provide first-line support using the LIVES approach (Listen, Inquire, Validate, Enhance safety and Support); provide essential clinical care for survivors; and identify local support resources (WHO, 2019). Additionally, this curriculum emphasizes participant-centred learning, which includes scenario-based activities, role-play, group work, and other activities designed to develop a better understanding of violence against women and the skills needed

to assist women who are affected by it (WHO, 2019). The LIVES approach helps nurses and nursing students to practice their knowledge and clinical skills when providing care to women who have experienced abuse and to connect them to available resources (WHO, 2019).

\section{Conclusion}

In practice, education, and research, nurses must address the important relationship between IPV and women's health in order to promote women's health more effectively. A synthesis of the current research on IPV and FGIDs and associated QOL outcomes among adult women was conducted. Based on this synthesis, there is clearly a need for future research on the relationship between IPV and FGIDs in adult women. In the meantime, this systematic review can serve to highlight the relationship between IPV and FGIDs to improve both care for the women affected, and nursing education and health care providers practice. Further, the findings could be used to guide future research on women's health. Thus, there is 
a need for future studies using longitudinal and interventional designs conducted by more diverse, and interprofessional research teams. Much more research is needed to develop an understanding of the mechanisms that moderate/mediate the effects of FGIDs associated with IPV on women's QOL. 


\section{References}

Ahmadabadi, Z., Najman, J. M., Williams, G. M., Clavarino, A. M., d’Abbs, P., \& Tran, N. (2020). Intimate partner violence and subsequent depression and anxiety disorders. Social Psychiatry and Psychiatric Epidemiology,55(5), 611-620. https://doi.org/10.1007/s00127-019-01828-1

Basnayake, C., Kamm, M., Salzberg, M., Wilson-O’ Brien, A., Stanley, A., \& Thompson, A. (2020). Delivery of care for functional gastrointestinal disorders: A systematic review. Journal of Gastroenterology and Hepatology, 35(2), 204-210. https://doi.org/10.1111/jgh.14830

Becker-Dreps, S., Morgan, D., Peña, R., Cortes, L., Martin, C. F., \& Valladares, E. (2010). Association between intimate partner violence and irritable bowel syndrome: A population-based study in nicaragua. Violence Against Women, 16(7), 832-845. https://doi.org/10.1177/1077801210374816

Capaldi, D. M., Knoble, N. B., Shortt, J. W., \& Kim, H. K. (2012). A systematic review of risk factors for intimate partner violence. Partner Abuse, 3(2), 231-280. https://doi:10.1891/1946-6560.3.2.231

Campbell, J., Jones, A. S., Dienemann, J., Kub, J., Schollenberger, J., O'Campo, P., . . . Wynne, C. (2002). Intimate partner violence and physical health consequences. Archives of Internal Medicine, 162(10), 1157-1163. https://doi:10.1001/archinte.162.10.1157

Chogle, A., Dhroove, G., Sztainberg, M., Di Lorenzo, C., \& Saps, M. (2010). How reliable are the Rome III criteria for the assessment of functional gastrointestinal disorders in children? The American Journal of Gastroenterology, 105(12), 2697-2701. https://doi:10.1038/ajg.2010.350

Coronel, A. L. C., \& Silva, H. T. H. (2018). Interrelation between functional constipation and domestic violence. Journal of Coloproctology, 38(2), 117-123. https://doi.org/10.1016/j.jcol.2017.12.003

Crisis Prevention Institute, (2020). Domestic violence: What can nurses do? https://www.crisisprevention.com/Blog/Domestic-Violence-What-Can-Nurses$\underline{\text { Do }}$

Drossman, D. A. (2016). Functional gastrointestinal disorders: history, pathophysiology, clinical features, and Rome IV. Gastroenterology, 150(6), 1262-1279. https://doi.org/10.1053/j.gastro.2016.02.032

Drossman, D. A., Tack, J., Ford, A. C., Szigethy, E., Törnblom, H., \& Van Oudenhove, L. (2018). Neuromodulators for functional gastrointestinal disorders (disorders of gutbrain interaction): A Rome foundation going team report. Gastroenterology, 154(4), 1140-1171. https://doi.org/10.1053/j.gastro.2017.11.279 
Feder, G., Hutson, M., Ramsay, J., \& Taket, A. (2006). Women exposed to intimate partner violence: Expectations and experiences when they encounter health care professionals: A meta-analysis of qualitative studies. Archives of Internal Medicine, 166(1), 22-37. https://doi.org/10.1001/archinte.166.1.22

Ford, A., Talley, N., Schoenfeld, P., Quigley, E., \& Moayyedi, P. (2009). Efficacy of antidepressants and psychological therapies in irritable bowel syndrome: Systematic review and meta-analysis. Gut, 58(3), 367-36778.

https://doi.org/10.1136/gut.2008.163162

Francisconi, C. F., Sperber, A. D., Fang, X., Fukudo, S., Gerson, M. J., Kang, J. Y., \& Schmulson, M. (2016). Multicultural aspects in functional gastrointestinal disorders (FGIDs). Gastroenterology, 150(6), 1344-1354. https://doi.org/10.1053/j.gastro.2016.02.013

Halmos, E., Power, V., Shepherd, S., Gibson, P., \& Muir, J. (2014). A diet low in FODMAPs reduces symptoms of irritable bowel syndrome. Gastroenterology, 146(1), 67-75. https://doi.org/10.1053/j.gastro.2013.09.046

Hearn, M., Whorwell, P. J., \& Vasant, D. H. (2020). Stigma and irritable bowel syndrome: A taboo subject?. The Lancet Gastroenterology \& Hepatology, 5(6), 607-615. https://doi.org/10.1016/S2468-1253(19)30348-6

John, R., Johnson, J. K., Kukreja, S., Found, M., \& Lindow, S. W. (2004). Domestic violence: Prevalence and association with gynaecological symptoms. BJOG: An International Journal of Obstetrics \& Gynaecology, 111(10), 1128-1132. https://doi.org/10.1111/j.1471-0528.2004.00290.x

Leserman, J., \& Drossman, D. A. (2007). Relationship of abuse history to functional gastrointestinal disorders and symptoms: Some possible mediating mechanisms. Trauma, Violence, \& Abuse: A Review Journal, 8(3), 331-343. https://doi:10.1177/1524838007303240

Longstreth, G. F., Thompson, W. G., Chey, W. D., Houghton, L. A., Mearin, F., \& Spiller, R. C. (2006). Functional bowel disorders. Gastroenterology, 130(5), 1480-1491. https://doi.org/10.1053/j.gastro.2005.11.061

Luborsky, L., Barber, J. P., \& Crits-Christoph, P. (1990). Theory-based research for understanding the process of dynamic psychotherapy. Journal of consulting and clinical psychology, 58(3), 281-287. https://doi.org/10.1037//0022-006x.58.3.281

Mahler, T. (2015). Education and hypnosis for treatment of functional gastrointestinal disorders (FGIDs) in pediatrics. American Journal of Clinical Hypnosis, 58(1), 115128. https://doi.org/10.1080/00029157.2015.1033676 
McEwen, B. S. (2000). Allostasis and allostatic load: Implications for neuropsychopharmacology. Neuropsychopharmacology, 22(2), 108-124. https://doi.org/10.1016/S0893-133X(99)00129-3

Nelson, H. D., Nygren, P., McInerney, Y., \& Klein, J. (2004). Screening women and elderly adults for family and intimate partner violence: A review of the evidence for the US preventive services task force. Annals of Internal Medicine, 140(5), 387-396. https://doi.org/10.7326/0003-4819-140-5-200403020-00015

Razeghi, S., \& Ouyang, A. (2020). Behavioral and non-pharmacological management of functional gastrointestinal disorders. In Clinical and Basic Neurogastroenterology and Motility. 577-586. https://doi.org/10.1016/B978-0-12-813037-7.00041-8

Rivas C, Vigurs C, Cameron J, Yeo L. (2019). A realist review of which advocacy interventions work for which abused women under what circumstances. Cochrane Database of Systematic Reviews, CD013135(6). https://doi.org/10.1002/14651858.CD013135.pub2

Perona, M., Benasayag, R., Perelló, A., Santos, J., Zárate, P., Zárate, N., \& Mearin, F. (2005). Prevalence of functional gastrointestinal disorders in women who report domestic violence to the police. Clinical Gastroenterology and Hepatology, 3(5), 436-441. https://doi:10.1016/S1542-3565(04)00776-1

Pierotti, R. S. (2013). Increasing rejection of intimate partner violence: Evidence of global cultural diffusion. American Sociological Review, 78(2), 240-265. https://doi.org/10.1177/0003122413480363

Punukollu, M. (2003). Domestic violence: Screening made practical. The Journal of Family Practice, 52(7), 1-6.

Puri, M., Tamang, J., \& Shah, I. (2011). Suffering in silence: Consequences of sexual violence within marriage among young women in Nepal. BMC Public Health, 11(1), 29. https://doi.org/10.1186/1471-2458-11-29

Schollenberger, J., Campbell, J., Sharps, P. W., O'Campo, P., Gielen, A. C., Dienemann, J., \& Kub, J. (2003). African American HMO enrollees: Their experiences with partner abuse and its effect on their health and use of medical services. Violence Against Women, 9(5), 599-618. https://doi.org/10.1177/1077801202250451

Shalley, C. E. (2012). Writing good theory: Issues to consider. Organizational Psychology Review, 2(3), 258-264. https://doi.org/10.1177/2041386611436029

Van Oudenhove, L., Levy, R. L., Crowell, M. D., Drossman, D. A., Halpert, A. D., Keefer, L., ... \& Naliboff, B. D. (2016). Biopsychosocial aspects of functional gastrointestinal disorders: How central and environmental processes contribute to the development and expression of functional gastrointestinal disorders. Gastroenterology, 150(6), 1355-1367. https://doi.org/10.1053/j.gastro.2016.02.027 
Varcoe, C., Ford-Gilboe, M., Browne, A. J., Perrin, N., Bungay, V., McKenzie, H., ... Dion Stout, M. (2019). The efficacy of a health promotion intervention for indigenous women: Reclaiming our spirits. Journal of Interpersonal

Violence. https://doi.org/10.1177/0886260518820818

Wong, J., \& Mellor, D. (2014). Intimate partner violence and women's health and wellbeing: Impacts, risk factors and responses. Contemporary Nurse, 46(2), 170-179. https://doi.org/10.5172/conu.2014.46.2.170

Wong, S. L. F., Wester, F., Mol, S. S., \& Lagro-Janssen, T. L. (2006). Increased awareness of intimate partner abuse after training: a randomised controlled trial. Br J Gen Pract, 56(525), 249-257.

World Health Organization. (2013). Responding to intimate partner violence and sexual violence against women: WHO clinical and policy guidelines. World Health Organization.

World Health Organization. (2019). Training healthcare providers to help women survivors of violence. https://www.who.int/reproductivehealth/training-health-care-providershelp-women-survivors-of-violence/en/ 


\section{Appendix A}

PRISMA-P Checklist (Preferred Reporting Items for Systematic review and Meta-Analysis Protocols) 2015 checklist: recommended items to address in a systematic review protocol*

\begin{tabular}{ll} 
Section and topic & $\begin{array}{l}\text { Item } \\
\text { No }\end{array}$ \\
\hline ADMINISTRATIVE INFORMATION
\end{tabular}

\begin{tabular}{lll}
\hline Title: & & \\
$\begin{array}{l}\text { Identification } \\
\text { Update }\end{array}$ & $1 \mathrm{a}$ & $\begin{array}{l}\text { Identify the report as a protocol of a systematic review } \\
\text { If the protocol is for an update of a previous systematic review, identify as such }\end{array}$ \\
\hline Registration & 2 & $\begin{array}{l}\text { If registered, provide the name of the registry (such as PROSPERO) and } \\
\text { registration number }\end{array}$ \\
\hline
\end{tabular}

Authors:

\begin{tabular}{lll} 
Contact & $3 \mathrm{a}$ & $\begin{array}{l}\text { Provide name, institutional affiliation, e-mail address of all protocol authors; } \\
\text { provide physical mailing address of corresponding author } \\
\text { Describe contributions of protocol authors and identify the guarantor of the } \\
\text { review }\end{array}$ \\
\hline Amendments & $3 \mathrm{~b}$ & $\begin{array}{l}\text { If the protocol represents an amendment of a previously completed or } \\
\text { published protocol, identify as such and list changes; otherwise, state plan for } \\
\text { documenting important protocol amendments }\end{array}$ \\
\hline
\end{tabular}

Support:

Sources $\quad 5 \mathrm{a} \quad$ Indicate sources of financial or other support for the review

Sponsor $\quad 5 b \quad$ Provide name for the review funder and/or sponsor

Role of sponsor or $\quad 5 \mathrm{c} \quad$ Describe roles of funder(s), sponsor(s), and/or institution(s), if any, in funder developing the protocol

\section{INTRODUCTION}

\begin{tabular}{lll}
\hline Rationale & 6 & Describe the rationale for the review in the context of what is already known \\
\hline Objectives & 7 & $\begin{array}{l}\text { Provide an explicit statement of the question(s) the review will address with } \\
\text { reference to participants, interventions, comparators, and outcomes (PICO) }\end{array}$ \\
\hline
\end{tabular}

\section{METHODS}

\begin{tabular}{|c|c|c|}
\hline Eligibility criteria & 8 & $\begin{array}{l}\text { Specify the study characteristics (such as PICO, study design, setting, time } \\
\text { frame) and report characteristics (such as years considered, language, } \\
\text { publication status) to be used as criteria for eligibility for the review }\end{array}$ \\
\hline Information sources & 9 & $\begin{array}{l}\text { Describe all intended information sources (such as electronic databases, contact } \\
\text { with study authors, trial registers or other grey literature sources) with planned } \\
\text { dates of coverage }\end{array}$ \\
\hline Search strategy & 10 & $\begin{array}{l}\text { Present draft of search strategy to be used for at least one electronic database, } \\
\text { including planned limits, such that it could be repeated }\end{array}$ \\
\hline \multicolumn{3}{|l|}{ Study records: } \\
\hline Data management & $11 \mathrm{a}$ & $\begin{array}{l}\text { Describe the mechanism(s) that will be used to manage records and data } \\
\text { throughout the review }\end{array}$ \\
\hline Selection process & $11 \mathrm{~b}$ & $\begin{array}{l}\text { State the process that will be used for selecting studies (such as two } \\
\text { independent reviewers) through each phase of the review (that is, screening, } \\
\text { eligibility and inclusion in meta-analysis) }\end{array}$ \\
\hline
\end{tabular}




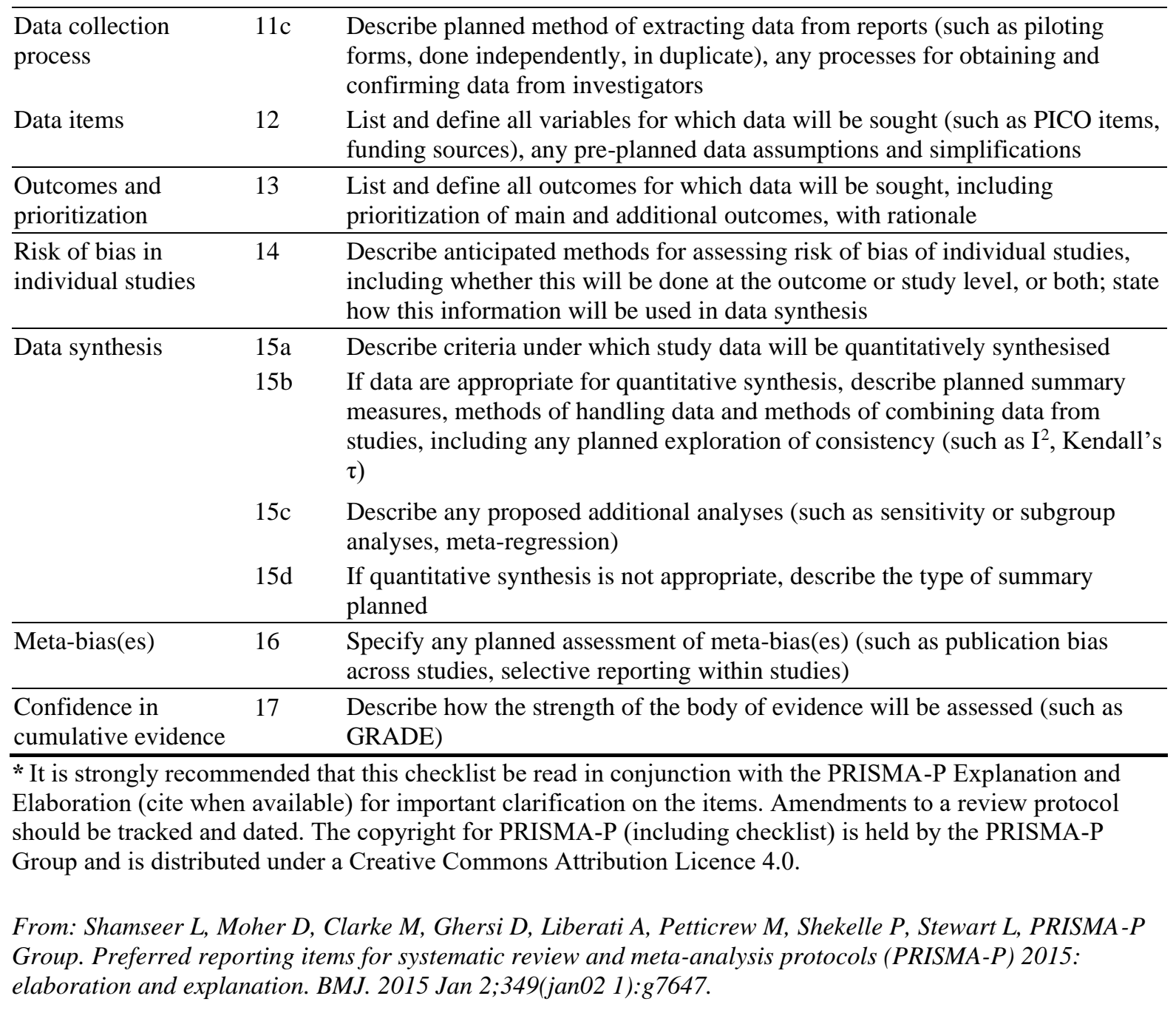




\section{Appendix B}

Research Question using PICO, and Inclusion and Exclusion Criteria

\begin{tabular}{|c|c|c|}
\hline $\begin{array}{l}\text { Key Concepts, } \\
\text { Synonyms }\end{array}$ & Inclusion Criteria & Rationale \\
\hline $\begin{array}{l}\text { Patient } \\
\text { population / } \\
\text { problem }\end{array}$ & $\begin{array}{l}\text { Population: } \\
\text {-Women who have experienced IPV } \\
\text { (physical, sexual, and/or psychological } \\
\text { abuse or coercive control). } \\
\text {-Perpetrator: husband, intimate partners, } \\
\text { or boyfriend/ girlfriend. } \\
\text { - Gender, age and ethnicity: } \\
\text {-Female, over } 15 \text { years old, and all } \\
\text { locations and ethnicities. } \\
\text { Health concern: } \\
\text {-Functional GI disorders: e.g., chronic } \\
\text { stomach pain syndromes, functional } \\
\text { dyspepsia, IBS, functional constipation, } \\
\text { functional diarrhea, and nausea and } \\
\text { vomiting disorders. }\end{array}$ & $\begin{array}{l}\text { Rationale: IPV among } \\
\text { women results in long-term } \\
\text { health problems, and } \\
\text { women with FGIDs and } \\
\text { symptoms were more likely } \\
\text { to have experienced adult } \\
\text { sexual assault, and severe } \\
\text { spousal or intimate partner } \\
\text { abuse. }\end{array}$ \\
\hline Indicators & $\begin{array}{l}\text { - Risk factors for FGIDs and symptoms } \\
\text { - Physiological factors are the } \\
\text { pathophysiological abnormalities that } \\
\text { lead to disease (e.g., the enhanced } \\
\text { visceral sensitivity associated with IBS } \\
\text { and/or functional dyspepsia) (McEwen \& } \\
\text { Seeman, 1999). } \\
\text { - Psychosocial factors refer to the factors } \\
\text { that affect an individual's response to life } \\
\text { events and stressors, such as } \\
\text { psychological distress (e.g., depression } \\
\text { and anxiety), coping strategies and skills, } \\
\text { social support or social isolation, } \\
\text { financial resources (Lutgendorf \& } \\
\text { Costanzo, 2003; Van Oudenhove et al., } \\
\text { 2016). }\end{array}$ & $\begin{array}{l}\text { Rationale: Psychosocial } \\
\text { factors and psychological } \\
\text { factors that could mediate } \\
\text { and/or moderate the } \\
\text { relationship have not been } \\
\text { well established in the } \\
\text { research, and there is a need } \\
\text { to explore the empirical } \\
\text { evidence available; what is } \\
\text { already known will help } \\
\text { guide future research. }\end{array}$ \\
\hline Comparison & N/A & N/A \\
\hline Outcome & $\begin{array}{l}\text { What do you hope to accomplish, } \\
\text { measure, improve, or affect? E.g. is the } \\
\text { relief or elimination of the symptoms? } \\
\text { Is to improve certain test scores? Is it } \\
\text { to improve adverse effects? Or to } \\
\text { diagnosis a disease? } \\
\text {-There is a gap in the literature when it } \\
\text { comes to explanations of the mechanisms } \\
\text { leading to the association between } \\
\text { functional GI disorders and symptoms } \\
\text { and IPV among women that needs } \\
\text { attention. This study seeks to begin to fill } \\
\text { that gap by examining the association }\end{array}$ & $\begin{array}{l}\text { Rationale: A review of the } \\
\text { kind proposed can } \\
\text { consolidate what is known, } \\
\text { which can point out the } \\
\text { way for future research and } \\
\text { form the basis for } \\
\text { improvements in clinical } \\
\text { interventions. }\end{array}$ \\
\hline
\end{tabular}




\begin{tabular}{|c|c|c|}
\hline & $\begin{array}{l}\text { between various types of IPV (i.e., } \\
\text { physical, sexual, and psychological) and } \\
\text { the risk of FGIDs and symptoms (such as } \\
\text { chronic abdominal pain symptoms, IBS, } \\
\text { functional dyspepsia, frequent diarrhea, } \\
\text { frequent constipation, and vomiting and } \\
\text { nausea disorders) among adult women. }\end{array}$ & \\
\hline $\begin{array}{l}\text { Study Types } \\
\text { Observational? } \\
\text { Experimental? } \\
\text { Qualitative? } \\
\text { Case reports? } \\
\text { Editorials, } \\
\text { letters, } \\
\text { comments? }\end{array}$ & $\begin{array}{l}\text {-Cohort studies } \\
\text {-Case control studies } \\
\text {-Observational: cross sectional study" } \\
\text { "retrospective studies" } \\
\text {-Qualitative studies }\end{array}$ & \\
\hline \multicolumn{3}{|c|}{$\begin{array}{l}\text { Please list } 3 \text { - } 5 \text { relevant references to represent the articles expected in the results: } \\
\text { - Coker, A. L., Smith, P. H., Bethea, L., King, M. R., \& McKeown, R. E. (2000). Physical } \\
\text { health consequences of physical and psychological intimate partner violence. Archives of } \\
\text { Family Medicine, 9(5), 451-457. http://dx.doi.org/10.1001/archfami.9.5.451 } \\
\text { - Becker-Dreps, S., Morgan, D., Peña, R., Cortes, L., Martin, C. F., \& Valladares, E. (2010). } \\
\text { Association between intimate partner violence and irritable bowel syndrome: a population- } \\
\text { based study in Nicaragua. Violence Against Women, 16(7), 832-845. } \\
\text { - Kernic, M. A., Wolf, M. E., \& Holt, V. L. (2000). Rates and relative risk of hospital } \\
\text { admission among women in violent intimate partner relationships. American Journal of } \\
\text { Public Health, 90(9), 1416. } \\
\text { Kelly, U. (2010). Intimate partner violence, physical health, posttraumatic stress disorder, } \\
\text { depression, and quality of life in Latinas. Western Journal of Emergency Medicine, 11(3), } \\
\text { 247-251. } \\
\text { Perona, M., Benasayag, R., Perelló, A., Santos, J., Zárate, N., Zárate, P., \& Mearin, F. } \\
\text { (2005). Prevalence of functional gastrointestinal disorders in women who report domestic } \\
\text { violence to the police. Clinical Gastroenterology and Hepatology, 3(5), 436-441. } \\
\text { Wuest, J., Merritt-Gray, M., Ford-Gilboe, M., Lent, B., Varcoe, C., \& Campbell, J. C. } \\
\text { (2008). Chronic pain in women survivors of intimate partner violence. The Journal of Pain, } \\
\text { 9(11), 1049-1057. }\end{array}$} \\
\hline \multicolumn{3}{|c|}{$\begin{array}{l}\text { Years: any as little is known } \\
\text { English Only } \\
\text { Adult Women ( } 15 \text { years of age or older) from any country } \\
\text { Have experienced IPV and reported functional GI disorders and symptoms (IBS, Functional } \\
\text { dyspepsia or indigestion, Functional abdominal pain syndrome, functional constipation, functional } \\
\text { diarrhea, and nausea and vomiting disorders.) }\end{array}$} \\
\hline \multicolumn{3}{|c|}{ Potential Databases } \\
\hline \multicolumn{3}{|c|}{$\begin{array}{l}\text { Databases: Medicine/Nursing } \\
\text { MEDLINE (Medical Literature On-Line) - Search via PubMed } \\
\text { CINAHL (Cumulative Index to Nursing Allies Health Literature) } \\
\text { Cochrane Database of Systematic Reviews } \\
\text { PsycINFO (Psychology Information) } \\
\text { Scopus } \\
\text { Social Work Abstracts } \\
\text { Nursing \& Allied Health (ProQuest) }\end{array}$} \\
\hline
\end{tabular}




\section{Systematic Review Policies}

\section{For Systematic Reviews Only}

- Given the expertise and significant time commitment involved in this work, it is our policy that librarians' contributions to most systematic reviews be recognized with co-authorship of manuscripts.

- Investigators submitting requests for comprehensive literature searches for projects with grant funding are expected to include library effort in the grant.

- If the above two policies are not met, we can offer limited consultation on searches.

Are there any related systematic reviews on this topic? If so, please list the citation below:

- Chitkara, D. K., van Tilburg, M. A. L., Blois-Martin, N., \& Whitehead, W. E. (2008). Early life risk factors that contribute to irritable bowel syndrome in adults: A systematic review. The American Journal of Gastroenterology, 103(3), 765-774. https://doi:10.1111/j.1572_ 0241.2007.01722.x

- Afari, N., Ahumada, S. M., Wright, L. J., Mostoufi, S., Golnari, G., Reis, V., \& Cuneo, J. G. (2014). Psychological trauma and functional somatic syndromes: a systematic review and meta-analysis. Psychosomatic Medicine, 76(1), 2. https://doi: 10.1097/PSY.0000000000000010

- Lee, C., Doo, E., Choi, J. M., Jang, S., Ryu, H., Lee, J. Y., . . Brain-Gut Axis Research Group of Korean Society of Neurogastroenterology and Motility. (2017). The increased level of depression and anxiety in irritable bowel syndrome patients compared with healthy controls: Systematic review and meta-analysis. Journal of Neurogastroenterology and Motility, 23(3), 349-362. https://doi:10.5056/jnm16220

\section{PROSPERO Registration Date:}

The process for the registration published under ID number CRD42020123745.

Who will be screening abstracts with you?

My supervisors: Dr. Marilyn Ford-Gilboe, Dr. Deanna Befus, Dr. Carol Wong

Collaborator: Bayan Alilyyani

Date for search to be confirmed: May 7, 2019

\section{Timeline}

Date for search to be translated to additional databases: May 7, 2019

Date for EndNote library to be sent to team: June 4, 2019

Date for search methods narrative: August 30, 2019.

Date for repeating the search: December 31, 2019

Target completion date: June, 2020.

These timelines are estimated and subject to supervisor feedback. 


\section{Appendix C}

Search results

\begin{tabular}{|c|c|c|}
\hline Database & Search Terms & $\begin{array}{l}\text { Number } \\
\text { of } \\
\text { Finding }\end{array}$ \\
\hline $\begin{array}{l}\text { MEDLINE } \\
\text { (Medical } \\
\text { Literature On- } \\
\text { Line) - Search } \\
\text { via PubMed } \\
\text { (1971- } \\
\text { December 31, } \\
\text { 2019) }\end{array}$ & $\begin{array}{l}\text { ((((spousal OR spouse OR spouses OR woman OR women OR wife OR } \\
\text { wives OR partner OR partners OR "intimate partner" OR "intimate } \\
\text { partners" OR "adult women" OR "adult woman"))) AND ((intimate } \\
\text { partner violence) OR ("abuse"[All Fields] OR abusing[tiab] OR } \\
\text { abuse[tiab] OR abused[tiab] OR abusive[tiab] OR violence[tiab] OR } \\
\text { violent[tiab] OR ("violence"[MeSH Terms] OR "violence"[All Fields]) } \\
\text { OR "domestic violence"[All Fields] OR "spousal abuse"[All Fields] OR } \\
\text { "gender based violence"[All Fields] OR "physical abuse"[All Fields] OR } \\
\text { "sexual abuse"[All Fields] OR "sex offense*"[All Fields] OR "emotional } \\
\text { abuse"[All Fields] OR "psychological abuse"[All Fields] OR "coercive } \\
\text { control"[All Fields]))) AND ((Gastrointestinal Diseases) OR } \\
\text { (("functional gastrointestinal disorder" OR "functional abdominal pain } \\
\text { syndrome" OR "abdominal pain" OR "functional dyspepsia" OR } \\
\text { dyspepsia OR "irritable bowel syndrome" OR diarrhea OR diarrhoeal } \\
\text { OR diarrhoea OR diarrheal OR constipation OR vomiting OR vomit OR } \\
\text { nausea))) }\end{array}$ & $\# 537$ \\
\hline $\begin{array}{l}\text { CINAHL } \\
\text { (Cumulative } \\
\text { Index to } \\
\text { Nursing Allies } \\
\text { Health } \\
\text { Literature) } \\
(1988- \\
\text { December } 31, \\
2019)\end{array}$ & $\begin{array}{l}\text { spous* OR wom* OR wife OR wives OR partner* OR "intimate } \\
\text { partner*" OR "adult wom*" AND (subject term "Intimate Partner } \\
\text { Violence") OR abus* OR violen* OR "domestic violence" OR "spousal } \\
\text { abuse" OR "gender based violence" OR "physical abuse" OR "sexual } \\
\text { abuse" OR "sex offenses" OR "emotional abuse" OR "psychological } \\
\text { abuse" OR "coercive control" AND (subject term "Gastrointestinal } \\
\text { Diseases+") OR "functional gastrointestinal disorder" OR "functional } \\
\text { abdominal pain syndrome" OR "abdominal pain" OR "functional } \\
\text { dyspepsia" OR dyspepsia OR "irritable bowel syndrome" OR diarrh* } \\
\text { OR constipation OR vomit* OR nausea }\end{array}$ & $\# 172$ \\
\hline $\begin{array}{l}\text { PsycINFO } \\
\text { (Psychology } \\
\text { Information) } \\
\text { (1879- } \\
\text { December 31, } \\
\text { 2019) }\end{array}$ & $\begin{array}{l}\text { (spousal OR spouse OR spouses OR woman OR women OR wife OR } \\
\text { wives OR partner OR partners OR "intimate partner" OR "intimate } \\
\text { partners" OR "adult women" OR "adult woman") AND ("Intimate } \\
\text { Partner Violence" OR abusing OR abuse OR abused OR abusive OR } \\
\text { violence OR violent OR "domestic violence" OR "spousal abuse" OR } \\
\text { "gender based violence" OR "physical abuse" OR "sexual abuse" OR } \\
\text { "sex offense" OR "emotional abuse" OR "psychological abuse" OR } \\
\text { "coercive control") AND ("Gastrointestinal Diseases" OR "functional } \\
\text { gastrointestinal disorder" OR "functional abdominal pain syndrome" OR } \\
\text { "abdominal pain" OR "functional dyspepsia" OR dyspepsia OR } \\
\text { "irritable bowel syndrome" OR diarrhea OR diarrhoeal OR diarrhoea } \\
\text { OR diarrheal OR constipation OR vomiting OR vomit OR nausea) }\end{array}$ & $\# 205$ \\
\hline
\end{tabular}




\begin{tabular}{|l|l|l|}
\hline Nursing \& & Same as psycINFO with quotes around phrases & $\# 146$ \\
Allied Health & & \\
1980 - & & \\
December 31, & & \\
$2019)$ & & $\# 3$ \\
\hline $\begin{array}{l}\text { Social Work } \\
\text { Abstracts } \\
\text { (1979- }\end{array}$ & Same as PsycINFO with quotes around phrases & \\
December 31, & & \\
2019) & & \\
\hline $\begin{array}{l}\text { Scopus (1970- } \\
\text { December 31, }\end{array}$ & Same as CINAHL with both quotes around phrases and truncation & \\
$2019)$ & & \\
\hline $\begin{array}{l}\text { Cochrane } \\
\text { Database of }\end{array}$ & Same as CINAHL with both quotes around phrases and truncation \\
Systematic & & $\# 2$ \\
Reviews (2010 & & \\
- December & & \\
31, 2019) & & \\
\hline Result & $\# 2008$ & \\
\hline
\end{tabular}




\section{Appendix D}

Quality Assessment Tool for Quantitative Studies

\begin{tabular}{|c|c|}
\hline Risk of bias items & Risk of bias levels \\
\hline \multicolumn{2}{|l|}{ External validity } \\
\hline $\begin{array}{l}\text { 1. Was the study's target } \\
\text { population a close } \\
\text { representation of the } \\
\text { national population in } \\
\text { relation to relevant } \\
\text { variables, e.g. age, sex, } \\
\text { occupation? }\end{array}$ & $\begin{array}{l}\text { Yes (LOW RISK): The study's target population was a close } \\
\text { representation of the national population. } \\
\text { No (HIGH RISK): The study's target population was clearly } \\
\text { NOT representative of the national population. }\end{array}$ \\
\hline $\begin{array}{l}\text { 2. Was the sampling } \\
\text { frame a true or close } \\
\text { representation of the } \\
\text { target population? }\end{array}$ & $\begin{array}{l}\text { Yes (LOW RISK): The sampling frame was a true or close } \\
\text { representation of the target population. } \\
\text { No (HIGH RISK): The sampling frame was NOT a true or close } \\
\text { representation of the target population. }\end{array}$ \\
\hline $\begin{array}{l}\text { 3. Was some form of } \\
\text { random selection used } \\
\text { to select the sample, } \\
\text { OR, was a census } \\
\text { undertaken? }\end{array}$ & $\begin{array}{l}\text { Yes (LOW RISK): A census was undertaken, OR, some form of } \\
\text { random selection was used to select the sample (e.g. simple random } \\
\text { sampling, stratified random sampling, cluster sampling, systematic } \\
\text { sampling). } \\
\text { No (HIGH RISK): A census was NOT undertaken, AND some form } \\
\text { of random selection was NOT used to select the sample. }\end{array}$ \\
\hline $\begin{array}{l}\text { 4.Was the likelihood of } \\
\text { non-response bias } \\
\text { minimal? }\end{array}$ & $\begin{array}{l}\text { Yes (LOW RISK): The response rate for the study was } \geq 75 \% \text {, OR, an } \\
\text { analysis was performed that showed no significant difference in } \\
\text { relevant } \\
\text { demographic characteristics between responders and non- responders } \\
\text { No (HIGH RISK): The response rate was }<75 \% \text {, and if any analysis } \\
\text { comparing responders and non-responders was done, it showed a } \\
\text { significant difference in relevant demographic characteristics between } \\
\text { responders and non-responders }\end{array}$ \\
\hline \multicolumn{2}{|l|}{ Internal validity } \\
\hline $\begin{array}{l}\text { 5. Were data collected } \\
\text { directly from the } \\
\text { subjects (as opposed } \\
\text { to a proxy)? }\end{array}$ & $\begin{array}{l}\text { Yes (LOW RISK): All data were collected directly from the subjects. } \\
\text { No (HIGH RISK): In some instances, data were collected from a } \\
\text { proxy. }\end{array}$ \\
\hline $\begin{array}{l}\text { 6.Was an acceptable } \\
\text { case definition used in } \\
\text { the study? }\end{array}$ & $\begin{array}{l}\text { Yes (LOW RISK): An acceptable case definition was used. } \\
\text { No (HIGH RISK): An acceptable case definition was NOT used }\end{array}$ \\
\hline $\begin{array}{l}\text { 7. Was the study } \\
\text { instrument that } \\
\text { measured the parameter } \\
\text { of interest (e.g. } \\
\text { prevalence of low back } \\
\text { pain) shown to have } \\
\text { reliability and validity }\end{array}$ & $\begin{array}{l}\text { Yes (LOW RISK): The study instrument had been shown to have } \\
\text { reliability and validity (if this was necessary), e.g. test-re- test, piloting, } \\
\text { validation in a previous study, etc. } \\
\text { No (HIGH RISK): The study instrument had NOT been shown to } \\
\text { have reliability or validity (if this was necessary). }\end{array}$ \\
\hline $\begin{array}{l}\text { 8. Was the same mode } \\
\text { of data collection used }\end{array}$ & $\begin{array}{l}\text { Yes (LOW RISK): The same mode of data collection was used for all } \\
\text { subjects. }\end{array}$ \\
\hline
\end{tabular}




\begin{tabular}{|l|l|}
\hline for all subjects? & $\begin{array}{l}\text { No (HIGH RISK): The same mode of data collection was NOT used } \\
\text { for all subjects. }\end{array}$ \\
\hline $\begin{array}{l}\text { 9. Was the length of the } \\
\text { shortest prevalence } \\
\text { period for the } \\
\text { parameter of interest } \\
\text { appropriate? }\end{array}$ & Yes (LOW RISK): Appropriate \\
\hline $\begin{array}{l}\text { 10. Were the } \\
\text { numerator(s) and } \\
\text { denominator(s) for the } \\
\text { parameter of interest } \\
\text { appropriate }\end{array}$ & $\begin{array}{l}\text { Yes (LOW RISK): The paper presented appropriate numerator(s) } \\
\text { AND denominator(s) for the parameter of interest (e.g. the prevalence }\end{array}$ \\
\hline $\begin{array}{l}\text { No (HIGH RISK): The paper did present numerator(s) AND } \\
\text { denominator(s) for the parameter of interest but one or more of these } \\
\text { were inappropriate. }\end{array}$ \\
\hline
\end{tabular}

Scoring: Each study was rated as having a low, moderate, or high risk of bias based on the total number of yes responses:

1. Low risk of bias: 8 or more yes answers

2. Moderate risk of bias: 6-7 yes answers

3. High risk of bias: 5 or fewer yes answer

Adapted from: Hoy, D., Brooks, P., Woolfc, A., Blythd, F., Marchd, L., Baina, C., .. . Buchbinder, R. (2012). Assessing risk of bias in prevalence studies: Modification of an existing tool and evidence of interrater agreement. Journal of Clinical Epidemiology, 65, 934-939. https://doi.org/10.1016/j.jclinepi.2011.11.014 


\section{Appendix E}

Quality Assessment Tool for Qualitative Studies

\begin{tabular}{|l|l|l|l|}
\hline CASP Qualitative Criteria* & $\begin{array}{l}\text { Study: } \\
\text { First Author: } \\
\text { Publication Date: } \\
\text { Journal: }\end{array}$ & Explanation of answer: \\
\hline $\begin{array}{l}\text { 1. Was there a clear statement } \\
\text { of the aims of the research? }\end{array}$ & $\begin{array}{l}\text { No } \\
\square\end{array}$ & $\begin{array}{l}\text { Yes } \\
\square\end{array}$ & \\
\hline $\begin{array}{l}\text { 2. Is a qualitative methodology } \\
\text { appropriate? }\end{array}$ & $\square$ & $\square$ & \\
\hline $\begin{array}{l}\text { 3. Was the research design } \\
\text { appropriate to address the } \\
\text { aims of the research? }\end{array}$ & $\square$ & $\square$ & \\
\hline $\begin{array}{l}\text { 4. Was the recruitment } \\
\text { strategy appropriate to the } \\
\text { aims of the research? }\end{array}$ & $\square$ & & \\
\hline $\begin{array}{l}\text { 5. Were the data collected in a } \\
\text { way that addressed the } \\
\text { research issue? }\end{array}$ & $\square$ & $\square$ & \\
\hline $\begin{array}{l}\text { 6. Has the relationship between } \\
\text { the researcher and } \\
\text { participants been adequately } \\
\text { considered? }\end{array}$ & $\square$ & $\square$ & \\
\hline $\begin{array}{l}\text { 7. Have the ethical issues been } \\
\text { taken into consideration? }\end{array}$ & $\square$ & $\square$ & \\
\hline $\begin{array}{l}\text { 8. Was the data analysis } \\
\text { sufficiently rigorous? }\end{array}$ & $\square$ & $\square$ & \\
\hline $\begin{array}{l}\text { 9. Is there a clear statement of } \\
\text { findings? }\end{array}$ & $\square$ & $\square$ & \\
\hline $\begin{array}{l}\text { 10. How valuable is the } \\
\text { research? }\end{array}$ & $\square$ & $\square$ & \\
\hline Total Score: & $\square$ & $\square$ & \\
\hline
\end{tabular}

Scoring: 9 or 10 criteria met indicates the highest quality rating and below 9 indicates the lowest quality rating.

Adapted from: Critical Appraisal Skills Programme (CASP), (2010). 10 questions to help you make sense of qualitative research.

http://media.wix.com/ugd/dded87_29c5b002d99342f788c6ac670e49f274.pdf 


\section{Appendix F}

Detailed Summary of Quality Assessment for Quantitative Studies

\begin{tabular}{|c|c|c|c|c|c|c|c|c|c|c|c|}
\hline \multirow{2}{*}{$\begin{array}{l}\text { First Author/ } \\
\text { Year/Journal }\end{array}$} & \multicolumn{4}{|c|}{ External validity } & \multicolumn{6}{|c|}{ Internal validity } & \multirow{2}{*}{$\begin{array}{l}\text { Summary } \\
\text { Score: } \\
\text { Risk of } \\
\text { Bias }\end{array}$} \\
\hline & $\begin{array}{l}\text { Target } \\
\text { population }\end{array}$ & $\begin{array}{l}\text { Sampling } \\
\text { frame }\end{array}$ & $\begin{array}{l}\text { Random } \\
\text { selection }\end{array}$ & $\begin{array}{l}\text { Response } \\
\text { rate }\end{array}$ & $\begin{array}{l}\text { Data } \\
\text { collection }\end{array}$ & $\begin{array}{l}\text { Definitio } \\
n\end{array}$ & Instrument & $\begin{array}{l}\text { Same } \\
\text { mode of } \\
\text { data } \\
\text { collectio } \\
n\end{array}$ & $\begin{array}{l}\text { Length of } \\
\text { the } \\
\text { shortest } \\
\text { prevalence } \\
\text { period }\end{array}$ & $\begin{array}{l}\text { Appropriat } \\
\text { eness of the } \\
\text { parameter }\end{array}$ & \\
\hline $\begin{array}{l}\text { Becker- } \\
\text { Dreps/2010/ } \\
\text { Violence } \\
\text { Against } \\
\text { Women }\end{array}$ & Low & Low & Low & Low & Low & Low & Low & Low & Low & Low & 10: Low \\
\hline $\begin{array}{l}\text { Bonomi/2009/ } \\
\text { Archives of } \\
\text { Family } \\
\text { Medicin }\end{array}$ & Low & Low & Low & High & Low & High & High & Low & Low & Low & $\begin{array}{l}\text { 7: } \\
\text { Moderate }\end{array}$ \\
\hline $\begin{array}{l}\text { Campbell/2002 } \\
\text { / Archives of } \\
\text { Family } \\
\text { Medicin }\end{array}$ & Low & Low & Low & Low & Low & Low & Low & Low & Low & Low & 10: Low \\
\hline $\begin{array}{l}\text { Coker/2000/ } \\
\text { Archives of } \\
\text { Family } \\
\text { Medicine }\end{array}$ & Low & Low & High & Low & Low & Low & Low & Low & Low & Low & 9: Low \\
\hline $\begin{array}{l}\text { Coronel/2018/ } \\
\text { Journal of } \\
\text { Coloproctolog } \\
\text { y }\end{array}$ & Low & Low & High & Low & Low & Low & Low & Low & Low & Low & 9: Low \\
\hline
\end{tabular}




\begin{tabular}{|c|c|c|c|c|c|c|c|c|c|c|c|}
\hline $\begin{array}{l}\text { Díez/2009/ } \\
\text { International } \\
\text { Journal of } \\
\text { Clinical and } \\
\text { Health } \\
\text { Psychology }\end{array}$ & Low & Low & High & Low & Low & Low & Low & Low & Low & Low & 9: Low \\
\hline $\begin{array}{l}\text { Fisher/2006/ } \\
\text { Gerontologist }\end{array}$ & Low & Low & Low & High & Low & Low & Low & Low & Low & Low & 9: Low \\
\hline $\begin{array}{l}\text { Hegarty/2008/ } \\
\text { British Journal } \\
\text { of General } \\
\text { Practice }\end{array}$ & Low & Low & Low & Low & Low & High & High & Low & Low & Low & 8: Low \\
\hline $\begin{array}{l}\text { John/2004/ An } \\
\text { International } \\
\text { Journal of } \\
\text { Obstetrics and } \\
\text { Gynecology }\end{array}$ & Low & Low & High & Low & Low & High & High & Low & Low & Low & $\begin{array}{l}7: \\
\text { Moderate }\end{array}$ \\
\hline $\begin{array}{l}\text { Nedd/2001/ } \\
\text { ABNF Journal }\end{array}$ & Low & Low & High & Low & Low & High & High & Low & Low & Low & $\begin{array}{l}\text { 7: } \\
\text { Moderate }\end{array}$ \\
\hline $\begin{array}{l}\text { Perona/2005/ } \\
\text { Clinical } \\
\text { Gastroenterolo } \\
\text { gy and } \\
\text { Hepatology }\end{array}$ & Low & Low & Low & High & Low & Low & High & Low & Low & Low & 8: Low \\
\hline $\begin{array}{l}\text { Salam/2006/ } \\
\text { Maternal and } \\
\text { Child Health } \\
\text { Journal }\end{array}$ & Low & Low & Low & Low & Low & Low & High & Low & Low & Low & 9: Low \\
\hline $\begin{array}{l}\text { Schollenberger } \\
\text { / 2003/ }\end{array}$ & Low & Low & Low & Low & Low & Low & High & Low & Low & Low & 9: Low \\
\hline
\end{tabular}




\begin{tabular}{|c|c|c|c|c|c|c|c|c|c|c|c|}
\hline $\begin{array}{l}\text { Violence } \\
\text { Against } \\
\text { Women }\end{array}$ & & & & & & & & & & & \\
\hline $\begin{array}{l}\text { Wuest/2008/ } \\
\text { The journal of } \\
\text { Pain }\end{array}$ & Low & Low & Low & Low & Low & Low & Low & Low & Low & Low & 10: Low \\
\hline
\end{tabular}

Maximum score $=10$, studies were categorized as high risk of bias if 5 or fewer 'yes' answers, Moderate risk of bias: 6-7 'yes' answers, or Low risk of bias: 8 or more 'yes' answers. 


\section{Appendix G}

The Data Extraction Table for Quantitative and Qualitative Studies

\begin{tabular}{|c|c|c|c|c|c|c|}
\hline $\begin{array}{l}\text { Author(s) } \\
\text { (Year)/ } \\
\text { Country }\end{array}$ & $\begin{array}{l}\text { Purposes \& Theoretical } \\
\text { Framework }\end{array}$ & Design \& data collection & Sample \& Setting & $\begin{array}{l}\text { Variables, Measures \& } \\
\text { Analysis }\end{array}$ & Results & Note \\
\hline $\begin{array}{l}\text { 1-Puri, Tamang, } \\
\text { Shah, (2011) } \\
\text { Nepal }\end{array}$ & $\begin{array}{l}\text { Purpose: } \\
\text {-To explore the definition } \\
\text { of sexual violence and its } \\
\text { various forms and } \\
\text { consequences as reported } \\
\text { by married women in } \\
\text { Nepal } \\
\text {-To describe the coping } \\
\text { mechanisms used by } \\
\text { women to avoid sexual } \\
\text { violence by their husbands } \\
\underline{\text { TF: }} \text { N/A }\end{array}$ & $\begin{array}{l}\text { Design: } \\
\text { Descriptive qualitative } \\
\text { study } \\
\text { Data collection: } \\
\text { Interview and screening } \\
\text { questionnaire }\end{array}$ & $\begin{array}{l}\text { Sample: } \\
39 \text { married women } \\
\text { aged } 15-24 \text { years } \\
\text { from the community } \\
\text { Setting: } \\
\text { N/A }\end{array}$ & $\begin{array}{l}\text { Analysis approach: } \\
\text {-Thematic analysis } \\
\text { (Campbell, Cleland, } \\
\text { Collumbein, Southwick, } \\
\text { 1999; Ulin, Robinson, } \\
\text { Tolley, McNeill, 2002) }\end{array}$ & $\begin{array}{l}\text { Types of sexual violence within marriage } \\
\text { (SVWM): } \\
\text { - High prevalence of SVWM in the study } \\
\text { population with } 9 \text { out of } 39 \text { women ever } \\
\text { experiencing SVWM } \\
\text {-A higher percentage of Tharu women } \\
(55 \%) \text { compared to Brahmin/Chhetri } \\
\text { women }(42 \%) \text { reported forced sex } \\
\text {-The type of SVWM ranged from verbal } \\
\text { abuse to beating, and unwanted sexual } \\
\text { touch to forced sex } \\
\text { Consequences of refusing to have sex: } \\
\text {-Case histories of } 15 \text { participants revealed } \\
\text { that women who refused to have sex with } \\
\text { their husbands suffered severe } \\
\text { repercussions, such as: } \\
\text {-Physical abuse: } 8 \text { women were beaten } \\
\text { for denying their husbands sex, or often } \\
\text { when the husbands were drunk } \\
\text {-Emotional harassment: } 6 \text { women } \\
\text { revealed that husbands told them they } \\
\text { must have sex to prove their love, and } 9 \\
\text { men threatened to take a co-wife } \\
\text {-Accusation of infidelity: } 10 \text { women } \\
\text { revealed that scolding, abusing, and } \\
\text { accusations of their infidelity were } \\
\text { common tactics used by a husband to } \\
\text { coerce sex } \\
\text { Health consequences: } \\
\text {-most women (n=10) reported that they } \\
\text { experienced health problems after forced } \\
\text { sex from their husbands such as lower } \\
\text { abdominal pain }\end{array}$ & \\
\hline
\end{tabular}




\begin{tabular}{|c|c|c|c|c|c|c|}
\hline $\begin{array}{l}\text { 2-Becker-Dreps et } \\
\text { al., (2010) } \\
\text { Nicaragua }\end{array}$ & $\begin{array}{l}\text { Purpose: } \\
\text { To examine the } \\
\text { relationship between IPV } \\
\text { \& IBS } \\
\text { TF: } \\
\text { Biopsychosocial model } \\
\text { (Drossman et al., 1990) }\end{array}$ & $\begin{array}{l}\text { Design: } \\
\text { Observational study: } \\
\text { cross-sectional study } \\
\text { Data collection: } \\
\text { Interview }\end{array}$ & $\begin{array}{l}\text { Sample: } \\
\text { 962, adult women, } \\
\text { age > 18yrs old from } \\
\text { community } \\
\text { Setting: } \\
\text { N/A }\end{array}$ & $\begin{array}{l}\text { IPV characteristic: } \\
\text { Physical and sexual IPV: } \\
\text { the physical aggression } \\
\text { scale of the Conflict } \\
\text { Tactics Scales (Straus, } \\
\text { 1979) } \\
\text { FGIDs \& symptoms: } \\
\text { IBS: Rome II diagnostic } \\
\text { criteria (Drossman, 1999). } \\
\text { Mechanisms: } \\
\text { N/A } \\
\text { QOL outcomes: } \\
\text { Validated poverty index ( } \\
\text { Unsatisfied Basic Needs } \\
\text { Assessment)(Renzi \& } \\
\text { Agurto, 1993). } \\
\text { Data Analysis: Logistic } \\
\text { regression (odds ratios) }\end{array}$ & $\begin{array}{l}\text { Abuse among women: } \\
-23.8 \text { physical, } 9.3 \% \text { sexual, } 11.3 \%, \\
\text { Sexual abuse prior to age } 12 \text {, and } 31.1 \% \\
\text { at least one form of violence } \\
\text { Relationship Between IPV and FGIDs } \\
\text { and symptoms: } \\
\text {-IBS }(15.7 \%) \\
\text {-Having experienced IPV increased the } \\
\text { likelihood of IBS based on abuse type: } \\
\text { physical abuse (OR=2.08), sexual abuse } \\
(\mathrm{OR}=2.85) \text {, sexual abuse prior to age } 12 \\
(\mathrm{OR}=1.82) \text {, any violence OR=2.22). } \\
\text { QOL outcomes: } \\
\text {-No statistically significant differences in } \\
\text { age, relationship status, poverty index, } \\
\text { religion, or educational attainment } \\
\text { between women with and without IBS. }\end{array}$ & $\begin{array}{l}\text { The } \\
\text { mechanism not } \\
\text { tested but } \\
\text { reported in the } \\
\text { background. }\end{array}$ \\
\hline $\begin{array}{l}\text { 3-Bonomi et al., } \\
\text { (2009) } \\
\text { US }\end{array}$ & $\begin{array}{l}\text { Purpose: } \\
\text { To compare relative risk of } \\
\text { wide range of diagnoses } \\
\text { between women with IPV } \\
\text { and non-abused women } \\
\text { TF: } \\
\text { N/A }\end{array}$ & $\begin{array}{l}\text { Design: } \\
\text { Descriptive study; Cross- } \\
\text { sectional study } \\
\text { Data collection: } \\
\text { Telephone survey }\end{array}$ & $\begin{array}{l}\text { Sample: } \\
3568, \text { women, ages } \\
\text { 18-64yrs old, patients } \\
\text { in a Health } \\
\text { Organization for at } \\
\text { least } 3 \text { years } \\
\text { Setting: } \\
\text { N/A }\end{array}$ & $\begin{array}{l}\text { IPV characteristic: } \\
\text { Physical, sexual, and } \\
\text { psychological abuse: } \\
\text { Women's Experience with } \\
\text { Battering (WEB) Scale } \\
\text { (Smith, Earp, \& DeVellis, } \\
\text { 1995), and Behavioral Risk } \\
\text { Factor Surveillance System } \\
\text { (BRFSS) survey (Bonomi } \\
\text { et al., 2006; Thompson et } \\
\text { al., 2006) } \\
\text { FGIDs \& symptoms: } \\
\text { IBS under the GI category: } \\
\text { the uses International } \\
\text { Disease Classification, 9th } \\
\text { Revision (ICD-9) } \\
\text { (Starfield, Weiner, } \\
\text { Mumford, \& Steinwachs, } \\
\text { 1991; Weiner, Starfield, } \\
\text { Steinwachs, \& } \\
\text { Mumford,1991) } \\
\text { Mechanisms: } \\
\text { N/A } \\
\text { QOL outcomes: } \\
\text { N/A } \\
\text { Data Analysis: } \\
\text { Logistic regression } \\
\text { (relative risk) }\end{array}$ & $\begin{array}{l}\text { Abuse among women: } \\
-242 \text { women (12.5\%) reported abuse } \\
\text { Relationship Between IPV and FGIDs } \\
\text { and symptoms: } \\
\text {-Having experienced IPV was positively } \\
\text { associated with IBS (RR 1.05) and } \\
\text { undifferentiated abdominal pain (RR } \\
1.48)\end{array}$ & \\
\hline
\end{tabular}




\begin{tabular}{|c|c|c|c|c|c|c|}
\hline $\begin{array}{l}\text { 4-Campbell, et al } \\
\text { (2002) } \\
\text { US }\end{array}$ & $\begin{array}{l}\text { Purpose: } \\
\text { To compare selected } \\
\text { physical health problems } \\
\text { of abused and never } \\
\text { abused women } \\
\text { TF: } \\
\text { N/A }\end{array}$ & $\begin{array}{l}\text { Design: } \\
\text { A case-control study } \\
\text { Data collection: } \\
\text { Telephone } \\
\text { survey interview }\end{array}$ & $\begin{array}{l}\text { Sample: } \\
2005 \text { women, aged } \\
21 \text { to } 55 \text { years, } \\
\text { patients in a health } \\
\text { care systems } \\
\text { Setting: } \\
\text { Family practice } \\
\text { clinics }\end{array}$ & $\begin{array}{l}\text { IPV characteristic: } \\
\text { Physical and/or sexual } \\
\text { abuse: Abuse Assessment } \\
\text { Screen (Soeken, } \\
\text { McFarlane, Parker } \\
\text { \&Lominack, 1998) } \\
\text { FGIDs \& symptoms: } \\
\text { Physical health problems: } \\
\text { Miller Abuse Physical } \\
\text { Symptom and Injury Scale } \\
\text { (Miller \& Campbell, 1993) } \\
\text { Mechanisms: } \\
\text { N/A } \\
\text { QOL outcomes: } \\
\text { N/A } \\
\text { Data Analysis: } \\
\text { Logistic Regressions }\end{array}$ & $\begin{array}{l}\text { Abuse among women: } \\
-60 \% \text { physical, } 6 \% \text { sexual, and } 33 \% \text { for } \\
\text { both physical and sexual abuse } \\
\text { Relationship Between IPV and FGIDs } \\
\text { and symptoms: } \\
\text {-Having experienced IPV was associated } \\
\text { (p } \leq .05 \text { ) chronic stress- related (ChS) } \\
\text { symptoms or conditions such as } \\
\text { abdominal pain }\end{array}$ & $\begin{array}{l}\text { Note: } \\
\text { Chronic } \\
\text { stress-related } \\
(\mathrm{ChS}) \\
\text { symptoms or } \\
\text { conditions } \\
\text { =High blood } \\
\text { pressure, loss } \\
\text { of appetite, } \\
\text { abdominal } \\
\text { pain, digestive } \\
\text { problem, bad } \\
\text { cold or flu }\end{array}$ \\
\hline $\begin{array}{l}\text { 5-Coker et al., } \\
\text { (2000) } \\
\text { US }\end{array}$ & $\begin{array}{l}\text { Purpose: } \\
\text { To estimate IPV } \\
\text { prevalence by type and } \\
\text { associated physical health } \\
\text { consequences among } \\
\text { women } \\
\text { TF: } \\
\text { N/A }\end{array}$ & $\begin{array}{l}\text { Design: } \\
\text { Observational study: a } \\
\text { cross-sectional study } \\
\text { Data collection: } \\
\text { Interview }\end{array}$ & $\begin{array}{l}\text { Sample: } \\
1152 \text { women, aged } \\
18 \text { to } 65 y \text { ys, patients } \\
\text { in a health care } \\
\text { system } \\
\text { Setting: } \\
\text { Family practice } \\
\text { clinics }\end{array}$ & $\begin{array}{l}\text { IPV characteristic: } \\
\text {-Current physical and } \\
\text { sexual IPV: Index of } \\
\text { Spouse Abuse-Physical } \\
\text { (Hudson, 1991) } \\
\text {-Women's Experience with } \\
\text { Battering (WEB) Scale to } \\
\text { assess battering (Smith, } \\
\text { Smith, \& Earp,1999; } \\
\text { Smith, Earp, \& DeVellis } \\
\text { 1995) } \\
\text {-For the past physical IPV: } \\
\text { Abuse Assessment Screen } \\
\text { (McFarlane, Parker, } \\
\text { Soeken \& Bullock,1992) } \\
\text { FGIDs \& symptoms: } \\
\text { Stomach ulcer, Gastric } \\
\text { reflux, Spastic colon, and } \\
\text { Frequent indigestion, } \\
\text { constipation, or diarrhea: } \\
\text { National Health Interview } \\
\text { Survey (Census, 1994) } \\
\text { Mechanisms: } \\
\text { N/A } \\
\text { QOL outcomes: } \\
\text { N/A } \\
\text { Data analysis: } \\
\text { Logistic regression } \\
\text { (relative risk) }\end{array}$ & $\begin{array}{l}\text { Abuse among women: } \\
\text { - } 87.5 \% \text { of women who had been in a } \\
\text { violent relationship: } \\
\text { *Any IPV in a current or most recent } \\
\text { relationship (16.4\%): Physical IPV } \\
\text { (includes physical and/or sexual violence) } \\
\text { ( } 8.9 \% \text { ) Psychological IPV (includes } \\
\text { psychological battering) (7.5\%) } \\
\text { *Any IPV in a past relationship (46.5\%): } \\
\text { Physical IPV (includes physical and/or } \\
\text { sexual violence) ( } 36.6 \%) \text {, Psychological } \\
\text { IPV (includes perceived emotional abuse) } \\
\text { (9.9\%) } \\
\text { *Lifetime, ever experienced any type of } \\
\text { IPV (53.6): Physical IPV (includes } \\
\text { physical and/or sexual violence) (40.0\%), } \\
\text { Psychological IPV (includes current } \\
\text { psychological battering and past } \\
\text { emotional abuse) (13.6\%) } \\
\text { Relationship Between IPV and FGIDs } \\
\text { and symptoms: } \\
\text { - Psychological IPV was as strongly } \\
\text { related to the range of health outcomes as } \\
\text { was physical IPV } \\
\text {-Psychological IPV was associated with } \\
\text { IBS (RR=3.62), frequent dyspepsia, and } \\
\text { frequent constipation and diarrhea (1.30). } \\
\text {-Physical IPV was associated with IBS } \\
\text { (RR=3.74), frequent dyspepsia, and } \\
\text { frequent constipation and diarrhea (1.60) }\end{array}$ & \\
\hline
\end{tabular}




\begin{tabular}{|c|c|c|c|c|c|}
\hline $\begin{array}{l}\text { 6-Coronel \& Silva } \\
\text { (2018) } \\
\text { Brazil }\end{array}$ & $\begin{array}{l}\text { Purpose: } \\
\text { To evaluate the prevalence } \\
\text { of domestic violence in } \\
\text { adults with functional } \\
\text { constipation and to identify } \\
\text { the services and standards } \\
\text { available to care for the } \\
\text { victims } \\
\text { TF: } \\
\text { N/A }\end{array}$ & $\begin{array}{l}\text { Design: } \\
\text { Part I: observational } \\
\text { study: A cross-sectional } \\
\text { study. } \\
\text { Part II: A narrative } \\
\text { review } \\
\text { Data collection: } \\
\text { Part I: structured } \\
\text { questionnaire } \\
\text { Part II: a narrative review }\end{array}$ & $\begin{array}{l}\text { Sample: } \\
146 \text { women aged } \\
\text { over } 18 \text { yrs old, } \\
\text { patients in health care } \\
\text { system } \\
\text { Setting: } \\
\text { The coloproctology } \\
\text { outpatient clinic }\end{array}$ & $\begin{array}{l}\text { IPV characteristic: } \\
\text { Life-time violence, } \\
\text { Aggressors, Place of } \\
\text { occurrence, and Violence } \\
\text { type: structured } \\
\text { questionnaires (Brasil-MS- } \\
\text { Secretaria de Vigilância } \\
\text { em Saúde, 2006) } \\
\text { FGIDs \& symptoms: } \\
\text { Intestinal constipation: } \\
\text { Rome III criteria } \\
\text { (Drossman \& Dumitrascu, } \\
\text { 2006) and the Bristol Scale } \\
\text { (Riegler \& Esposito, 2001) } \\
\text { Mechanisms: } \\
\text { N/A } \\
\text { QOL outcomes: } \\
\text { N/A } \\
\text { Data analysis: } \\
\text { Pearson's Chi-square (odds } \\
\text { ratio) }\end{array}$ & $\begin{array}{l}\text { Abuse among women: } \\
-65 \text { women ( } 44.5 \%) \text { reported domestic } \\
\text { violence; in these women, psychological } \\
95.4 \% \text {, physical } 81.5 \% \text {, sexual } 53.8 \% \text {, } \\
\text { and } 90.8 \% \text { more than one type of } \\
\text { violence throughout their lives. } \\
\text {-life time violence: Childhood } 46.2 \% \\
\text { adolescence } 47.7 \% \text { adulthood } 61.5 \% \text { old } \\
\text { age } 9.2 \% \text { more than one phase } 52.3 \% \\
\text {-The abusive person was most often a } \\
\text { former partner ( } 41.5 \% \text { ) or spouse (18.5\%) } \\
\text { Relationship Between IPV and FGIDs } \\
\text { and symptoms: } \\
\text {-34.9\% suffered functional intestinal } \\
\text { constipation (FIC), and functional } \\
\text { subtype was the most frequent diagnosis } \\
\text { (82.4\%) } \\
\text { - FIC was associated with domestic } \\
\text { violence } \\
\text { - Having experienced IPV was associated } \\
\text { with greater likelihood of FIC OR=2.71 } \\
\text { than women who have not experienced } \\
\text { violence }\end{array}$ \\
\hline $\begin{array}{l}\text { 7- Díez et al., } \\
\text { (2009) } \\
\text { Ecuador }\end{array}$ & $\begin{array}{l}\text { Purpose: } \\
\text { To know the prevalence of } \\
\text { women who suffer from } \\
\text { IPV and quantify the } \\
\text { victims of each type of } \\
\text { abuse: physical, emotional } \\
\text { and sexual } \\
\text { To determine if this abuse } \\
\text { was significantly } \\
\text { associated with somatic } \\
\text { symptoms or with } \\
\text { psychological health } \\
\text { indicators } \\
\text { TF: N/A }\end{array}$ & $\begin{array}{l}\text { Design: } \\
\text { Observational study: a } \\
\text { cross sectional ex post } \\
\text { facto design } \\
\text { Data collection: } \\
\text { Structured interview }\end{array}$ & $\begin{array}{l}\text { Sample: } \\
333 \text { women, age } 30- \\
65 \text { yrs, patients in a } \\
\text { health care system } \\
\text { Setting: } \\
\text { Two Public Primary } \\
\text { Health Centers } \\
\text { (PHC) }\end{array}$ & $\begin{array}{l}\text { IPV characteristic: } \\
\text { IPV abuse: } \\
\text { the Woman Abuse } \\
\text { Screening Tool (WAST) } \\
\text { (Brown, Lent, Schmidt, } \\
\text { and Sas, 2000) } \\
\text { FGIDs \& symptoms: } \\
\text { Researcher-developed list } \\
\text { of symptoms, including } \\
\text { Abdominal pain and } \\
\text { Diarrhea/constipation } \\
\text { Mechanisms: } \\
\text { N/A } \\
\text { QOL outcomes: } \\
\text { N/A } \\
\text { Data analysis: } \\
\text { Logistic Regression (odds } \\
\text { Ratios) }\end{array}$ & $\begin{array}{l}\text { Abuse among women: } \\
-1 \text { out of } 5 \text { women reported to suffer or } \\
\text { have suffered some form of IPV } \\
\text {-Emotional abuse was the most frequent } \\
\text { type (physical } 3.60 \% \text {, emotional } 13.80 \% \\
\text { and sexual abuse is } 5.10 \% \text { ) } \\
\text { Relationship Between IPV and FGIDs } \\
\text { and symptoms: } \\
\text {-Having experienced IPV was associated } \\
\text { with greater likelihood of abdominal pain } \\
(\mathrm{OR}=2.19) \text { and lack of appetite } \\
(\mathrm{OR}=3.81)\end{array}$ \\
\hline $\begin{array}{l}\text { 8-Fisher \& Regan } \\
\text { (2006) } \\
\text { US }\end{array}$ & $\begin{array}{l}\text { Purpose: } \\
\text { To assess the difference } \\
\text { types of abuse, repeated } \\
\text { and multiple abuse } \\
\text { experiences among women } \\
\text { aged } 60 \text { and older, and } \\
\text { their effects on the } \\
\text { women's self-reported } \\
\text { health } \\
\text { TF: }\end{array}$ & $\begin{array}{l}\text { Design: } \\
\text { Observational study: A } \\
\text { cross-sectional study } \\
\text { Data collection: } \\
\text { Telephone survey }\end{array}$ & $\begin{array}{l}\text { Sample: } \\
842 \text { women aged } 60 \\
\text { and older, patients in } \\
\text { a health care system } \\
\text { Setting: } \\
\text { Adult primary care } \\
\text { clinics }\end{array}$ & $\begin{array}{l}\text { IPV characteristic: } \\
\text { The women health and } \\
\text { relationship survey } \\
\text { (WHRS) (Bonnie \& } \\
\text { Wallace, 2002; Saltzman, } \\
\text { Fanslow, McMahon, \& } \\
\text { Shelley, 1999/2002) } \\
\text { FGIDs \& symptoms: } \\
\text { Health conditions (Tjaden } \\
\text { \& Thoennes, 1998) }\end{array}$ & $\begin{array}{l}\text { Abuse among women: } \\
\text {-nearly half (47\%) of older women had } \\
\text { experienced psychological/emotional } \\
\text { abuse, control, threats, physical, or sexual } \\
\text { abuse since turning } 55 \text { years' old } \\
\text { - Abuse Victim: } 44.6 \% \\
\text { psychological/emotional abuse, } 3.8 \% \\
\text { physical abuse, } 3.4 \% \text { sexual abuse }\end{array}$ \\
\hline
\end{tabular}




\begin{tabular}{|c|c|c|c|c|c|}
\hline & N/A & & & $\begin{array}{l}\text { Mechanisms: } \\
\text { N/A } \\
\text { QOL outcomes: } \\
\text { N/A } \\
\text { Data analysis: } \\
\text { Logistic regression (odds } \\
\text { ratios) }\end{array}$ & $\begin{array}{l}\text {-Repeat Abuse Victim: } 47.3 \% \\
\text { psychological/emotional abuse, } 31.6 \% \\
\text { physical abuse, or } 21.4 \% \text { sexual abuse } \\
-21 \% \text { of women had been threatened by a } \\
\text { spouse/boyfriend } \\
\text {-A majority of the women reported that } \\
\text { their spouse/boyfriend had perpetrated: } \\
\text { control }(56 \%) \text {, sexual abuse }(73 \%), \\
\text { physical abuse (39\%), threats }(21 \%) \\
\text { Relationship Between IPV and FGIDs } \\
\text { and symptoms: } \\
\text { - Having experienced only } \\
\text { psychological/emotional abuse increased } \\
\text { the likelihood (OR=1.70) of having } \\
\text { digestive problems (IBS, and ulcer } \\
\text { heartburn) } \\
\text { - Repeated psychological/emotional } \\
\text { abuse was significant associated with } \\
\text { increased risk (OR=1.45) of digestive } \\
\text { problems } \\
\text { - Any abuse increased the likelihood } \\
\text { (OR=1.60) of women reporting digestive } \\
\text { problems }\end{array}$ \\
\hline $\begin{array}{l}\text { 9-Hegarty, Gunn, } \\
\text { Chondros, \& Taft } \\
\text { (2008) } \\
\text { Australia }\end{array}$ & $\begin{array}{l}\text { Purpose: } \\
\text { To develop physical } \\
\text { symptoms and } \\
\text { sociodemographic } \\
\text { indicators for partner abuse } \\
\text { for women attending } \\
\text { general practice } \\
\text { TF: } \\
\text { N/A }\end{array}$ & $\begin{array}{l}\text { Design: } \\
\text { Observational study: } \\
\text { cross-sectional survey } \\
\text { Data collection: } \\
\text { Self-report questionnaire }\end{array}$ & $\begin{array}{l}\text { Sample: } \\
1257 \text { women } \\
\text { between } 16-50 \text { years } \\
\text { old, patients in a } \\
\text { health care system } \\
\text { Setting: } \\
30 \text { general practices } \\
\text { in Victoria }\end{array}$ & $\begin{array}{l}\text { IPV characteristic: } \\
\text { Composite Abuse Scale } \\
\text { (CAS) (Hegarty, Bush, \& } \\
\text { Sheehan, 2005) } \\
\text { FGIDs \& symptoms: } \\
\text { A list of common physical } \\
\text { symptoms presenting in } \\
\text { general practice: (Britt et } \\
\text { al., 1999) } \\
\text { Three physical symptoms } \\
\text { (injuries, diarrhea, and } \\
\text { vaginal discharge): } \\
\text { (McCauley et al.,1995) } \\
\text { SF-36 } \\
\text { Mechanisms: } \\
\text {-Psychosocial (depression } \\
\text { and anxiety): Beck } \\
\text { Depression Inventory } \\
\text { (BDI) (Hegarty, Gunn, } \\
\text { Chondros, \& Small, 2004) } \\
\text {-Edinburgh } \\
\text { Postnatal Depression Scale } \\
\text { (Murray \& Carothers, } \\
\text { 1990) } \\
\text {-Self-report of depression } \\
\text { and anxiety (McHorney, } \\
\text { Ware, Lu, \& Sherbourne, }\end{array}$ & $\begin{array}{l}\text { Abuse among women: } \\
-158 \text { women }(17.08 \%) \text { reported abuse } \\
\text { Relationship Between IPV and FGIDs } \\
\text { and symptoms: } \\
\text {-Many physical symptoms were } \\
\text { associated with partner abuse such as } \\
\text { diarrhea } 20.3 \% \text { chronic abdominal pain } \\
11.4 \% \\
\text {-Having experienced partner abuse in the } \\
\text { last } 12 \text { months was associated with } \\
\text { diarrhea (OR 1.8) and chronic abdominal } \\
\text { pain (OR } 1.7) \text {. } \\
\text { Mechanism: } \\
\text {-Psychological variables had the strongest } \\
\text { association with abuse } \\
\text {-Women who were currently abused } \\
\text { were: more likely to be probably } \\
\text { depressed, experience suicidal thoughts, } \\
\text { have poorer mental health on the SF-36 } \\
\text {-Multivariable analysis showed that the } \\
\text { psychological variables (probable } \\
\text { depression BDI or EPDS, SF-36 mental } \\
\text { health score) had the strongest association } \\
\text { with abuse. }\end{array}$ \\
\hline
\end{tabular}




\begin{tabular}{|c|c|c|c|c|c|c|}
\hline & & & & $\begin{array}{l}\text { 1994) using (SF-36) } \\
\text { mental health part } \\
\text { QOL outcomes: } \\
\text { N/A } \\
\text { Data analysis: } \\
\text { Logistic regression (odds } \\
\text { ratios) }\end{array}$ & & \\
\hline $\begin{array}{l}\text { 10-John, Johnson, } \\
\text { Kukreja, Found, } \\
\text { Lindow (2004) } \\
\text { UK }\end{array}$ & $\begin{array}{l}\text { Purpose: } \\
\text { To determine the } \\
\text { prevalence of DV in } \\
\text { women attending a } \\
\text { gynecology outpatient } \\
\text { clinic in the UK } \\
\text { To investigate whether } \\
\text { women who reported DV } \\
\text { were more likely to } \\
\text { complain of certain } \\
\text { gynecological symptoms } \\
\text { TF: } \\
\text { N/A }\end{array}$ & $\begin{array}{l}\text { Design: } \\
\text { Descriptive survey study: } \\
\text { Cross-sectional study } \\
\text { Data collection: } \\
\text { Questionnaire }\end{array}$ & $\begin{array}{l}\text { Sample: } \\
820 \text { women } \\
\text { Women who were } \\
\text { patients in a health } \\
\text { care system } \\
\text { Setting: } \\
\text { A gynecology } \\
\text { outpatient clinic }\end{array}$ & $\begin{array}{l}\text { IPV characteristic: } \\
\text { Abuse Assessment Screen } \\
\text { (McFarlane, Parker, } \\
\text { Soeken, \& Bullock, 1992; } \\
\text { Norton, Peipert, Zierler, } \\
\text { Lima,\& Hume, 1995) } \\
\text { FGIDs \& symptoms: } \\
\text { Lower abdominal pain, } \\
\text { abdominal discomfort, } \\
\text { bowel symptoms are } \\
\text { reported: survey questions } \\
\text { developed by authors } \\
\text { Mechanisms: } \\
\text { N/A } \\
\text { QOL outcomes: } \\
\text { Asking for consultations } \\
\text { (McFarlane et al, 1992; } \\
\text { Norton et al., 1995) } \\
\text { Data Analysis: } \\
\text { Chi square }\end{array}$ & $\begin{array}{l}\text { Abuse among women: } \\
\text {-The prevalence of physical abuse was } \\
21 \%, 4 \% \text { had experienced violence in the } \\
\text { past year by (e.g., husband, ex-husband, } \\
\text { boyfriend, father, mother, stranger, son, } \\
\text { daughter) } \\
\text {-(48\%) women who had experienced } \\
\text { physical violence also reported forced } \\
\text { sexual activity } \\
\text { Relationship Between IPV and FGIDs } \\
\text { and symptoms: } \\
\text {-Domestic violence was significantly } \\
\text { associated with reports of lower } \\
\text { abdominal pain and bowel symptoms } \\
\text { QOL outcomes: } \\
\text {-women who had experiencing domestic } \\
\text { violence also had significantly more } \\
\text { consultations in the past year for health } \\
\text { problems }\end{array}$ & \\
\hline $\begin{array}{l}\text { 11-Nedd (2001) } \\
\text { US }\end{array}$ & $\begin{array}{l}\text { Purpose: } \\
\text { To examine the social and } \\
\text { psychological effects of } \\
\text { battering on black women } \\
\text { health } \\
\text { TF: } \\
\text { N/A }\end{array}$ & $\begin{array}{l}\text { Design: } \\
\text { Observational study: } \\
\text { Cross-sectional study } \\
\text { Data collection: } \\
\text { A structured interview }\end{array}$ & $\begin{array}{l}\text { Sample: } \\
128 \text { women, } 18 \mathrm{yrs} \text { or } \\
\text { older women from } \\
\text { the community } \\
\text { Setting: } \\
\text { N/A }\end{array}$ & $\begin{array}{l}\text { IPV characteristic: } \\
\text { Physical and emotional } \\
\text { abuse: Index of Spouse } \\
\text { Abuse (Hudson \& } \\
\text { McIntosh, 1981) } \\
\text { FGIDs \& symptoms: } \\
\text { physical health (nausea, } \\
\text { stomach ache): Health } \\
\text { Response Scale (Brown, } \\
\text { 1986), and daily hassles } \\
\text { scale (Lazarus \& Folkman, } \\
\text { 1989) } \\
\text { Mechanisms: } \\
\text { Depressions: The Beck } \\
\text { depression inventory } \\
\text { (Beck, 1972) } \\
\text { QOL outcomes: } \\
\text { N/A } \\
\text { Data Analysis: } \\
\text { ANOVA and MANOVA }\end{array}$ & $\begin{array}{l}\text { Abuse among women: } \\
\text {-Participants had a mean score of } 38.42 \\
\text { for physical abuse, and a mean score of } \\
47.29 \text { for emotional abuse } \\
\text { Relationship Between IPV and FGIDs } \\
\text { and symptoms: } \\
\text {-no differences in gastrointestinal upsets } \\
\text { between women who had and had not } \\
\text { experienced emotional abuse (when } \\
\text { multiple analysis of variance was applied) } \\
\text { Mechanisms: } \\
\text {-Emotionally abused women had } \\
\text { significantly higher levels of depression } \\
\text { and stress than non-abused women }\end{array}$ & \\
\hline $\begin{array}{l}\text { 12-Perona et al } \\
\text { (2005) } \\
\text { Spain }\end{array}$ & $\begin{array}{l}\text { Purpose: } \\
\text { To investigate the } \\
\text { prevalence of the main } \\
\text { FGIDs, functional }\end{array}$ & $\begin{array}{l}\text { Design: } \\
\text { Observational study: } \\
\text { Cross-sectional study } \\
\text { Data collection: }\end{array}$ & $\begin{array}{l}\text { Sample: } \\
70 \text { woman age } 18 \text { or } \\
\text { older women from } \\
\text { community }\end{array}$ & $\begin{array}{l}\text { IPV characteristic: } \\
\text { Duration of the abuse } \\
\text { situation, relationship with } \\
\text { the aggressor, and form of }\end{array}$ & $\begin{array}{l}\text { Abuse among women: } \\
\text {-In most cases the aggressor was the } \\
\text { current partner or ex-partner of the victim }\end{array}$ & $\begin{array}{l}\text { The } \\
\text { mechanism not } \\
\text { tested but }\end{array}$ \\
\hline
\end{tabular}




\begin{tabular}{|c|c|c|c|c|c|c|}
\hline & $\begin{array}{l}\text { dyspepsia and irritable } \\
\text { bowel syndrome } \\
\text { To evaluate the level of } \\
\text { psychological distress and } \\
\text { its relationship with the } \\
\text { presence of FGID } \\
\text { TF: } \\
\text { Biopsychosocial model } \\
\text { (Camilleri, Heading \& } \\
\text { Thompson, 2002; } \\
\text { Drossman et al., 1999) }\end{array}$ & Self-report survey & $\begin{array}{l}\text { Setting: } \\
\text { National Police } \\
\text { Department }\end{array}$ & $\begin{array}{l}\text { abuse (psychological, } \\
\text { physical, or both): } \\
\text { questions developed by the } \\
\text { authors } \\
\text { FGIDs \& symptoms: } \\
\text { IBS and FD: Rome II } \\
\text { criteria (Drossman, 1999). } \\
\text { Psychological Status } \\
\text { (anxiety \& depression in } \\
\text { stressful situations): the } \\
\text { hospital anxiety and } \\
\text { depressive scale (HAD) } \\
\text { (Tejero, Guimerá, Farré \& } \\
\text { Peri, 1986) } \\
\text { Mechanisms: } \\
\text { N/A } \\
\text { QOL outcomes: } \\
\text { Asking for consultations } \\
\text { and seeking medical } \\
\text { services: developed by } \\
\text { authors } \\
\text { Data Analysis: } \\
\text { T-test \& Chi Square }\end{array}$ & $\begin{array}{l}\text {-Physical abuse } 4 \% \text {, psychological } 29 \%, \\
\text { and both } 67 \% \\
\text { Relationship Between IPV and FGIDs } \\
\text { and symptoms: } \\
\text {-FGID prevalence was } 71 \%,(4 \%) \text { IBS, } \\
\text { (24\%) FD, and both disorders were } \\
\text { present in ( } 43 \% \text { ). Thus, total FD } \\
\text { prevalence was } 67 \% \text {, and total IBS } \\
\text { prevalence was } 47 \% \text { (n=33) diarrhea } \\
\text { subtype (n=9), constipation subtype } \\
\text { (n=12), and diarrhea/ constipation } \\
\text { subtype (n=12) } \\
\text { - A significant association was reported } \\
\text { between IPV and FGIDs based on t-tests } \\
\text { and Chi square } \\
\text {-no differences in types of IPV among } \\
\text { women with or without FGID } \\
\text { QOL outcomes: } \\
\text {-women with FGID had consulted their } \\
\text { doctor for gastrointestinal symptoms } \\
\text {-a significant association between } \\
\text { experiencing abuse and gastrointestinal } \\
\text { symptoms that started after at least } 6 \\
\text { months of ongoing abuse, and the } \\
\text { subjective perception of a positive } \\
\text { association between their digestive } \\
\text { discomfort and the abuse situation was } \\
\text { similar in women consulted physician and } \\
\text { women did not consulted physician. -The } \\
\text { women who consulted their physician had } \\
\text { higher pain intensity (P.044) }\end{array}$ & $\begin{array}{l}\text { reported in the } \\
\text { background. }\end{array}$ \\
\hline $\begin{array}{l}\text { 13-Salam, Abdul } \\
\text { Alim, and Noguchi } \\
\text { (2006) } \\
\text { Bangladesh }\end{array}$ & $\begin{array}{l}\text { Purpose: } \\
\text { To compare the } \\
\text { socioeconomic, } \\
\text { demographic, and } \\
\text { behavioral characteristics } \\
\text { of abused and non-abused } \\
\text { women } \\
\text { To examine the association } \\
\text { between spousal violence } \\
\text { and the reproductive health } \\
\text { of women } \\
\text { TF: } \\
\text { N/A }\end{array}$ & $\begin{array}{l}\text { Design: } \\
\text { Observational study: a } \\
\text { cross-sectional study } \\
\text { Data collection: } \\
\text { Interviewer-administered } \\
\text { questionnaires }\end{array}$ & $\begin{array}{l}\text { Sample: } \\
496 \text { married women } \\
\text { from community } \\
\text { Setting: } \\
\text { N/A }\end{array}$ & $\begin{array}{l}\text { IPV characteristic: } \\
\text { Physical, psychological, } \\
\text { and sexual abuse: } \\
\text { developed by the authors } \\
\text { FGIDs \& symptoms: } \\
\text { Pelvic pain, RTI, and } \\
\text { irritable bowel syndrome: } \\
\text { developed by authors } \\
\text { Mechanisms: } \\
\text { N/A } \\
\text { QOL outcomes: } \\
\text { N/A } \\
\text { Data Analysis: } \\
\text { Descriptive analysis, Chi- } \\
\text { square, t-tests, \& Logistic } \\
\text { Regression (Odds Ratios) }\end{array}$ & $\begin{array}{l}\text { Abuse among women: } \\
\text {-physical } 96 \% \text {, sexual } 78 \% \text {, and } \\
\text { psychological (74\%) abuse } \\
\text {-Frequency of violence: } 44 \% \text { more than } \\
\text { once in a month, } 36.2 \% \text { once or less in a } \\
\text { month, } 19 \% \text { one or less in a month } \\
\text { Relationship Between IPV and FGIDs } \\
\text { and symptoms: } \\
\text { - Sexual violence adversely affected } \\
\text { women's reproductive health outcomes: } \\
\text { pelvic pain ( } 81.8 \%) \text {, reproductive tract } \\
\text { infection (RTI; } 52.2 \%) \text {, and symptoms of } \\
\text { IBS (51.9\%); } \\
\text { - IPV was significantly associated with } \\
\text { some reproductive health problems such } \\
\text { as RTI, but the association between IPV } \\
\text { and IBS was not examined. }\end{array}$ & \\
\hline
\end{tabular}




\begin{tabular}{|c|c|c|c|c|c|}
\hline $\begin{array}{l}\text { 14-Schollenberger } \\
\text { et al (2003) } \\
\text { US }\end{array}$ & $\begin{array}{l}\text { Purpose: } \\
\text { To examine partner abuse } \\
\text { and health consequences } \\
\text { among a group of } \\
\text { primarily middle-class, } \\
\text { employed African } \\
\text { American women } \\
\text { TF: } \\
\text { N/A }\end{array}$ & $\begin{array}{l}\text { Design: } \\
\text { Observational study: a } \\
\text { cross-sectional study } \\
\text { Data collection: } \\
\text { Telephone survey }\end{array}$ & $\begin{array}{l}\text { Sample: } \\
\text { 206 women, ages of } \\
21-55 \text { year, patients } \\
\text { in a health care } \\
\text { systems } \\
\text { Setting: } \\
\text { N/A }\end{array}$ & $\begin{array}{l}\text { IPV characteristic: } \\
\text { Physical and/or sexual } \\
\text { assault by a husband or } \\
\text { partner or ex-husband or } \\
\text { ex-partner: Abuse } \\
\text { Assessment Screen } \\
\text { (Soeken, McFarlane, } \\
\text { Parker, \& Lominack, } \\
\text { 1998) } \\
\text { FGIDs \& symptoms: } \\
\text { The Miller Abuse Physical } \\
\text { Symptoms and Injury } \\
\text { Scale (Miller \& Campbell, } \\
\text { 1993) } \\
\text { Mechanism: } \\
\text { N/A } \\
\text { QOL outcomes: } \\
\text { Hospitalization and } \\
\text { emergency visits } \\
\text { (developed by authors) } \\
\text { Data analysis: } \\
\text { Bivariate analyses - Chi } \\
\text { square }\end{array}$ & $\begin{array}{l}\text { Abuse among women: } \\
-14.6 \% \text { of women experienced abuse in } \\
\text { the past year, } 57.8 \% \text { experienced abuse } \\
\text { for less than one year, } 19.3 \% \text { for } 1 \text { to } 5 \\
\text { years, and } 22 \% \text { for } 5 \text { years or more } \\
\text { Relationship Between IPV and FGIDs } \\
\text { and symptoms: } \\
\text {-abdominal pain reported at a } \\
\text { significantly higher level by abused } \\
\text { women } \\
\text { QOL outcomes: } \\
\text {-women from both groups had seen a } \\
\text { physician in the previous year for nearly } \\
\text { all of the health problems } \\
\text {-Half of the women who were abused in } \\
\text { the past year had gone to an emergency } \\
\text { room at least once, but there was no } \\
\text { difference in the total number of clinic } \\
\text { visits reported for the past year by abused } \\
\text { and never-abused women }\end{array}$ \\
\hline $\begin{array}{l}\text { 15-Wuest et al } \\
\text { (2008) } \\
\text { Canada }\end{array}$ & $\begin{array}{l}\text { Purpose: } \\
\text { To describe the pattern of } \\
\text { the severity of chronic pain } \\
\text { To illustrate the variation } \\
\text { in site, frequency and } \\
\text { interference of pain } \\
\text { reported as problematic in } \\
\text { the past month by chronic } \\
\text { pain severity } \\
\text { To describe the } \\
\text { relationships between } \\
\text { chronic pain severity as } \\
\text { indicated by disability } \\
\text { category } \\
\text { To document the pattern of } \\
\text { use of selected medications } \\
\text { by chronic pain severity } \\
\text { TF: } \\
\text { N/A }\end{array}$ & $\begin{array}{l}\text { Design: } \\
\text { Descriptive study: Cross- } \\
\text { sectional study } \\
\text { Data collection: } \\
\text { Structured interviews }\end{array}$ & $\begin{array}{l}\text { Sample: } \\
292 \text { women from } \\
\text { community who had } \\
\text { separated from an } \\
\text { abusive partner } \\
\text { Setting: } \\
\text { N/A }\end{array}$ & $\begin{array}{l}\text { IPV Characteristic: } \\
\text { Severity of physical and } \\
\text { nonphysical IPV: Index of } \\
\text { Spouse Abuse (ISA) } \\
\text { (Hudson \& McIntosh, } \\
\text { 1981) } \\
\text { FGIDs \& symptoms: } \\
\text { Chronic Pain: the chronic } \\
\text { pain grade (CPG) scale } \\
\text { (Von Korff, Ormel, Keefe } \\
\text { \& Dworkin, 1992) } \\
\text { Health problems linked to } \\
\text { IPV: Partner Abuse } \\
\text { Symptom Scale (Ford- } \\
\text { Gilboe et al) } \\
\text { Depression: Center for } \\
\text { Epidemiologic Studies- } \\
\text { Depression (CES-D) scale } \\
\text { (Jarvis, Gordon \& Novaco, } \\
\text { 2005; Radloff, 1977) } \\
\text { PTSD: Davidson Trauma } \\
\text { Scale (DTS) (Davidson, } \\
\text { 1996) } \\
\text { Mechanisms: } \\
\text { N/A } \\
\text { QOL outcomes: } \\
\text { N/A } \\
\text { Data analysis: }\end{array}$ & $\begin{array}{l}\text { Abuse result: } \\
\text {-Abuse History: severe abuse } 54.3 \%, \\
\text { Adult sexual assault history } 39.4 \%, \\
\text { Abuse ongoing since leaving } 37.7 \%, \\
\text { Abuse-related injuries ever } 82.5 \%, \\
\text { Taken to emergency department for } \\
\text { abuse-related injuries ever } 45.5 \% \\
\text { Relationship Between IPV and FGIDs } \\
\text { and symptoms: } \\
-144 \text { women reported pain related to } \\
\text { bowel problems; } 135 \text { women reported } \\
\text { upset stomach aspain } \\
\text {-Women with high disability CP reported } \\
\text { more severe spousal abuse than did those } \\
\text { with low disability CP. } \\
\text {-High disability CP was associated both } \\
\text { with a history of child abuse and adult } \\
\text { sexual assault by someone other than the } \\
\text { abusive ex-partner } \\
\text {-Women who had experienced abuse- } \\
\text { related injuries in their lifetime were } \\
\text { more likely to have high disability CP } \\
\text { and to visit the ED for abuse-related } \\
\text { injury } \\
\text {-Depressive symptoms, symptoms of } \\
\text { PTSD, and ever having attempted suicide } \\
\text { were associated with high disability CP }\end{array}$ \\
\hline
\end{tabular}




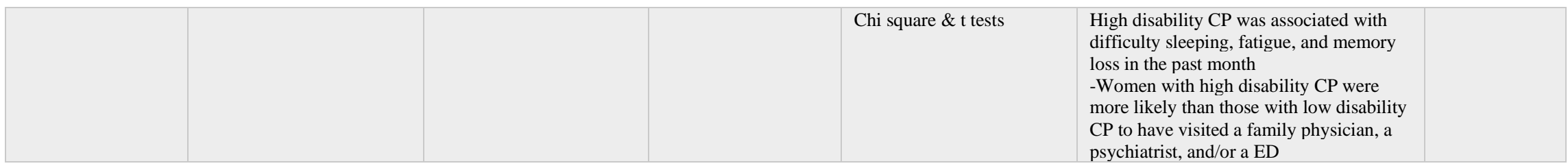




\section{Appendix H}

\section{Curriculum Vitae}

Name

Ohud Shawqi Ang Banjar

\section{POST-SECONDARY EUCATION \& DEGREES}

HONOURS \& AWARDS
King Saud bin Abdulaziz University for Health Sciences

Jeddah, Saudi Arabia

2010-2015 BSc

Western University

London, Ontario, Canada

2017-2020 MScN

First rank for the best research project

Nursing Department, King Saud bin Abdulaziz University for Health Sciences

Jeddah, Saudi Arabia

2015

Western English Language Centre

Western University

2017 - 2017

London Language Institution

London Ontario, Canada.

2017-2017

Sigma Theta Tau International (Iota Omicron Chapter)

Western University

London, ON, Canada

2019 - Present

King Salman Scholarship

Ministry of Higher Education

Riyadh, Saudi Arabia.

2016 - Present

Intern Student

National Guard Health Affairs Hospital

Jeddah, Saudi Arabia

09/2014-09/2015

Staff Nurse in Labor and Delivery 
The International Medical Center

Jeddah, Saudi Arabia

01/2016 - 05/2016

Office Administration and Database Support

Heart and Stroke Foundation

London, Ontario, Canada.

2017-2018

One-on-one support

Canadian Mental Health Association (CMHA)

London, Ontario, Canada.

2018- 2019

Shadowing in mental healthcare long and short-term care St Joseph's Hospital

London, ON, Canada

2020

PROFESSIONAL MEMBERSHIPS

Registered Nurses Association of Saudi Arabia

Sigma Theta Tau International Honor Society of Nursing Western University

Saudi Nursing Society

King Saud bin Abdulaziz University for Health Sciences

Saudi Commission for Health Specialties

King Saud bin Abdulaziz University for Health Sciences 